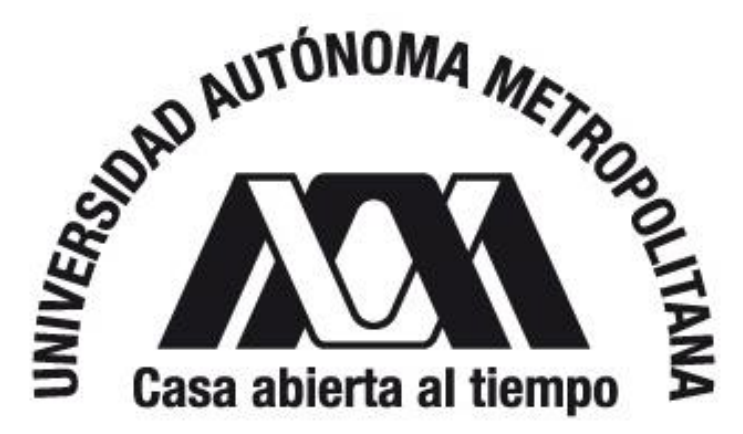

UNIDAD IZTAPALAPA

\title{
ACTIVIDAD ANTIOXIDANTE DE POLIFENOLES EXTRAÍBLES Y NO EXTRAÍBLES DEL CUERPO FRUCTíFERO DE Pleurotus ostreatus.
}

\section{TES IS}

Para obtener el grado de

Maestra en Biotecnología

PRESENTA

I.A . Sac Nicte Salgado Castillo

Director: Dr. Jorge Soriano Santos

Asesores: Dra. Edith Ponce Alquicira

Dra. Ruth Pedroza Islas 
"La maestría en Biotecnología de la Universidad Autónoma Metropolitana está incluida en el Padrón Nacional de Posgrados de Calidad (PNPC) de CONACyT, con la referencia 001465".

Este trabajo contó con el apoyo del CONACyT a través de la beca 544085 


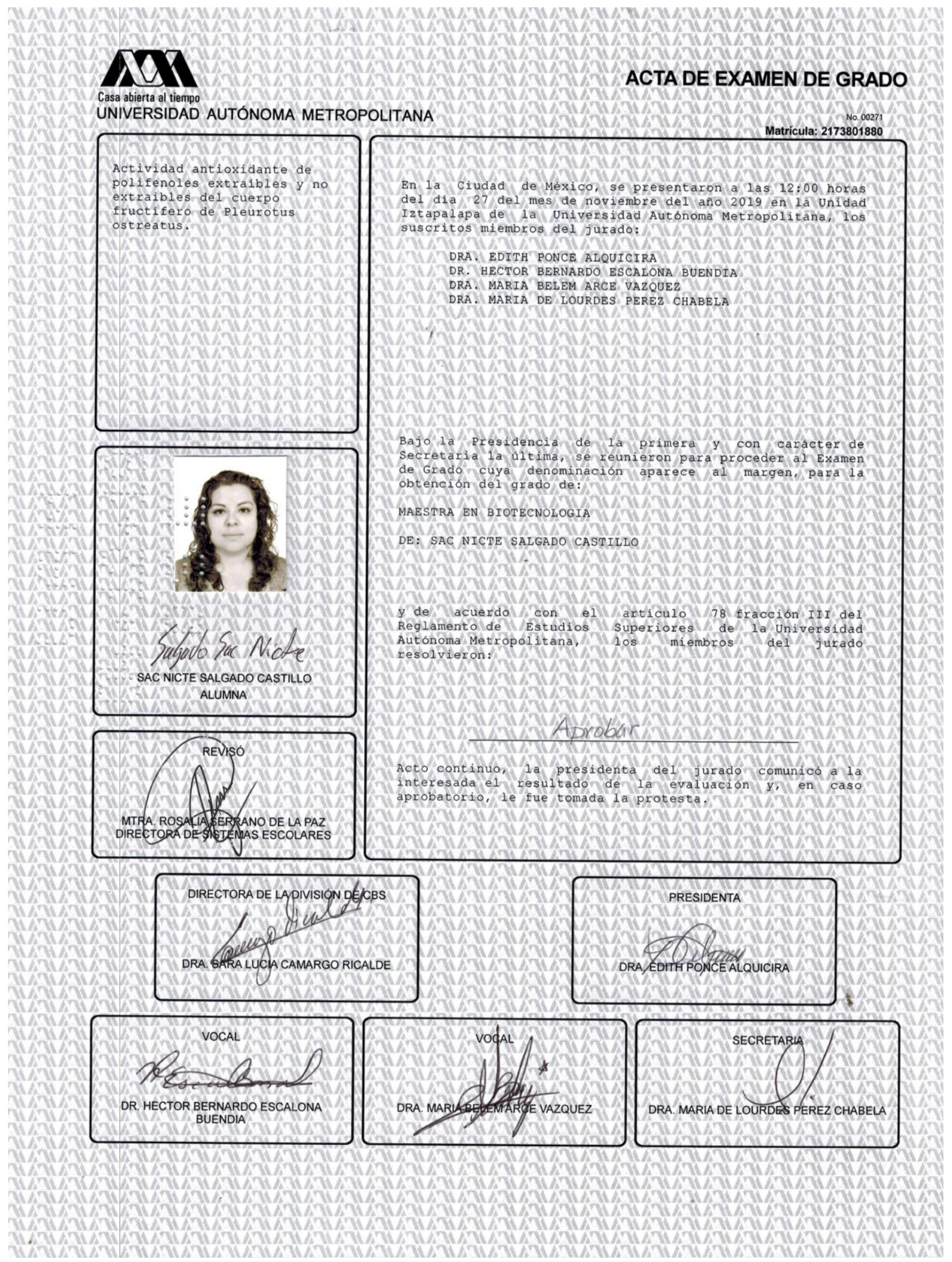


El jurado designado por la División de Ciencias Biológicas y de la salud de la Unidad iztapalapa aprobó la tesis

\section{ACTIVIDAD ANTIOXIDANTE DE POLIFENOLES EXTRAÍBLES Y NO EXTRAÍBLES DEL CUERPO FRUCTÍFERO DE Pleurotus ostreatus. \\ que presenta}

I.A Sac Nicte Salgado Castillo

Comité Tutoral:

Director: Dr. Jorge Soriano Santos

Asesora: Dra. Edith Ponce Alquicira

Asesora: Dra. Ruth Pedroza Islas

Jurado:

Presidente:

Dra. Edith Ponce Alquicira

Secretaria:

Dra. Ma. De Lourdes Pérez Chavela

Vocal:

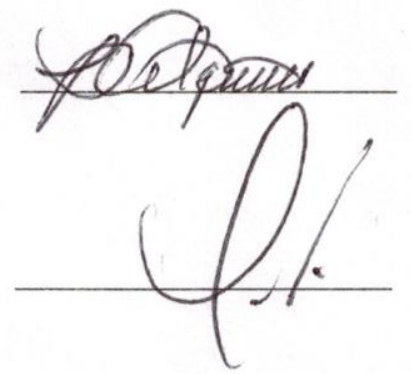

Dr. Héctor Bernardo Escalona Buendía

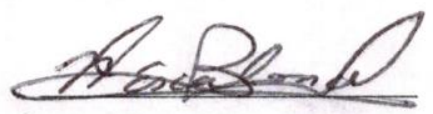

Vocal:

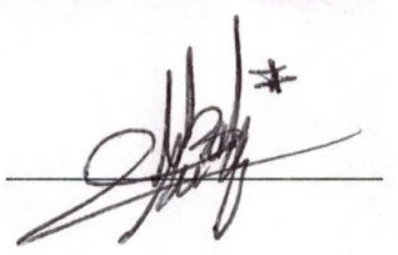




\section{DEDICATORIAS}

A mis padres Blanca y José Luis que han estado conmigo en todo momento, que han fomentado en mi la responsabilidad y el compromiso con las metas que me propongo en la vida. Quiero agradecer a la vida por darme la oportunidad de tener a mis papás conmigo para que puedan verme subir un escalón más en mi vida profesional.

Quiero agradecer a mi familia, primos, tíos, sobrinos, abuelos, por sus enseñanzas, por su apoyo. Porque en cada reunión, en cada plática me hacen saber que están cerca para cuando los necesite y porque ellos saben que estaré ahí para ayudarlos. Gracias también por enseñarme a no rendirme, a ser independiente y a apreciar lo que tengo en mi vida.

A mis amigos que soportan mi carácter, que son hermanos de espíritu, que están ahí en todo momento cada uno a su manera, amigos que me ayudan a entender la vida, que sin ellos no sería lo que soy, que muchos de ellos han sido inspiración para mí, mi vida personal y profesional, infinitas gracias a todos ellos.

A la ciencia, la tecnología y a aquellos investigadores que desarrollan sus proyectos con pasión, aquellos que han logrado salvar vidas con sus investigaciones, porque de alguna manera esto que tanto amo y en lo que tanto creo me ha dado la oportunidad de regalarle a mi mamá un título más. De no ser por la ciencia y la tecnología quizás ella no estaría ahora conmigo. A todos ellos infinitas gracias. 


\section{AGRADECIMIENTOS}

Al doctor Soriano por su paciencia y sus enseñanzas, por darme la oportunidad de equivocarme para aprender. Por la confianza que ha depositado en mí para realizar este proyecto por ayudarme a incrementar el amor por la ciencia, la investigación y sobre todo transmitir conocimientos a personas que deseen aprender. 


\section{RESUMEN}

Pleurotus ostreatus es un hongo superior comestible al que se le atribuyen efectos medicinales que pueden estar asociados al efecto antioxidante de polifenoles. El objetivo del presente trabajo es evaluar la presencia de polifenoles extraíbles y no extraíbles de Pleurotus ostreatus, así como evaluar si estos compuestos presentan actividad antioxidante aplicando métodos de optimización para la extracción y cuantificación de dichos polifenoles. Se encontraron las condiciones óptimas para la extracción metanólica de polifenoles extraíbles en donde se obtuvo una concentración de $4.34 \pm 0.003 \mathrm{mg}$ EAG/g de muestra seca a las siguientes condiciones óptimas: tiempo de extracción de $15 \mathrm{~min}, 60{ }^{\circ} \mathrm{C}$ y $92 \%$ metanol/agua. Posteriormente a los residuos de la extracción metanólica se les realizó una optimización con acetona/agua para obtener los polifenoles que pudieran haber quedado en el residuo, para este ensayo se obtuvieron las siguientes condiciones: proporción de acetona del 8\%, $11 \mathrm{~min}$ y $56{ }^{\circ} \mathrm{C}$ como valores óptimos de extracción para obtener una concentración de $1.75 \mathrm{mg}$ EAG/g de muestra seca. Por otro lado, se aplicó el método de la vainillina para la cuantificación de taninos condensados extraíbles obteniendo $0.590 \pm 0.1 \mathrm{mg}$ de catequina/ g de muestra seca. Adicionalmente se realizó la evaluación de flavonoides, sin embargo, tal como se dice en la literatura, no hay presencia de estos compuestos en Pleurotus ostreatus. Mediante el análisis por HPLC -MS se pudo observar que existe presencia de galatos de glucosa que pueden contener de tres hasta siete unidades de ácido gálico. Para los taninos

condensados no extraíbles se obtuvo una concentración de $0.630 \mathrm{mg}$ de proantocianidina / g de muestra seca a $104{ }^{\circ} \mathrm{C}, 80 \mathrm{~min}$ y $15 \mathrm{~mL}$ volumen del solvente como condiciones óptimas para la cuantificación. Se realizó la evaluación de la actividad antioxidante mediante la inhibición del radical $\mathrm{DPPH}^{\cdot}$ obteniendo $61 \% \pm 0.001$ de inhibición para extractos metanólicos, $71 \% \pm 0.008$ para los extractos acetónicos, $70 \% \pm 0.002$ para los taninos condensados extraíbles y $85 \% \pm 0.004 \%$. para taninos hidrolizables - condensados. También se evaluó la capacidad de quelar metales, en todos los casos se encontró esta capacidad con los siguientes valores $56 \% \pm 0.005$ para extractos metanólicos, $30 \% \pm 0.006$ para extractos acetónicos, $75 \% \pm 0.01$ para taninos condensados extraíbles y $21 \% \pm 0.006$ para taninos hidrolizables - condensados no extraíbles. 


\section{ABSTRACT}

Pleurotus ostreatus is an edible mushroom that is attributed medicinal characteristics that could be associated to the antioxidant effect of polyphenols. The objective of this work is to evaluate the presence of extractable and non-extractable polyphenols of Pleurotus ostreatus, and evaluate if these compounds have antioxidant activity applying optimization methods for the extraction and quantification of said polyphenols. The optimal conditions for methanolic extraction of extractable polyphenols were found where a concentration of $4.34 \pm 0.003 \mathrm{mg}$ EAG / $\mathrm{g}$ of dry sample and was obtained at the following optimal conditions: extraction time of $15 \mathrm{~min}, 60^{\circ} \mathrm{C}$ and $92 \%$ methanol / water. Subsequently, the methanolic extraction residues were optimized with acetone / water to obtain the polyphenols that may have remained in the residue, for this test the following conditions were obtained: acetone ratio of $8 \%, 11 \mathrm{~min}$ and $56^{\circ} \mathrm{C}$ as optimal extraction values to obtain a concentration of $1.75 \mathrm{mg}$ EAG / $\mathrm{g}$ of dry sample. On the other hand, the vanillin method was applied for the quantification of extractable condensed tannins to obtain $0.590 \pm 0.1 \mathrm{mg}$ of catechin / g of dry sample. Additionally, the evaluation of flavonoids was performed, however, as stated in the literature, there is no presence of these compounds in Pleurotus ostreatus. Through HPLC-MS analysis, it was observed that there is a presence of glucose gallates that can contain three to seven units of gallic acid. For non-extractable condensed tannins, a concentration of $0.630 \mathrm{mg}$ of proanthocyanidin / $\mathrm{g}$ of dry sample was obtained at $104{ }^{\circ} \mathrm{C}, 80 \mathrm{~min}$ and $15 \mathrm{~mL}$ solvent volume as optimal conditions for quantification. The antioxidant activity was evaluated by inhibiting the DPPH ' radical, obtaining $61 \% \pm 0.001$ inhibition for methanolic extracts, $71 \%$ \pm 0.008 for acetonic extracts, $70 \% \pm 0.002$ for extractable condensed tannins and $85 \% \pm$ $0.004 \%$ for hydrolysable tannins - condensates. The ability to chelate metals was also evaluated, in all cases this capacity was found with the following values: $56 \% \pm 0.005$ for methanolic extracts, $30 \% \pm 0.006$ for acetonic extracts, $75 \% \pm 0.01$ for extractable condensed tannins and $21 \% \pm 0.006$ for hydrolysable tannins - non extractable condensates tannins 


\section{Contenido}

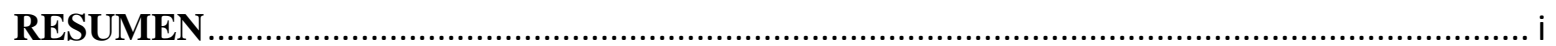

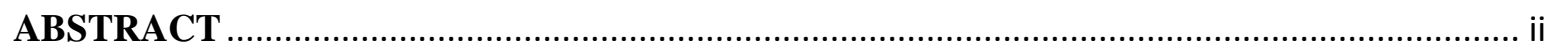

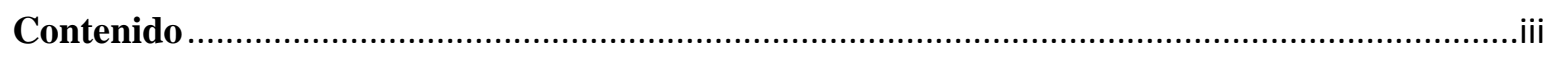

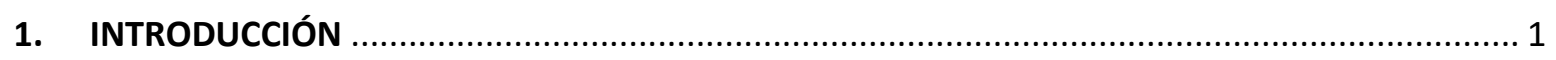

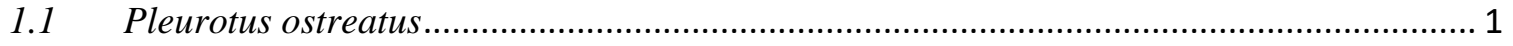

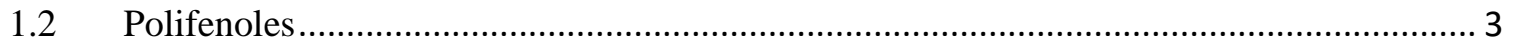

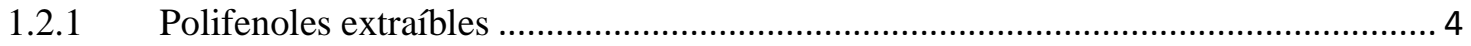

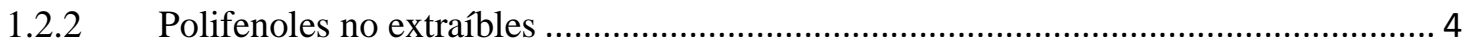

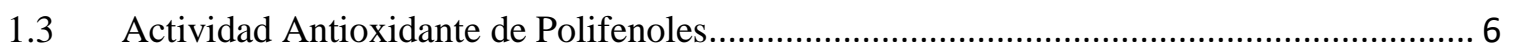

1.4 Efectos benéficos de los polifenoles a la salud. ........................................................ 9

1.5 Métodos para la cuantificación de polifenoles ............................................................... 10

1.6 Métodos de evaluación de la actividad antioxidante ........................................................ 11

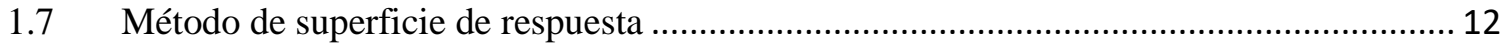

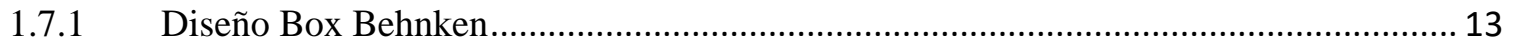

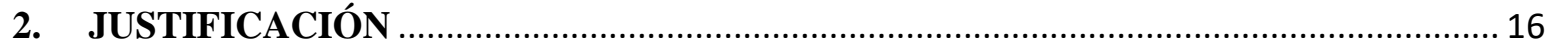

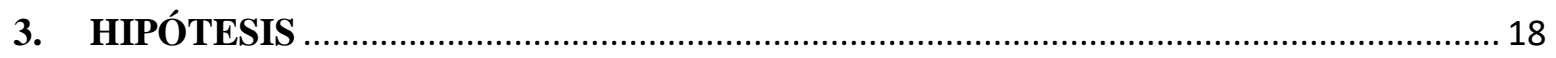

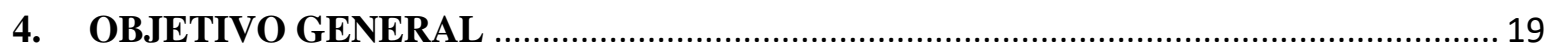

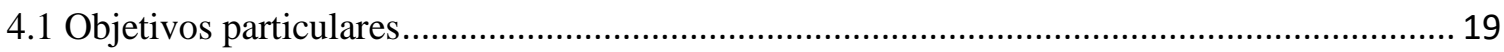

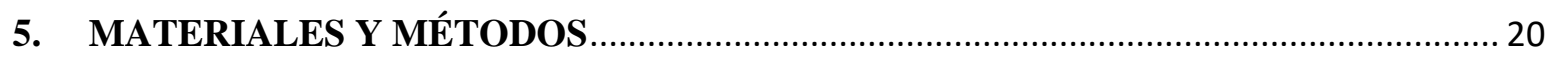

5.1 Recolección y acondicionamiento de Pleurotus ostreatus .................................................... 20

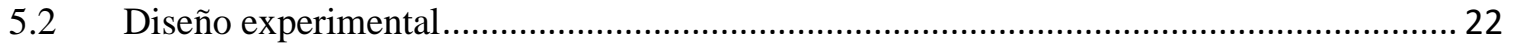

5.3 Cuantificación de polifenoles por el método de Folin-Ciocalteu..................................... 22

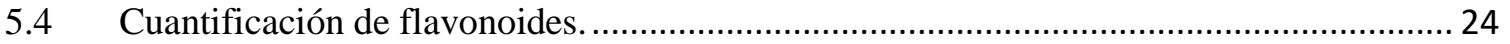

5.5 Cuantificación de taninos condensados extraíbles por el método de la vainillina. ........... 24

5.6 Cuantificación de taninos hidrolizables por HPLC .......................................................... 25

5.7 Cuantificación de taninos condensados no extraíbles por el método de Porter.................. 26

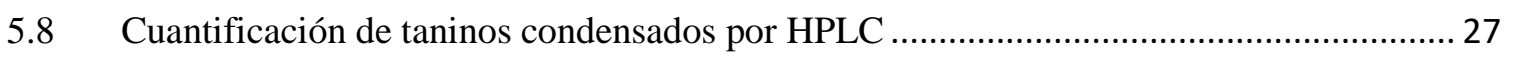

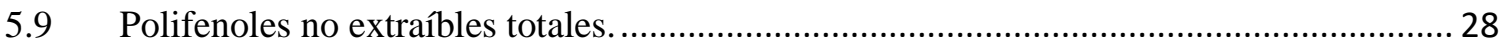

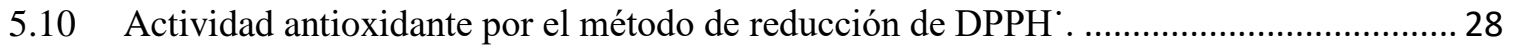




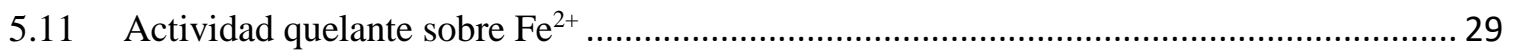

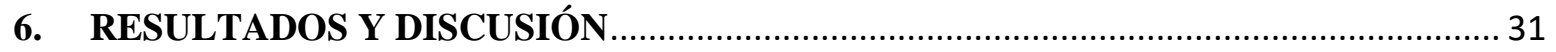

6.1 Selección del método de deshidratado para la obtención de la harina. ................................ 31

6.2 Diseño experimental para extracción de polifenoles extraíbles y no extraíbles de

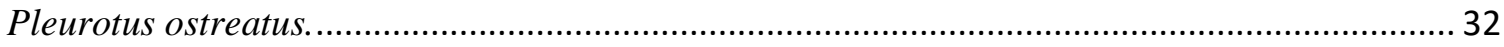

6.3 Polifenoles extraíbles por el método de Folin-Ciocalteu ................................................... 35

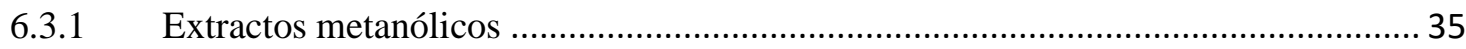

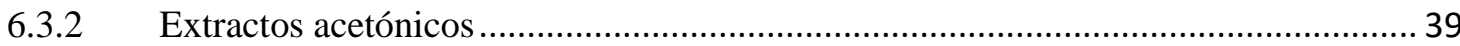

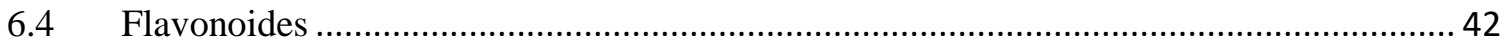

6.5 Taninos condensados extraíbles por el método de la vainillina. ....................................... 43

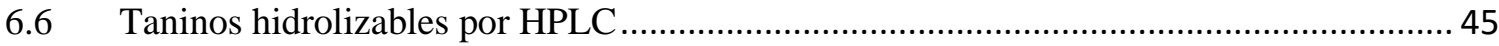

6.7 Taninos condensados no extraíbles por el método de Porter ......................................... 47

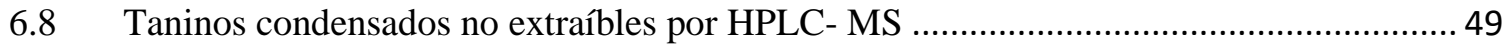

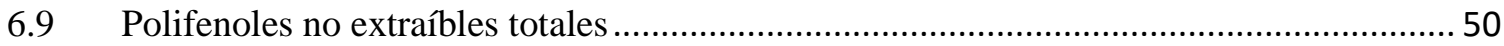

6.10 Actividad antioxidante por inhibición del radical $\mathrm{DPPH}^{\circ}$............................................... 51

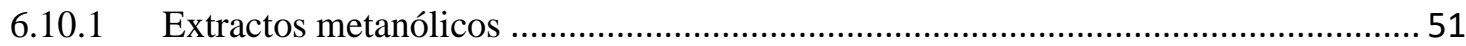

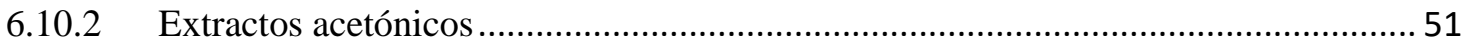

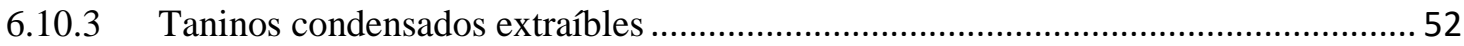

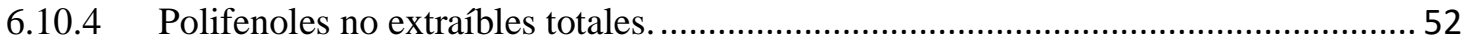

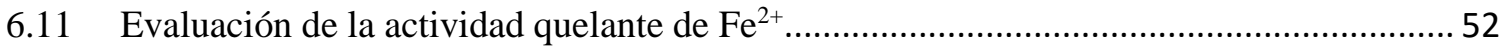

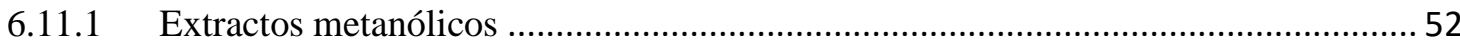

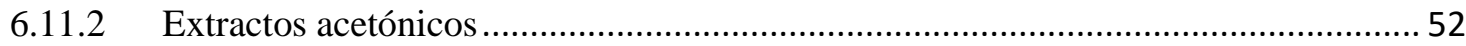

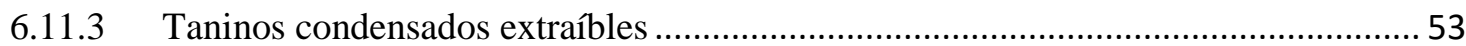

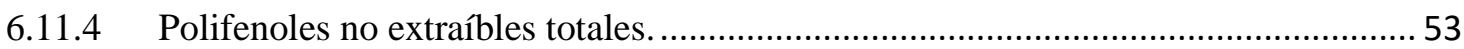

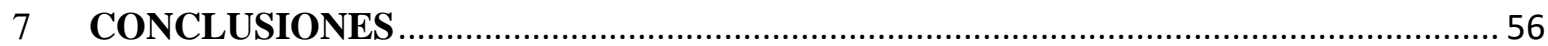

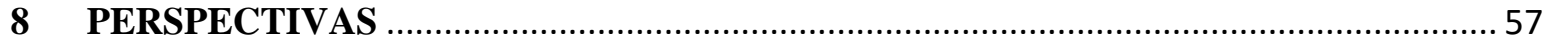

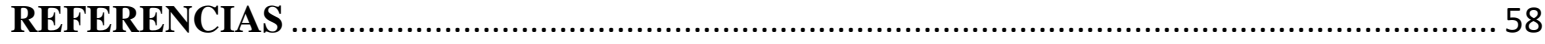

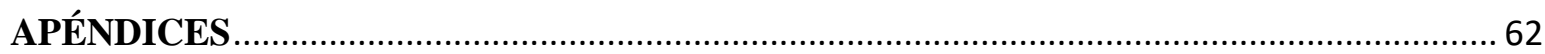

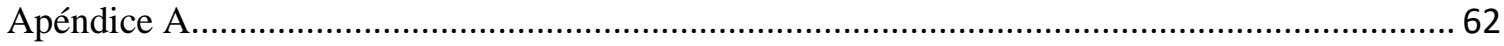

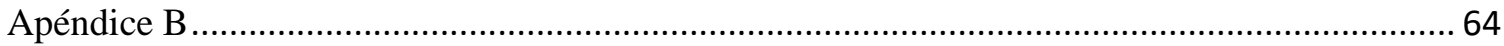

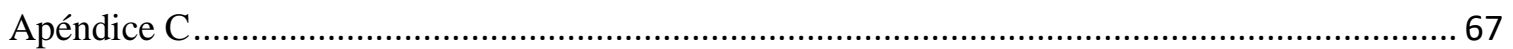




\section{Índice de figuras}

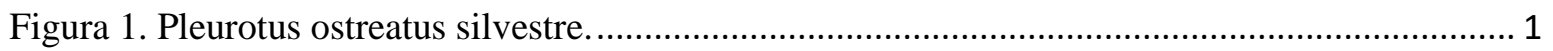

Figura 2. Producción de Pleurotus ostreatus en México. …......................................................... 2

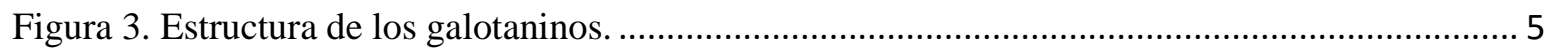

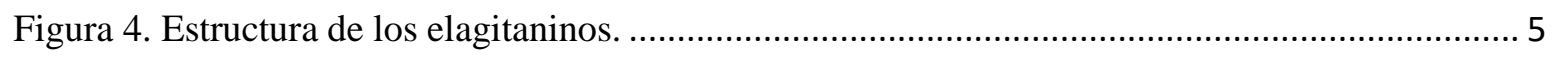

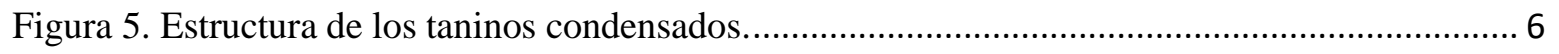

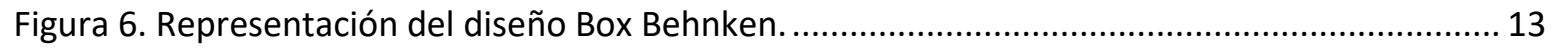

Figura 7. Representación del diseño central rotatorio para dos factores....................................... 14

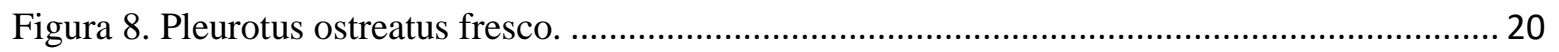

Figura 9. Harina de Pleurotus ostreatus. ............................................................................... 20

Figura 10. Estrategia general del trabajo a partir de la recolección de Pleurotus ostreatus. ............. 21

Figura 11. Reacción de los compuestos polifenólicos con el reactivo de Folin -Ciocalteu.............. 23

Figura 12. Reacción de flavonoides con rutina....................................................................... 24

Figura 13. Reacción de la vainillina con los taninos condensados............................................... 25

Figura 14. Depolimerización de taninos condensados por el método de Porter. .............................. 26

Figura 15. Reacción de un antioxidante con el radical DPPH ${ }^{*}$..................................................... 28

Figura 16. Reacción de quelación del $\mathrm{Fe}^{2+}$ con un antioxidante. .................................................... 29

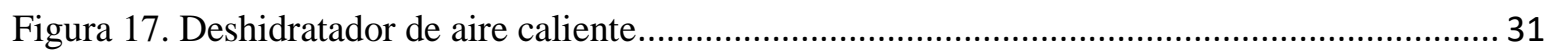

Figura 18. Superficie de respuesta de extractos metanólicos: concentración /tiempo. .................... 36

Figura 19. Diagrama de Pareto de extractos metanólicos: concentración / tiempo............................ 36

Figura 20. Superficie de respuesta de extractos metanólicos: temperatura/ tiempo......................... 37

Figura 21. Diagrama de Pareto de extractos metanólicos: temperatura / tiempo............................. 38

Figura 22. Superficie de respuesta de extractos acetónicos: temperatura/tiempo............................ 39

Figura 23. Diagrama de Pareto de extractos acetónicos: temperatura/tiempo. ............................... 39

Figura 24. Superficie de respuesta de extractos acetónicos: tiempo/ proporción (agua/acetona). .... 40

Figura 25. Diagrama de Pareto de extractos acetónicos: tiempo/proporción (agua/acetona). .......... 41

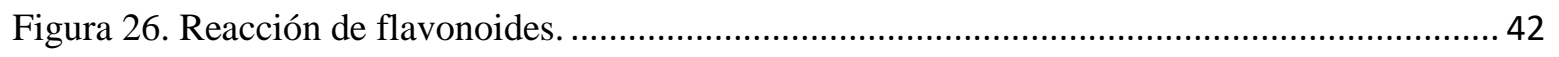

Figura 27. Superficie de respuesta de taninos condensados extraíbles. .......................................... 43

Figura 28. Diagrama de Pareto de taninos condensados extraíbles................................................ 44

Figura 29. Cromatograma obtenido de la metilación de taninos hidrolizables de Pleurotus ostreatus,

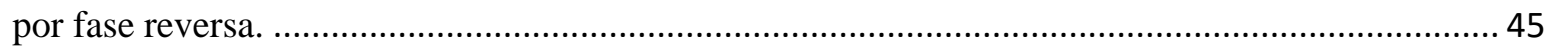

Figura 30. Superficie de respuesta de taninos condensados no extraíbles. .................................... 47

Figura 31. Diagrama de Pareto de taninos condensados no extraíbles............................................. 48

Figura 32. Reactor para método de Porter............................................................................... 49

Figura 33. Cromatograma obtenido de la degradación enzimática de Pleurotus ostreatus, por fase

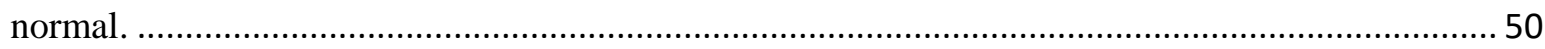




\section{Índice de tablas}

Tabla 1. Comparación de medias de los métodos de secado........................................................... 31

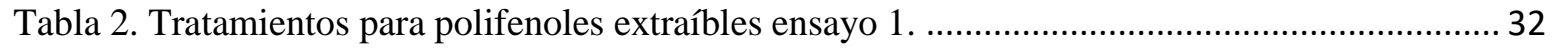

Tabla 3. Tratamientos para polifenoles extraíbles ensayo 2 ..................................................... 33

Tabla 4. Tratamientos para polifenoles extraíbles ensayo 1 . ........................................................... 33

Tabla 5. Tratamientos para polifenoles extraíbles ensayo 2.......................................................... 34

Tabla 6. Tratamientos para taninos condensados extraíbles. ...................................................... 34

Tabla 7. Tratamientos para taninos condensados no extraíbles. …............................................... 35

Tabla 8. Condiciones óptimas de extracción de extractos metanólicos. ........................................... 37

Tabla 9. Condiciones óptimas de extracción de extractos metanólicos. .......................................... 38

Tabla 10. Condiciones óptimas de extracción de extractos acetónicos.......................................... 40

Tabla 11. Condiciones óptimas de extracción de extractos acetónicos........................................... 41

Tabla 12. Condiciones óptimas para la cuantificación de taninos condensados extraíbles................ 44

Tabla 13. Producción de metil galato de taninos hidrolizables, el rendimiento del metil galato es calculado de los pesos moleculares de los taninos y metil galato, y se expresa en gramos de metil

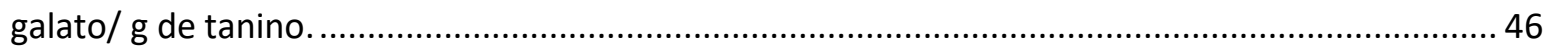

Tabla 14. Condiciones óptimas para la cuantificación de taninos condensados no extraíbles.......... 48

Tabla 15. concentración de taninos condensados no extraíbles por HPLC ....................................... 49

Tabla 16. Concentración de polifenoles no extraíbles totales. ....................................................... 50

Tabla 17. Inhibición del radical DPPH de polifenoles totales no extraíbles.....................................52

Tabla 18. Actividad quelante de pofenoles no extraíbles............................................................5 53

Tabla 19. Comparación de la actividad antioxidante.................................................................... 54 


\section{INTRODUCCIÓN}

\subsection{Pleurotus ostreatus}

Los hongos son conocidos como medicina tradicional en China y también son usados comúnmente como alimento (Mau, Lin, \& Chen, 2002). Pleurotus ssp., es uno de los veinticuatro hongos comestibles y medicinales producidos dentro de granjas de cultivo

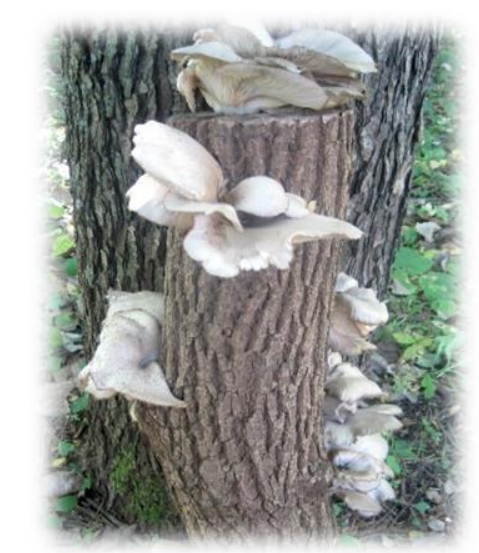

Figura 1. Pleurotus ostreatus silvestre.

especiales. El género Pleurotus ostreatus pertenece al grupo Basidiomycota en más de setenta especies (Owaid, Abed, \& Al-Saeedi, 2016). Los hongos tienen un gran valor nutricional debido a que son ricos en proteína, con un importante contenido de aminoácidos esenciales, fibra y bajos en grasas. Los hongos comestibles pueden ser una fuente de diferentes nutracéuticos como ácidos grasos insaturados, compuestos fenólicos, tocoferoles, ácido ascórbico y carotenoides. Además de un contenido significante de vitaminas como B1, B2, B12, C, D, y E (Jeena, Punetha, Prakash, Chandra, \& Kushwaha, 2014).

En condiciones naturales, crece en árboles vivos como parásito o en ramas de árboles muertos como un agente de descomposición primario y saprófito. Estas especies tienen complejos sistemas enzimáticos, por lo que son capaces de utilizar materiales que contengan lignocelulosa (Yıldız, Yılmaz, Can, Kılıç, \& Yıldız, 2017). Debido a ello pueden crecer en distintos sustratos que contengan celulosa, hemicelulosa y lignina como paja de soya, paja de arroz, pulpa de café, desechos de algodón, desechos de mazorcas de maíz, y aserrín 
(Owaid et al., 2016). El cultivo y consumo de hongos, especialmente de especies Pleurotus ha ido incrementando día con día, gracias al corto tiempo de producción.

Los hongos en México, se han destacado como un alimento excepcional y nos han acompañado en nuestra dieta desde época prehispánica. Los aztecas llamaban a los hongos "nanacatl”, vocablo que significa carne. En México se cultivan cinco especies de hongos: champiñón, portobello, seta, hongo blanco y shiikate. La producción anual de hongos y setas en México supera las mil cuatrocientas toneladas (SAGARPA, 2016).

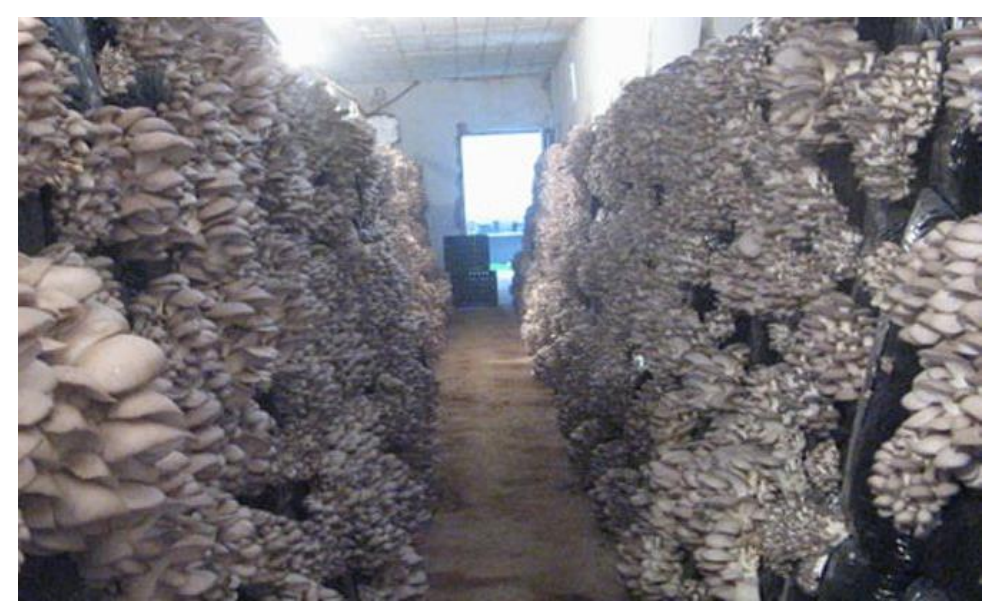

Figura 2. Producción de Pleurotus ostreatus en México.

Los hongos acumulan varios metabolitos secundarios como compuestos fenólicos de los cuales se han observado que poseen actividad antioxidante y que poseen actividades anticancerígenas, anticarcinogénicas, anti-mutagénicas, antibacteriales, antivirales y antiinflamatorias. Algunas investigaciones han observado que la bioactividad de los fenólicos puede estar relacionada con su habilidad de inhibir la lipoxigenasa, quelación de metales, y la inhibición de radicales libres. Los compuestos fenólicos presentes en los hongos son conocidos como antioxidantes naturales, la composición de estos compuestos generalmente dependen de la genética, contaminación y otros factores (Yıldız et al., 2017). 


\subsection{Polifenoles}

Los alimentos son sistemas complejos que varían en composición y destino biológico. Son fuente de nutrimentos tradicionales como proteínas, carbohidratos, y grasas, además de otros compuestos que cuando provienen de fuentes vegetales, se les conoce como fitoquímicos (Álvarez, De la Rosa, López, Vázquez, \& Wall, 2012). Los también llamados polifenoles, son fitoquímicos que se originan principalmente en las plantas y son sintetizados en gran cantidad, como producto de su metabolismo secundario. En la naturaleza existe una amplia variedad de compuestos polifenólicos que presentan una estructura molecular caracterizada por la presencia de uno o varios anillos fenólicos. (Quiñones, Miguel, \& Aleixandre, 2012). En general están distribuidos en el reino vegetal actualmente se conocen más de 8000 estructuras polifenólicas, que van desde moléculas simples, ácidos fenólicos hasta sustancias altamente polimerizadas como los taninos, (Dai \& Mumper, 2010). Los polifenoles pueden ser divididos en varios subgrupos atendiendo a su estructura básica. Los flavonoides, incluyen a las antocianinas, los flavonoles y flavonas, las flavanonas, isoflavonas y los flavan-3-oles. Otro subgrupo importante es el de los fenilpropanoides que incluye a los derivados de ácidos hidroxicinámicos (caféico, ferúlico, sinápico, p-cumárico). También tienen importancia los estilbenoides (resveratrol) y los derivados del ácido benzóico (ácido gálico y elágico, etc.). Muchos compuestos fenólicos son en parte responsables de las propiedades organolépticas de los alimentos de origen vegetal y por tanto tienen importancia en la calidad de los mismos. Entre éstos también hay pigmentos (antocianinas), responsables de los tonos rojos, azules y violáceos de muchas frutas, hortalizas (fresas, ciruelas, uva, berenjena, rábano, etc.) y del vino tinto. Las proantocianidinas (taninos condensados) y los taninos hidrolizables confieren astringencia a los frutos (F. A. Tomás-Barberán, 2003).

Sin embargo se sabe que una fracción significante de polifenoles permanece retenida en el correspondiente residuo después de la extracción, estos polifenoles son llamados no extraíbles (Pérez-Jiménez, Díaz-Rubio, \& Saura-Calixto, 2013).

Los polifenoles no extraíbles, son en su mayoría taninos hidrolizables y proantocianidinas asociadas a la fibra dietética y proteína. 


\subsubsection{Polifenoles extraíbles}

Las investigaciones actuales de polifenoles, se enfocan principalmente a una fracción de polifenoles de la dieta, que corresponden a aquellos que pueden ser extraídos de los alimentos con solventes acuoso-orgánicos (Pérez-Jiménez et al., 2013). Todos los métodos son comúnmente realizados en extractos de alimentos, los cuales se obtienen usando diferentes combinaciones de agua y solventes orgánicos, ciertas técnicas optimizadas han sido desarrolladas para extraer clases específicas de polifenoles. Los compuestos polifenólicos detectados en tales extractos de alimentos constituyen a los polifenoles extraíbles e incluye compuestos fenólicos que pertenecen a diferentes clases como flavonoides (catequinas, proantocianidinas, antocianinas, flavonoides, flavonas, isoflavonas), ácidos fenólicos, estilbenos, lignanos (Pérez-Jiménez \& Torres, 2011). Los polifenoles encontrados en estos extractos son llamados polifenoles extraíbles, y son utilizados como base para calcular el consumo en la dieta y la biodisponibilidad (Pérez-Jiménez et al., 2013).

\subsubsection{Polifenoles no extraíbles}

Los compuestos polifenólicos son un complejo grupo de sustancias con un amplio rango de masa molecular y pueden encontrarse libres en el alimento o enlazados a proteínas o fibra dietética. Los polifenoles extraíbles son de bajo o intermedio peso molecular que pueden ser extraídos fácilmente usando distintos solventes (agua, metanol, acetona acuosa), mientras

que los no extraíbles que son en su mayoría taninos condensados de alto peso molecular (más de $5000 \mathrm{u}$ ) y taninos hidrolizables se encuentran enlazados a proteínas y fibra. 


\section{Taninos Hidrolizables}

Los taninos hidrolizables son sintetizados por una gran variedad de plantas y árboles, y muchos de éstos son utilizados como alimento para animales. Pueden encontrarse en hojas, frutos, tallos, raíces (Mueller-Harvey, 2001). Los taninos hidrolizables, provienen de la esterificación de compuestos polifenólicos no flavonoides (Álvarez et al., 2012).

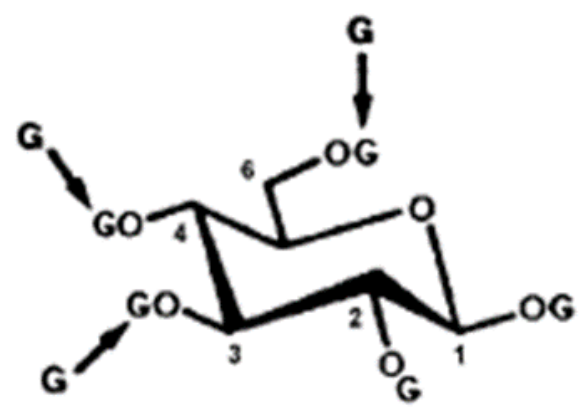

Figura 3. Estructura de los galotaninos.

La estructura de estos taninos se basa en un centro típicamente de glucosa, que puede estar esterificada con una unidad de ácido gálico, los llamados galotaninos, o por el ácido elágico llamados elagitaninos (Quideau, Deffieux, Douat-Casassus, \& Pouységu, 2011).

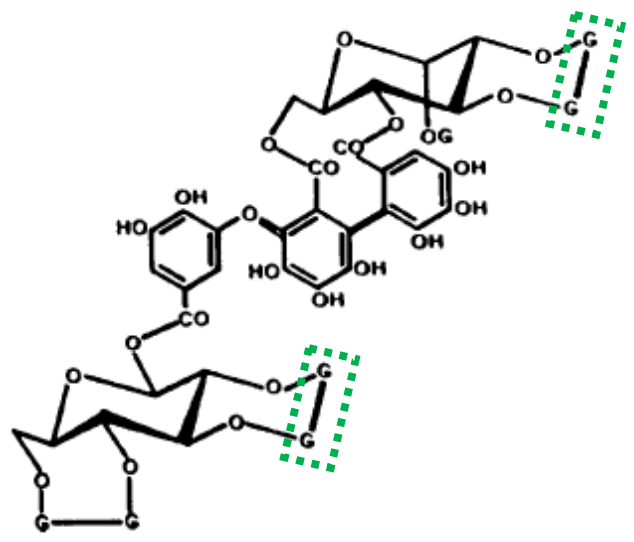

Figura 4. Estructura de los elagitaninos.

En la naturaleza existe un gran número de taninos hidrolizables. La variación estructural entre estos compuestos es causada por el acoplamiento de las unidades vecinas de ácido gálico o por la oxidación de los anillos aromáticos. Las reacciones oxidativas de acoplamiento, pueden producir grandes y complejos taninos hidrolizables (Mueller-Harvey, 2001). 


\section{Taninos Condensados}

Los taninos condensados también son llamados proantocianidinas, provienen de la esterificación de compuestos polifenólicos flavonoides es decir flavan-3-oles, como lo es el caso de las catequinas (Álvarez et al., 2012).

La gran diversidad estructural encontrada en esta familia de polifenoles se atribuye a las variaciones estereoquímicas de las interacciones flavanol, además de los cambios en el patrón de hidroxilación de los polifenoles y en la configuración del anillo central hidroxilado del flavan-3-ol (Quideau et al., 2011).
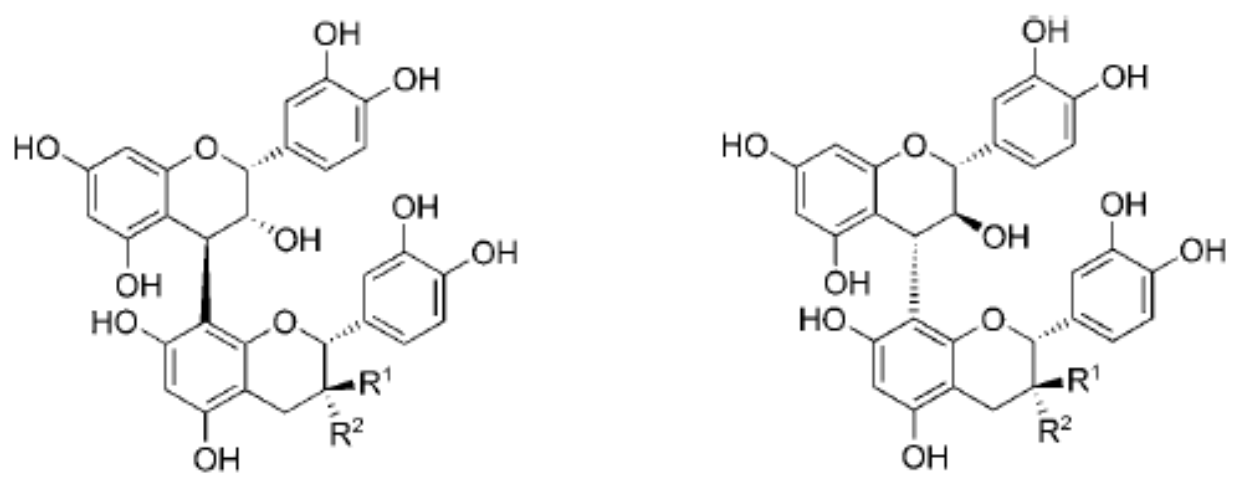

Figura 5. Estructura de los taninos condensados.

Los taninos son compuestos que no sólo poseen un elevado peso molecular, sino además presentan suficientes grupos hidroxilo unidos a estructuras fenólicas que les confieren la característica de formar complejos con proteínas, minerales y otras macromoléculas (Álvarez et al., 2012)

\subsection{Actividad Antioxidante de Polifenoles}

Se considera oxidación a todo proceso en el que ocurre una pérdida de electrones, captación de oxígeno o una cesión de hidrógeno (deshidrogenación). En la naturaleza casi todo es oxidado por el oxígeno: las grasas se vuelven rancias, la goma pierde elasticidad, el papel se torna amarillo, etc. Aunque el oxígeno es indispensable para la vida de los organismos 
aerobios, a altas concentraciones o bajo ciertas condiciones a la concentración normal llega a ser tóxico que puede explicarse por la formación incontrolada de especies reactivas de oxígeno (ROS) (Cárdenas-Rodríguez \& Pedraza-Chaverri, 2005) que dañan las macromoléculas como lípidos, proteína hidratos de carbono y ácidos nucleicos, y alteran los procesos celulares entre ellos la funcionalidad de las membranas, producción de enzimas, respiración celular, inducción génica, etc. (Elejalde Guerra, 2001).

Los radicales libres son moléculas, que presentan al menos un electrón desapareado y son extraordinariamente reactivos, un exceso de estas moléculas rompe el equilibrio molecular produciendo el llamado estrés oxidativo. Se producen durante las reacciones metabólicas, mientras las células del organismo transforman los alimentos en energía, especialmente en situaciones de hiperoxia, ejercicio intenso e isquemia y también por exposición a determinados agentes externos como las radiaciones ionizantes o luz ultravioleta, contaminación ambiental, humo de tabaco, etc. (Elejalde Guerra, 2001). Esto ocurre cuando la producción de especies reactivas en un sistema biológico excede la habilidad del sistema de detoxificar y eliminarlos. La acumulación de las ROS conduce a un daño oxidativo de componentes estructurales (como lípidos, proteínas, y DNA) (Soares, 1975). De las ROS inorgánicas las más importantes son el oxígeno molecular $\mathrm{O}_{2}$, el radical anión superóxido $\left(\mathrm{O}_{2}{ }^{-}\right)$, el radical hidroxilo $\left(\mathrm{HO}^{-}\right)$y su precursor inmediato el peróxido de hidrógeno $\left(\mathrm{H}_{2} \mathrm{O}_{2}\right)$. De las orgánicas: el radical peroxilo ( $\left.\mathrm{ROO}^{-}\right)$, el hidroperóxido orgánico $(\mathrm{ROOH})$ y los lípidos peroxidados (5-9) (Elejalde Guerra, 2001).

En los organismos aerobios, la producción de ROS está controlada por los mecanismos antioxidantes de defensa. Sin embargo, este equilibrio se pierde cuando hay una excesiva producción de ROS o una deficiencia de los mecanismos antioxidantes lo que conlleva a daños a las moléculas, debido a ello es importante consumir compuestos antioxidantes a través de fuentes externas como lo son los alimentos de origen vegetal. Las ROS dañan al ácido desoxirribonucleico (ADN) al reaccionar con las bases nitrogenadas y con la desoxirribosa. El daño oxidativo al ADN es de extrema importancia, debido a que las bases nitrogenadas dañadas pueden generar mutaciones que a su vez pueden resultar en carcinogénesis, apoptosis, necrosis y aun enfermedades hereditarias. En relación con esto, se han detectado más de 20 tipos de modificaciones estructurales de las bases. Se ha observado 
que en presencia de las ERO se fragmenta el ADN y aparecen fragmentos internucleosomales, formados por la ruptura de ADN entre los nucleosomas (estructuras fundamentales para la organización del ADN dentro de los cromosomas), ocasionando con ellos problemas en la compactación y enrrollamiento del ADN dentro de la cromatina y con ello, alteraciones en las propiedades funcionales de la misma cromatina, la cual juega un papel importante en la regulación de la transcripción genética.

El efecto principal de las ROS sobre los lípidos es la lipoperoxidación, que se produce tras el contacto de los lípidos de las membranas con un agente oxidante, como cualquiera de las ROS. En esta reacción el radical libre formado oxida una cadena insaturada de lípido, dando la formación de un lípido hidroperoxidado y un radical alquilo. El alquilo reacciona con una molécula de oxígeno y produce una ROS que interactúa con una nueva cadena de lípido oxidándola, y así se constituye una reacción que se repite. Esta lipoperoxidación trae como consecuencia alteraciones en la estructura de la membrana, afectando su fluidez y provocando daño en su integridad. La peroxidación de los lípidos genera especies como el malondialdehído y el 4-hidroxi-2-nonenal, los cueles son considerados como citotóxicos, ya que pueden funcionar como agentes electrofílicos capaces de interactuar con otros componentes celulares, principalmente proteínas y ADN. Cabe mencionar que la lipoperoxidación es un proceso identificado en enfermedades cardiovasculares. Uno de los procesos importantes es la oxidación de las lipoproteínas de baja densidad, efecto que se ha correlacionado con la aterosclerosis.

Uno de los aspectos más críticos del estrés oxidativo es el daño causado a las proteínas, debido a que puede causar la pérdida de la actividad catalítica de enzimas, daños en la integridad de proteínas estructurales o interrumpir la regulación de las vías metabólicas. Los sistemas de reparación de las proteínas se limitan a los residuos de metionina, por lo que las proteínas oxidadas por acción de las ROS deben ser hidrolizadas para evitar su difusión en la red metabólica o su interacción con otras proteínas. Los efectos de las ROS sobre las proteínas son: la oxidación de los residuos de los aminoácidos, el rompimiento de los enlaces peptídicos y la agregación entre proteínas. Se ha vinculado una amplia variedad de enfermedades con la presencia de las proteínas oxidadas, algunas de esas son: Alzheimer, artritis reumatoide y la catarogénesis. 
Por diversos motivos puede perderse el equilibrio entre condiciones oxidantes y defensas antioxidantes, debido a ello es importante obtener compuestos antioxidantes de fuentes externas como frutos y vegetales que contribuyen a prevenir el estrés oxidativo, como compuestos carotenoides (licopeno, luteína, $\beta$-caroteno) y compuestos fenólicos como flavonoles, flavonas, flavononas, antocianidinas y fenilpropanoides (Cárdenas-Rodríguez \& Pedraza-Chaverri, 2005).

\subsection{Efectos benéficos de los polifenoles a la salud.}

Comprender el conocimiento del contenido total de este tipo de compuestos bioactivos, en alimentos, y las dietas, es esencial para estudios biológicos, epidemiológicos y clínicos, abordando sus posibles efectos a la salud. El primer estudio epidemiológico de polifenoles fue de interés sólo con flavonoles y flavonas (Arranz, Saura-Calixto, Shaha, \& Kroon, 2009). Existe creciente evidencia científica de la existencia de una relación entre dietas ricas en antioxidantes naturales y la prevención de varias enfermedades crónicas. Los antioxidantes obtenidos a través de la dieta son un grupo diverso de compuestos químicos, con solubilidad variable en fluidos biológicos o biomembranas y mecanismos de acción; estos incluyen carotenoides, vitaminas C y E, y polifenoles (Pérez-Jiménez et al., 2013).

Cuando un alimento se consume, este incluye polifenoles extraíbles (PE) y no extraíbles (PNE), se ha observado que mientras un 50\% de los polifenoles extraíbles se vuelven bioaccesibles y se absorben en el intestino delgado, para los polifenoles no extraíbles (específicamente proantocianidinas no extraíbles) llegan intactos al colon. De manera similar, otros estudios han mostrado que las proantocianidinas no extraíbles (NEPA) son parcialmente depolimerizadas en el intestino delgado. Una vez en el colon estos PNE que no se solubilizan en el intestino delgado, se vuelven accesibles ya sea por: a) fermentación por la microbiota colónica de moléculas a las que están asociados (carbohidratos o proteínas); o b) la acción de algunas enzimas intestinales que pueden romper enlaces covalentes, como las esterasas. Se estima que el $95 \%$ de las NEPA que llegan al colon son liberadas de la matriz alimentaria por estos dos mecanismos (Pérez-Jiménez et al., 2013)

Los taninos son compuestos polifenólicos cuyo consumo puede traer numerosos impactos benéficos a la salud. Los taninos hidrolizables como los galotaninos o elagitaninos, provienen 
de la esterificación de compuestos polifenólicos no flavonoides como el ácido gálico o el ácido elágico. Por su parte los taninos condensados o proantocianidinas, provienen de la esterificación de compuestos polifenólicos flavonoides, como las catequinas (flavan-3-oles) Ambos tipos de taninos, al ser compuestos polifenólicos, han sido tema de múltiples revisiones científicas destacando su propiedad antioxidante in vitro e in vivo. Dentro de los taninos hidrolizables, el más estudiado es pentagaloil glucosa (PGG), al que se le reconoce cierta actividad anticancerígena, antidiabética y antioxidante en modelos experimentales in vitro. La actividad anticancerígena in vivo de la PGG se ha probado para cáncer de próstata y pulmón. El efecto antidiabético fue probado con una variedad de PGG en adipocitos, donde se observó que el tanino tenía un efecto muy similar al de la insulina, puesto que se unía a los receptores específicos de insulina de la membrana celular, favoreciendo el transporte de la glucosa al interior de la célula, aún en ausencia de esta hormona. Los taninos condensados han sido más estudiados respecto a su actividad antioxidante. Además, in vivo se ha observado el efecto bacteriostático del jugo de arándano, atribuido a los taninos condensados presentes es decir que el jugo no solo mantiene saludable el tracto urinario por la acidificación del medio, sino además las proantocianidinas presentes exhiben actividad antibacterial, impidiendo la adhesión de E.coli a superficies celulares del tracto urinario (Álvarez et al., 2012).

\subsection{Métodos para la cuantificación de polifenoles}

Los diversos efectos biológicos de los polifenoles, y su común aparición en plantas usadas para hacer alimentos, bebidas, medicinas herbales y alimento para animales, ha creado un amplio interés en métodos para analizarlos. El método de Folin-Denis fue creado para medir la tirosina en proteínas, sin embargo, también sirve para medir polifenoles de tipo tanino y no tanino (Schofield, Mbugua, \& Pell, 2001). El ensayo de Folin-Ciocalteu es una versión mejorada de Folin-Denis y es actualmente la más utilizada. En este método, el analito polifenólico es oxidado y el reactivo es reducido para formar un cromóforo azul (Hagerman, Zhao, \& Johnson, 1997).

Por otro lado, los polifenoles inhiben la actividad de diferentes enzimas los métodos basados en esta propiedad son atractivos porque podrían explorar las interacciones de las proteínas 
con los polifenoles en una solución. Los polifenoles que interfieren frecuentemente con enzimas digestivas como la tripsina o la amilasa pueden ser opciones naturales para este tipo de estudio. Existen ensayos para la inhibición de distintas enzimas como: $\beta$-glucosidasa, tripsina, amilasa, celulasa y alcalina fosfatasa. Otra característica de los polifenoles es la capacidad de inhibir el crecimiento microbiano que lleva a reducir la digestión de en rumiantes y disminuye la infección por patógenos en las plantas. El impacto de los polifenoles en los microorganismos puede ser evaluado ya sea por comparación del crecimiento microbiano medido en tubos con y sin polifenoles o midiendo la diferencia en la desaparición del sustrato (Schofield et al., 2001).

Debido a la complejidad y variabilidad en la estructura de los polifenoles, se han desarrollado métodos más específicos para determinados polifenoles, por ejemplo, el método del yodato es un método para cuantificar taninos hidrolizables el cual depende de la reacción del yodato de potasio con esteres de galato para formar un cromóforo. La química de la producción del color es poco entendida (Hagerman et al., 1997).

Los taninos condensados (proantocianidinas, PA) comprenden a un grupo de oligomeros de polihidroxy-flavan-3-ol y polímeros unidos mediante enlaces carbono-carbono entre subunidades de flavanol. La reactividad de las PAs con moléculas de significado biológico, tiene consecuencias nutricionales y fisiológicas importantes. El análisis de los taninos condensados es complicado debido a la diversidad de estructuras moleculares. El método de la vainillina depende de la reacción de la vainillina con taninos condensados y la formación de complejos coloridos. El método del ácido-butanol es una reacción colorimétrica y consiste en una depolimerización oxidativa ácida catalizada de los taninos condensados para producir antocianidinas rojas (Schofield, P., Mbugua, D.M., and Pell \& Schofield, P., Mbugua, D. M., \& Pell, 2013).

\subsection{Métodos de evaluación de la actividad antioxidante}

Una de las estrategias más aplicadas en la medición in vitro de la capacidad antioxidante total de un compuesto, mezcla o alimento, consiste en determinar la actividad antioxidante frente a sustancias cromógenas de naturaleza radical; la pérdida de color ocurre de forma proporcional con la concentración. No obstante, las determinaciones de la capacidad 
antioxidante realizadas in vitro nos dan tan solo una idea aproximada de lo que ocurre en situaciones complejas in vivo. La capacidad antioxidante de una mezcla no viene dada sólo por la suma de las capacidades antioxidantes de cada uno de sus componentes; también depende del microambiente en que se encuentra el compuesto. Alternativamente, diversos compuestos cromógenos (ABTS, DPPH y FRAP) son utilizados para determinar la capacidad de los compuestos fenólicos que contienen los frutos para captar los radicales libres generados, operando así en contra de los efectos perjudiciales de los procesos de oxidación, que implican especies reactivas de oxígeno (ROS) (Roth, 2009).

El ensayo 2,2-diphenylpicrylhydrazyl ( $\mathrm{DPPH}^{\circ}$ ) es ampliamente utilizado para evaluar las propiedades de los constituyentes de las plantas para eliminar radicales libres. El método se basa en la medición espectrofotométrica del cambio en la concentración del DPPH'resultado de la reacción con un antioxidante (Pyrzynska \& Pękal, 2013).

La capacidad de quelar metales es uno de los mecanismos más importantes de actividad antioxidante. Los iones ferrosos son los pro- oxidantes más potentes entre varias especies de metales de transición presentes en sistemas de alimentos (Wang, Jónsdóttir, \& Ólafsdóttir, 2009). La capacidad de los polifenoles de quelar metales está relacionado con la presencia de grupos orto-dihidroxi, moléculas que tienen grupos catecol o galoil (Andjelković et al., 2006).

\subsection{Método de superficie de respuesta}

En el campo de la química, el término de optimización se ha usado para referirse a la mejora de las condiciones en las cuales se desea obtener la mejor respuesta posible de un sistema, proceso o producto. El proceso de optimización se ha llevado a cabo evaluando la influencia de un solo factor sobre la respuesta experimental, sin embargo, la mayor desventaja de éste proceso es que no estudia las posibles interacciones entre todos los factores involucrados en el sistema, siendo incapaz de describir los efectos de las variables sobre la respuesta de estudio. Con el objetivo de disminuir estos problemas, se han desarrollado distintas técnicas, una de ellas es el método de superficie de respuesta (MSR) (Moreno Vallespir \& Jaime, 2015). 
El método de superficie de respuesta, es un conjunto de técnicas matemáticas y estadísticas utilizadas para modelar y analizar problemas en los que una variable de interés es influenciada por otras, siguiendo el siguiente modelo matemático (Gutiérrez Pulido, 2004).

$$
Y=\beta_{0}+\sum_{i=1}^{k} \beta_{i} x_{i}+\sum_{i=1}^{k} \beta_{i i} x_{i}^{2}+\sum_{i=1<}^{k} \sum_{j=1}^{k} \beta_{i j} x_{i} x_{j}+\varepsilon
$$

\subsubsection{Diseño Box Behnken}

Los diseños de Box Behnken se forman al combinar diseños factoriales en dos niveles con los llamados diseños en bloques incompletos balanceados. Los puntos de este diseño se ubican en medio de las aristas del cubo centrado en el origen, lo que hace que los tratamientos sean menos extremos, en cualquier tratamiento del diseño al menos uno de los factores se fija en la mitad de su rango de prueba. El diseño se aplica cuando se tienen tres o más factores, y suelen ser eficientes en cuanto al número de corridas. Es un diseño rotable o casi rotable que se distingue por que no incluye como tratamientos a los vértices de la región experimental.

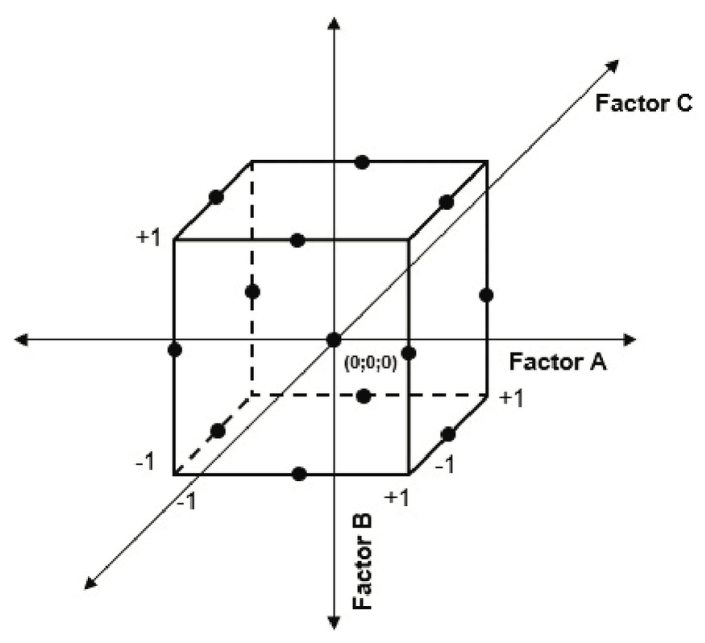

Figura 6. Representación del diseño Box Behnken. 


\subsubsection{Diseño central rotatorio $2^{\wedge} 2$ estrella}

Draper y Lin (1990) proponen un diseño central compuesto cuya parte factorial se construye a partir de columnas de diseños que con excepción de $k=8$ y $\mathrm{k}=9$ factores, para valores de $\mathrm{k} \leq 10$ resulta tener el mínimo número de corridas experimentales que se requieren para estimar los parámetros. Este diseño es sin duda una de las opciones más económicas que se pueden tener para ajustar el modelo de segundo orden.

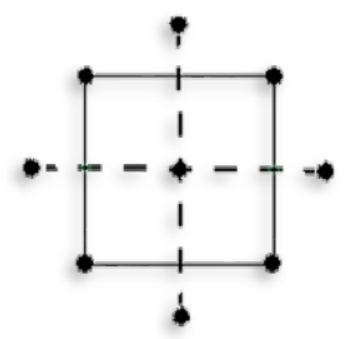

Figura 7. Representación del diseño central rotatorio para dos factores.

Un diseño se llama rotable si la varianza de $\hat{Y}(\mathrm{x})$ sólo depende de la distancia del punto $\mathrm{x}$ al centro del diseño y no de la dirección en que se encuentra. Es decir, si pensamos en la variable $[\hat{Y}(\mathrm{x})]$ como otra respuesta, su gráfica de contornos tiene la forma de círculos concéntricos alrededor del centro del diseño. La rotabilidad del diseño asegura que la calidad de la predicción, medida por var $[\hat{Y}(\mathrm{x})]$, sea invariante a cualquier rotación del diseño alrededor del centro mismo; de aquí se deriva el nombre de esta propiedad (Gutiérrez Pulido, 2004). 


\subsection{ANTECEDENTES}

Muchas investigaciones han probado que altas concentraciones de antioxidantes pueden prevenir el estrés oxidativo producido por la presencia de radicales libres que conducen al desorden fisiológico como el daño celular, generación de células cancerosas y el envejecimiento de las células cerebrales. Los antioxidantes juegan un papel importante en el mantenimiento de la salud humana debido a su habilidad de eliminar radicales libres del cuerpo es por esto que el consumo de antioxidantes presentes en la dieta como frutos, vegetales y hongos es muy importante (Arbaayah \& Umi Kalsom, 2013). Los taninos son compuestos de alto peso molecular de importancia en procesos nutricionales y ecológicos lo que hace a los análisis cualitativos y cuantitativos críticos para su estudio. Los estudios ecológicos y nutricionales podrían requerir del análisis de cientos de muestras, haciendo impráctico intentar caracterizar y cuantificar cada compuesto de manera individual. En lugar de aplicar métodos de detección, basados en grupos químicos similares de grupos de compuestos relacionados. Esta estrategia se ha utilizado en muchos estudios de taninos condensados, que son comprendidos en subunidades de flavanoides. Bajo condiciones apropiadas, todos los taninos condensados pueden ser degradados para producir antocianidinas que pueden ser determinadas espectrofotométricamente. Este método conocido como el ensayo del ácido-butanol (Porter) estima todos los taninos condensados en términos de un solo producto químico que es común en una amplia gama de compuestos. Los taninos hidrolizables usualmente pueden ser determinados mediante HPLC pero los métodos para la detección conveniente de muestras con grandes cantidades de varios taninos hidrolizables no han sido desarrollados (Hartzfeld, Forkner, Hunter, \& Hagerman, 2002a). 


\section{JUSTIFICACIÓN}

En la literatura se encuentra ampliamente documentada la actividad antioxidante y biológica de los fitoquímicos de naturaleza polifenólica de diversas plantas. Muchas de ellas ya utilizadas en la herbolaria mundial. También se encuentra ampliamente documentado el beneficio a la salud cuando, estas plantas, se consumen como parte de la dieta diaria, como infusiones o cuando se utilizan como una preparación farmacéutica para coadyuvar en el tratamiento de diversas enfermedades.

Los hongos comestibles pueden ser fuente de diferentes nutracéuticos como ácidos grasos insaturados, compuestos fenólicos, tocoferoles, ácido ascórbico y carotenoides. Así, pueden ser utilizados directamente en la dieta para promover la salud, aprovechando los efectos aditivos y sinérgicos de todos los compuestos bioactivos presentes. Las propiedades antioxidantes de los polifenoles podrían ayudar al sistema de defensa endógeno, asumiendo una mayor importancia como posible agente protector reduciendo el daño oxidativo. Los hongos comestibles analizados pueden ser utilizados directamente en la dieta humana para combatir el estrés oxidativo, también pueden representar una fuente de polifenoles para ser usados como aditivos en la industria de alimentos o como componentes en formulaciones cosméticas y farmacéuticas. (Jeena et al., 2014).

El cultivo y consumo de hongos especialmente de la especie Pleurotus han sido incrementados día a día, gracias al corto tiempo de cultivo, su valor nutricional y medicinal. Existe información muy limitada en la literatura acerca de las propiedades bioactivas de Pleurotus spp (Y1ldı et al., 2017), debido a que hasta ahora, la investigación ha tendido a enfocarse en el valor de la dieta y en su cultivo (Jeena et al., 2014).

De la poca información que tenemos en la literatura, sabemos que Pleurotus ostreatus no tiene flavonoides presentes (González-Palma et al., 2016; Y1ldiz et al., 2017). Sin embargo sabemos que si están presentes taninos condensados extraíbles, y qué la concentración de estos varía dependiendo del sustrato que utilice el hongo para su crecimiento (Y1ldı et al., 2017). Debido a lo anterior, es importante continuar con estudios que permitan ampliar el 
conocimiento de las características bioactivas de los polifenoles presentes en Pleurotus ostreatus, así como determinar si es posible encontrar polifenoles extraíbles, ya que hasta el momento no se ha encontrado en la literatura algún reporte acerca de ello. 


\section{HIPÓTESIS}

Pleurotus ostreatus contiene polifenoles extraíbles, pero también es fuente de polifenoles no extraíbles, principalmente taninos hidrolizables y condensados, cuya capacidad reductora actúa en diferentes sistemas de óxido-reducción de la célula. 


\section{OBJETIVO GENERAL}

Estudiar las condiciones de extracción, cuantificación y evaluación de la actividad antioxidante de la fracción de polifenoles extraíbles y no extraíbles de Pleurotus ostreatus.

\subsection{Objetivos particulares}

a) Optimizar las condiciones de extracción de polifenoles extraíbles y no extraíbles de Pleurotus ostreatus por el método de superficie de respuesta.

b) Evaluar y comparar la actividad antioxidante de extractos de polifenoles extraíbles y no extraíbles de Pleurotus ostreatus. 


\section{MATERIALES Y MÉTODOS}

\subsection{Recolección y acondicionamiento de Pleurotus ostreatus}

En la realización de esta investigación, Pleurotus ostreatus (32783) se obtuvo del laboratorio de Biotecnología de la Universidad Autónoma de Tlaxcala de la American Type Culture Collection (ATCC), el cuerpo fructífero se recolectó con madurez comercial a los 30 días de haber sido inoculado en paja de trigo esterilizada.

Los hongos se lavaron con agua destilada y se sometieron a una prueba de deshidratación para seleccionar el método por el cual hay menor pérdida en la concentración de polifenoles en la muestra. El primer método fue una estufa a $60^{\circ} \mathrm{C}$ durante 6 horas, el segundo método secado al sol durante 8 horas, y el tercer método un deshidratador de aire caliente (Hamilton Beach 32100 ) a $70^{\circ} \mathrm{C}$ durante 12 horas, en todos los casos hasta obtener una humedad del $10 \%$. Una vez deshidratado el hongo se molió y la harina se tamizó hasta obtener un tamaño de partícula de $420 \mu \mathrm{m}$.

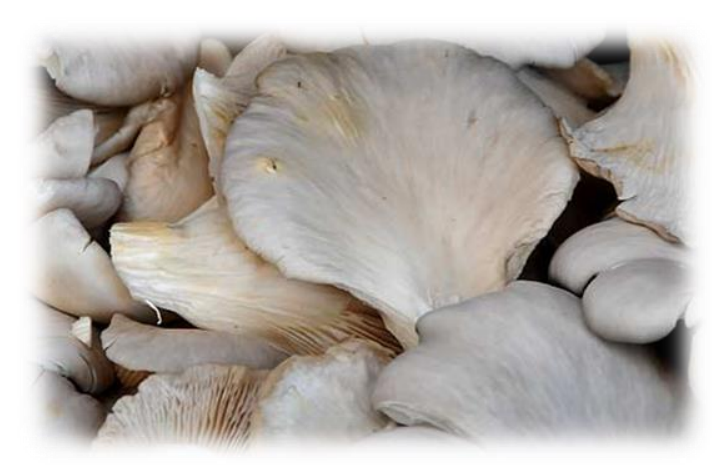

Figura 8. Pleurotus ostreatus fresco.

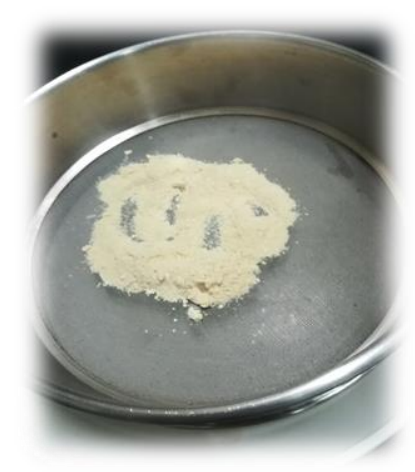

Figura 9. Harina de Pleurotus ostreatus. 


\section{Recolección de $P$. ostreatus}

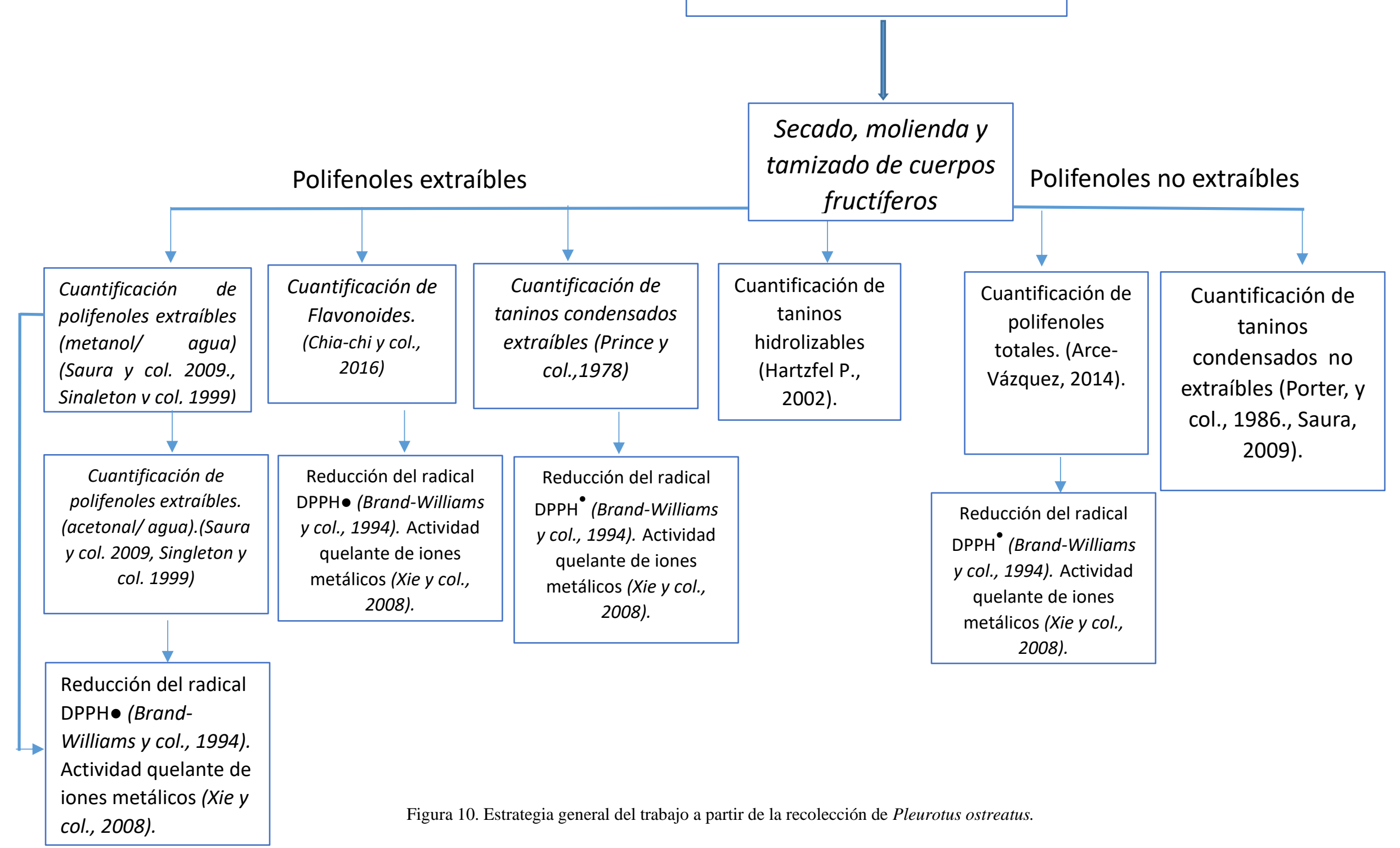




\subsection{Diseño experimental}

Para la optimización de la extracción de polifenoles se realizaron distintos diseños experimentales, para el caso de los polifenoles extraíbles se realizó una superficie de respuesta mediante el uso del diseño experimental central rotatorio $2^{\wedge} 3$ estrella y se utilizaron 3 factores de estudio: tiempo, temperatura, proporción. Para la evaluación de los taninos condensados por el método de la vainillina, de igual manera se aplicó el diseño central rotatorio $2^{\wedge} 3$ estrella con tiempo de extracción y temperatura de reacción como factores de estudio. Para la evaluación de los taninos condensados se utilizó el diseño experimental Box Behnken donde el tiempo, la temperatura y el volumen del solvente fueron los factores utilizados para la optimización.

\subsection{Cuantificación de polifenoles por el método de Folin-Ciocalteu.}

Este método mide el contenido de polifenoles en una muestra. El reactivo de Folin-Ciocalteu se prepara poniendo en ebullición por $10 \mathrm{~h}$ una mezcla de $100 \mathrm{~g}$ de tungstato de sodio $\left(\mathrm{Na}_{2} \mathrm{WO}_{4} .2 \mathrm{H}_{2} \mathrm{O}\right), 25 \mathrm{~g}$ de molibdato de sodio $\left(\mathrm{Na}_{2} \mathrm{MoO}_{4} .2 \mathrm{H}_{2} \mathrm{O}\right), 100 \mathrm{ml}$ de HCL concentrado, $50 \mathrm{~mL}$ de ácido fosfórico al $85 \%$ y $700 \mathrm{~mL}$ de agua. Posteriormente se agrega a la mezcla $150 \mathrm{~g}$ de sulfato de litio $\left(\mathrm{Li}_{2} \mathrm{SO}_{4} .4 \mathrm{H}_{2} \mathrm{O}\right)$ lo que le confiere un intenso color amarillo. 
La oxidación de los fenoles, presentes en la muestra, causa la aparición de una coloración azulada que presenta un máximo de absorción a $765 \mathrm{~nm}$, y que se cuantifica por espectrofotometría en base a una recta patrón de ácido gálico. Los compuestos fenólicos reaccionan con el reactivo bajo condiciones alcalinas (Chung, Wong, Wei, Huang, \& Lin, 1998).

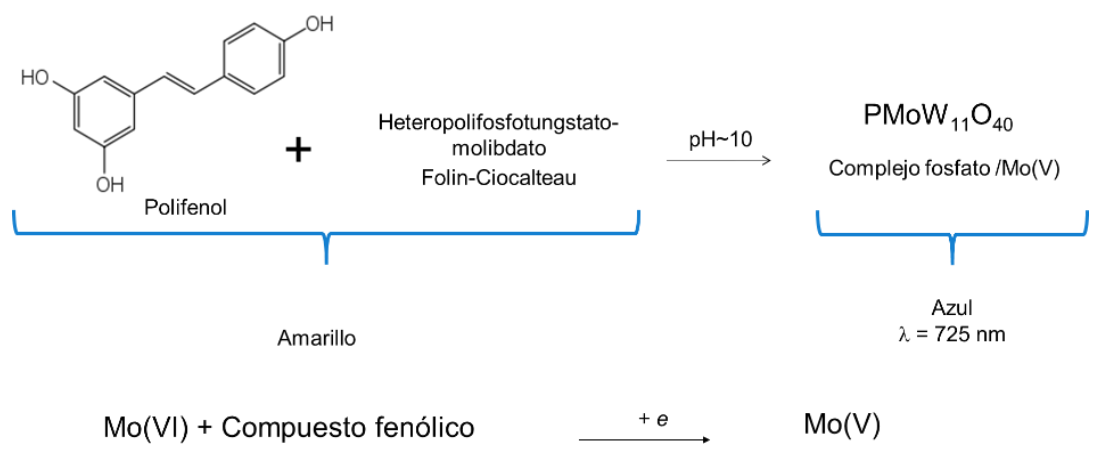

Figura 11. Reacción de los compuestos polifenólicos con el reactivo de Folin Ciocalteu.

Procedimiento experimental

Se realizó la curva patrón de ácido gálico para obtener la ecuación de la recta.

La mezcla de reacción consistió en $500 \mu \mathrm{L}$ de muestra con $4.5 \mu \mathrm{L}$ de agua destilada, se agregaron $200 \mu \mathrm{L}$ de reactivo de Folin y $500 \mu \mathrm{L}$ de solución saturada de $\mathrm{Na}_{2} \mathrm{CO}_{3}$, se agitaron los tubos, y se adicionaron por último $4.3 \mathrm{~mL}$ de agua destilada. Después de $1 \mathrm{~h}$ de reposo en la oscuridad se leyó la absorbencia a $725 \mathrm{~nm}$ en un espectro Thermo Genesis $10 \mathrm{UV}$, Madrid, España. El contenido total de polifenoles se calculó en equivalentes de ácido gálico. 


\subsection{Cuantificación de flavonoides.}

Los grupos hidroxilo de las posiciones 3 y 5 en flavonoides, son revelados por desplazamiento batocrómico causado por la reacción con cloruro de aluminio.

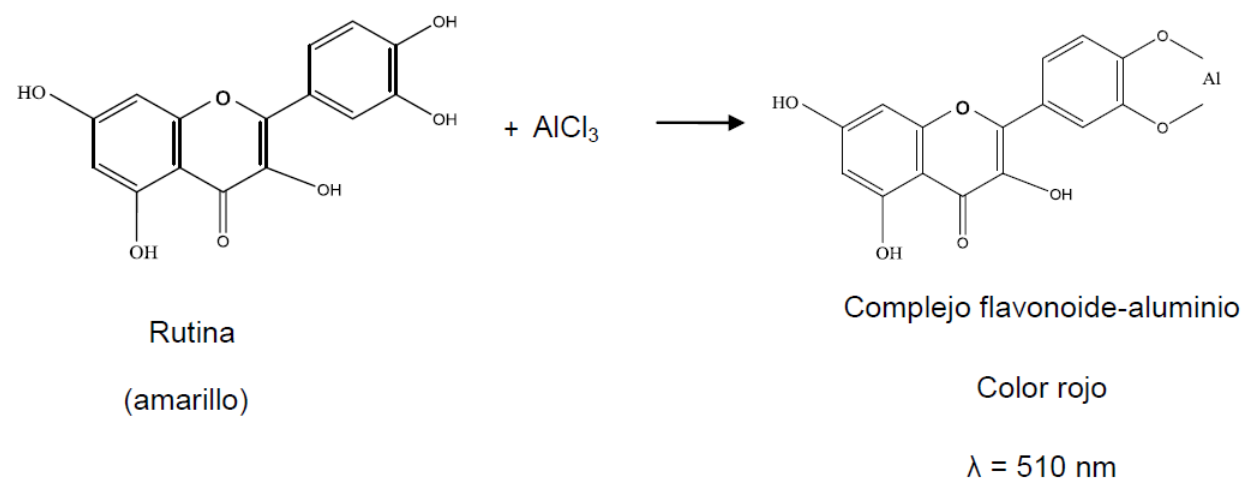

Figura 12. Reacción de flavonoides con rutina.

Se determinan usando rutina como compuesto de referencia. Se tomaron $100 \mu \mathrm{L}$ del extracto, diluido con $1250 \mu \mathrm{L}$ de agua destilada y mezclada con $75 \mu \mathrm{L}$ de NaNO2 al 5\%. Tras reposar 6 min, se adicionaron $150 \mu \mathrm{L}$ de $\mathrm{NaOH} 1 \mathrm{M}$ y $425 \mu \mathrm{L}$ de agua destilada. La absorbencia fue leída inmediatamente a $510 \mathrm{~nm}$ en un espectro Thermo Genesis $10 \mathrm{UV}$, Madrid, España (Hossain, Shah, Gnanaraj, \& Iqbal, 2011).

\subsection{Cuantificación de taninos condensados extraíbles por el método de la vainillina.}

La reacción de la vainillina implica la reacción de un aldehído aromático, vainillina, con el anillo meta-sustituido de flavanoles para producir un aducto rojo (Hagerman, 2002). 


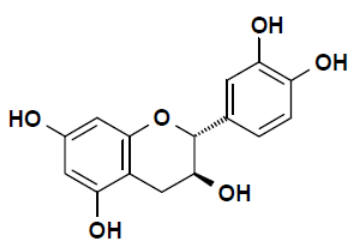

catechin

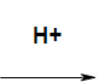

$\mathrm{O}^{\mathrm{H}}$

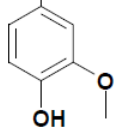

vanillin

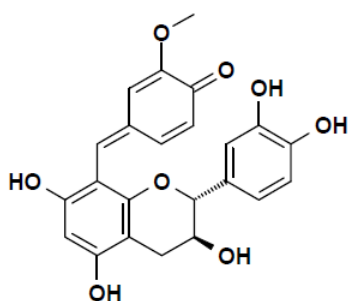

vanillin adduct $\lambda \max 500 \mathrm{~nm}$

Figura 13. Reacción de la vainillina con los taninos condensados.

\section{Procedimiento experimental}

Se realizaron las extracciones con metanol absoluto. Se tomó colocó $1 \mathrm{~mL}$ de alícuota de cada extracto en tubos de ensayo, los tubos se incubaron en un baño de agua. A los tubos se les adicionaron $5 \mathrm{~mL}$ del reactivo de vainillina en intervalos de $1 \mathrm{~min}$ al primer set de muestras y $5 \mathrm{ml}$ de la solución de HCL $4 \%$ en intervalos de $1 \mathrm{~min}$ al segundo set de muestras (blancos). Las muestras se colocaron en un baño de temperatura controlada LAB-LINE SHAKE-R-BATH durante 20 min y la temperatura de reacción se utilizó según lo obtenido en el diseño experimental. Una vez concluido el tiempo de la reacción se leyó la absorbencia a $500 \mathrm{~nm}$ en un espectro Thermo Genesis $10 \mathrm{UV}$, Madrid, España.

\subsection{Cuantificación de taninos hidrolizables por HPLC}

Se colocaron $20 \mathrm{mg}$ de muestra con $2.0 \mathrm{~mL}$ de metanol y $200 \mu \mathrm{L}$ de ácido sulfúrico concentrado $(18 \mathrm{M})$, la mezcla se dejó reaccionar durante 20 h a $85^{\circ} \mathrm{C}$. Las muestras se centrifugaron a 3500 rpm en una centrífuga Solbat J-600, y el sobrenadante se transfirió a otro tubo, el volumen se ajustó a $3.0 \mathrm{~mL}$ de agua destilada y posteriormente se adicionaron 4 alicuotas de $50 \mu \mathrm{L}$ de etanolamina. A cada muestra se le adicionaron $500 \mu \mathrm{L}$ de acetato de amonio 3.7 M hasta que el pH se ajustó a a 5.5 utilizando un potenciómetro conductronic pH 
120. Después del ajuste del $\mathrm{pH}$ las muestras se llevaron a un volumen final de $4.0 \mathrm{~mL}$ con agua destilada.

Se tomaron $200 \mu 1$ de alícuota de la muestra se mezcló con $20 \mu 1$ de duodecilsulfato de sodio (SDS) al 12\% acuoso, y $10 \mu \mathrm{l}$ de esa solución fue analizada por fase reversa (RP-HPLC), utilizando un equipo de cromatografía líquida HP-1100. La separación se realizó en una columna C-18 $100 \mathrm{~mm}$ x $4.6 \mathrm{~mm}$ con una tasa de flujo de $1.0 \mathrm{ml} / \mathrm{min}$, con un gradiente de solvente: $20-40 \%$ acetonitrilo durante $7 \mathrm{~min}$, regresando a las condiciones iniciales durante 3 min, seguida de 5 min isocrático. Ambos el acetonitrilo y agua fueron modificados con ácido trifluroacético al $0.04 \%$. la detección se hiso a 220 nm (Hartzfeld, Forkner, Hunter, \& Hagerman, 2002).

\subsection{Cuantificación de taninos condensados no extraíbles por el método de Porter.}

El método depende de la escisión oxidativa del enlace interflavan en soluciones alcohólicas de un mineral ácido para producir la colorida antocianidina (Hagerman et al., 1997).

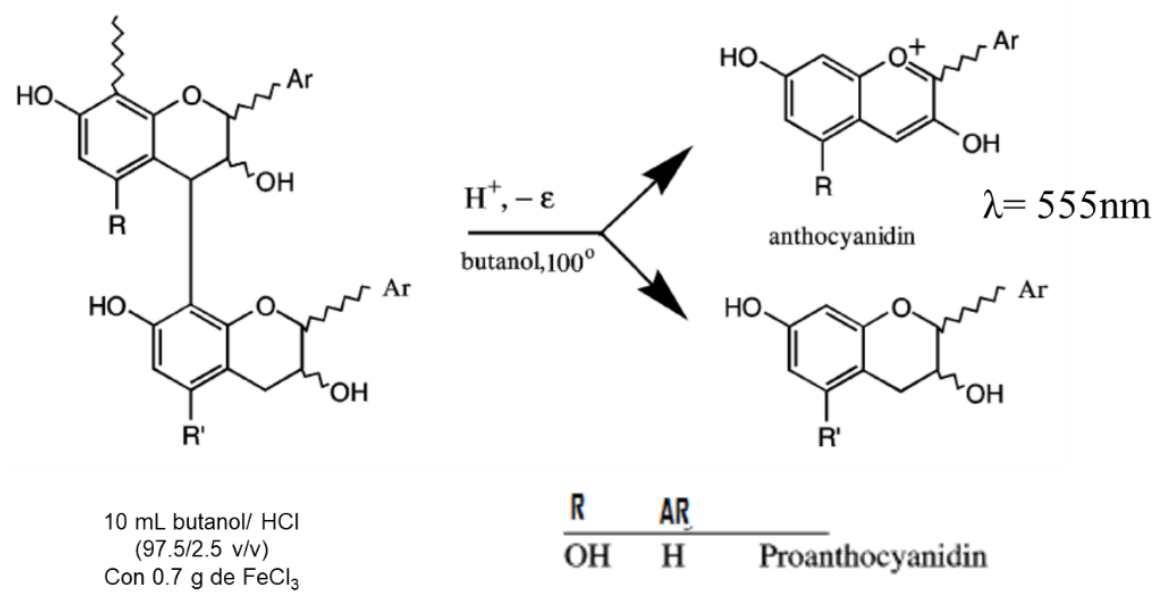

Figura 14. Depolimerización de taninos condensados por el método de Porter.

Procedimiento experimental (Pérez-Jiménez, Arranz, \& Saura-Calixto, 2009) 
Se colocaron $0.5 \mathrm{~g}$ de la muestra con $20 \mathrm{~mL}$ de metanol/agua acidificado (volumen depende del diseño experimental/ pH=2), permaneció en agitación durante 1 h y se centrifugó a 2500 rpm durante $10 \mathrm{~min}$, el sobrenadante se desechó. Al residuo se le adicionaron $20 \mathrm{~mL}$ de acetona/agua, tanto la agitación como la centrifugación se repitieron y el otro sobrenadante también se desechó. Al residuo se le adicionó butanol/HCL (97.5:2.5 v/v) con 0.7 g de $\mathrm{FeCl}_{3}$ a temperatura $\mathrm{T}$ (dependiente del diseño) durante un tiempo t (dependiente del diseño). Una vez que la reacción se llevó a cabo se centrifugó a 3000 rpm durante 10 min. El sobrenadante se recolecto y después de dos lavados con $10 \mathrm{~mL}$ de butanol, se mezclaron los sobrenadantes y se midió la absorbancia a 555nm.

\subsection{Cuantificación de taninos condensados por HPLC}

Se tomaron alicuotas de $50 \mathrm{mg}$ de residuio deshidratado con 74 (uL/ residuo) de quitinasa de Trichoderma viride (Sigma-aldrich) en $20 \mathrm{~mL}$ de un buffer de fosfatos $100 \mathrm{mM}$ a un pH 6.8 y $37^{\circ} \mathrm{C}$ durante 24 h (González, 2010). Una vez concluido el tiempo de incubación las muestras se dejaron enfriar y posteriormente se centrifugaron a $3500 \mathrm{rpm}$ durante $10 \mathrm{~min}$. Posteriormente el sobrenandante se inyectó en un sistema Aglient Technologies Serie 1100 HPLC acoplado a un detector de florescencia en un phenomenex (torrence, CA). Los componentes se separaron mediante fase normal, utilizando una columna Phenomenex Luna C18 (250mm x 4,6 mm i.d., tamaño de partículas 5 $\mu \mathrm{m}$ ) con una columna de guarda C-18. La fase móvil consistió cuaternaria en (A) diclorometano, (B) metanol y (C) ácido acético y agua (1:1 v/v). Con un gradiente linear: 0-30 min, $14.028 .4 \% \mathrm{~B} ; 30-45 \mathrm{~min}, 28.4-39.6 \% \mathrm{~B}$; $45-$ $50 \mathrm{~min}, 39.6-86.0 \% \mathrm{~B}$; 50-55 min, 86\% isocrático; 55-60 min 86-14\% B, seguido de 10 min de reequilibración de la columna. El el gradiente lineal $65 \mathrm{~min}$ fue el siguiente: 0-20 min, 1423.6\% B; 20-50 min, 23.6-35\% B; 50-55 min, 35-86\% B; 55-60 min 86\% B isocrático; 60$65 \mathrm{~min}, 86-14 \%$ B, seguido de $10 \mathrm{~min}$ de reequilibración de la columna antes de la siguiente corrida. Una constante de $4 \%$ de $\mathrm{C}$ se mantuvo durante todo el gradiente. El eluyente (1mL/min) que salió del HPLC se introdujo en un espectrómetro de masas con trampa de iones mejorando la ionización de proantocianidinas usando $10 \mathrm{mmol} / \mathrm{L}$ de acetato de amonio. 


\subsection{Polifenoles no extraíbles totales.}

Para poder cuantificar y liberar a los polifenoles no extraíbles atrapados en la fibra dietética de Pleurotus ostreatus se realizó una hidrólisis ácida como se describe a continuación. La muestra se mezcló 106 mL de ácido sulfúrico 5\% (v/v). La reacción de la hidrólisis se realizó en un reactor a $80^{\circ} \mathrm{C}$ x $90 \mathrm{~min}, 90^{\circ} \mathrm{C}$ x $60 \mathrm{~min}$ y $80^{\circ} \mathrm{C}$ x $80 \mathrm{~min}$. El resultado de la hidrólisis se neutralizó $(\mathrm{pH}=7)$ con una solución saturada de carbonato de sodio, después de centrifugarse a $3500 \mathrm{rpm}$ durante $10 \mathrm{~min}$, los PNE se extrajeron con etil acetato (1:20 v/v). El solvente se recolectó en un rotavapor Yamato RE200 y el precipitado se disolvió con 10 mL DMSO (Arce-vazquez, Fornué, Esther, \& Rosales, 2014).

\subsection{Actividad antioxidante por el método de reducción de DPPH}

El radical 2,2-difenol-1-picrilhidrazilo ( $\left.\mathrm{DPPH}^{*}\right)$ en su forma radical tiene un color púrpura con absorbencia máxima de $517 \mathrm{~nm}$. En su forma reducida, después de la acción de un antioxidante sobre el radical, la disolución se torna a color amarillo (Brand-Williams, Cuvelier, \& Berset, 1995).

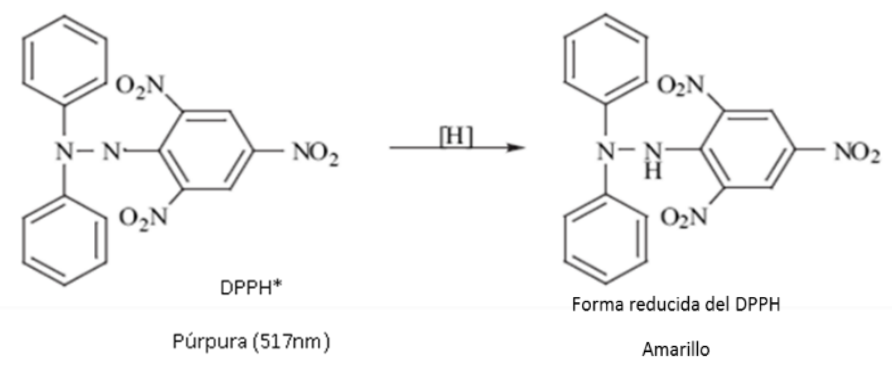

Figura 15. Reacción de un antioxidante con el radical DPPH.

Procedimiento experimental 
Se preparó una solución metanólica de $\mathrm{DPPH}^{`} 0.01 \mathrm{mM}$. La reacción se llevó a cabo con 500 $\mu \mathrm{L}$ de muestra en $3 \mathrm{~mL}$ de metanol, posteriormente se adicionaron $300 \mu \mathrm{L}$ de solución de DPPH', el decremento de absorbencia fue monitoreado a $517 \mathrm{~nm}$ después de $45 \mathrm{~min}$ de reacción. El porcentaje de inhibición del radical DPPH se calculó mediante la siguiente ecuación.

$$
\% \text { inhibición }=\frac{\left(A C_{(0)}-A A_{(t)}\right)}{A C_{(0)}} \times 100
$$

Dónde

$\mathrm{AC}_{(0)}=$ Absorbencia de control negativo

$\mathrm{AA}_{(\mathrm{t})}=$ absorbencia de la muestra después del tiempo $\mathrm{t}(45 \mathrm{~min})$.

\subsection{Actividad quelante sobre $\mathrm{Fe}^{2+}$}

El $\mathrm{Fe}^{2+}$ forma un complejo con 3 moléculas de ferrozina de color púrpura que presenta absorbencia máxima a $562 \mathrm{~nm}$. En presencia del antioxidante el $\mathrm{Fe}^{2+}$ puede quelarse y la intensidad de color púrpura del complejo con ferrozina es menor y es proporcional a la concentración del antioxidante en la muestra de interés (Xie, Huang, Xu, \& Jin, 2008).

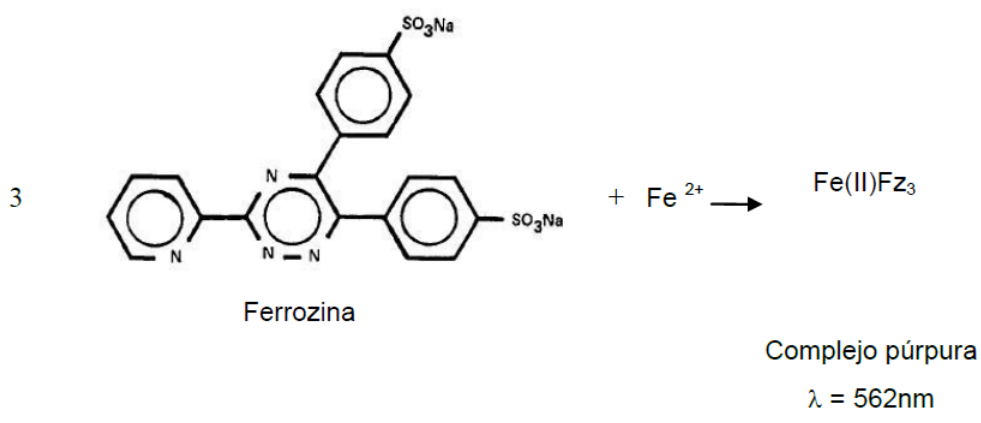

Figura 16. Reacción de quelación del $\mathrm{Fe}^{2+}$ con un antioxidante.

Se mezcló $1 \mathrm{~mL}$ de solución muestra con $50 \mu \mathrm{L}$ de $\mathrm{FeCl}_{2}$ y $1.85 \mathrm{~mL}$ de agua destilada. Después se agregaron $100 \mu \mathrm{L}$ de solución de ferrozina y se leyó la absorbencia a $562 \mathrm{~nm}$ 
después de 10 min de reposo a temperatura ambiente. Como control se usó agua destilada. Para determinar el porcentaje de quelación se aplicó la siguiente fórmula:

$$
\% \text { efecto quelante }=\frac{\left(A_{\text {control }}-A_{(\text {muestra })}\right)}{A_{(\text {control })}} x
$$




\section{RESULTADOS Y DISCUSIÓN}

6.1 Selección del método de deshidratado para la obtención de la harina.

En el método de secado en estufa se obtuvo una concentración de 2.2128 mg equivalentes de ácido gálico (EAG)/g de muestra seca, mientras que para el secado directo al sol se obtuvo $2.01537 \mathrm{mg}$ EAG/g de muestra seca y finalmente para el secado en deshidratador $2.605 \mathrm{mg}$ EAG/g de muestra seca. Para determinar si los diferentes métodos de secado del hongo afectan la concentración de los polifenoles, los resultados anteriores se compararon mediante una prueba de comparación de medias.

Tabla 1. Comparación de medias de los métodos de secado.

\begin{tabular}{|l|l|l|l|}
\hline Col_1 & Casos & Media & Grupos Homogéneos \\
\hline Sol & 3 & 2.15379 & $\mathrm{X}$ \\
\hline Horno & 3 & 2.21288 & $\mathrm{X}$ \\
\hline Deshidratador & 3 & 2.6053 & $\mathrm{X}$ \\
\hline
\end{tabular}

Se obtuvo un valor $p=0.002$ con un $\alpha=0.05$, tal como se muestra en la tabla 1 , entre el secado por horno y secado al sol no existe diferencia significativa, sin embargo, el método de secado en deshidratador si difiere de los métodos anteriores además de que con éste se obtiene una mayor concentración de polifenoles totales extraíbles. Debido al resultado anterior se determinó utilizar el secado mediante el deshidratador $\left(70^{\circ} \mathrm{C} \times 12 \mathrm{~h}\right)$ para la obtención de la harina ya que se utilizaría en todos los experimentos del presente trabajo.

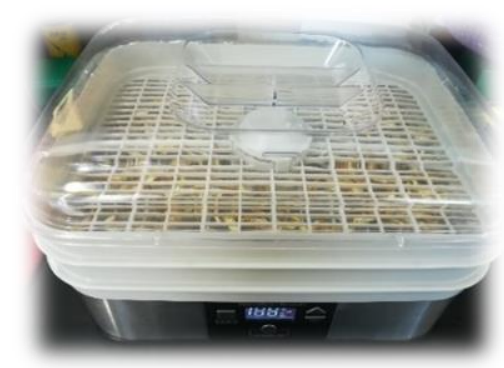

Figura 17. Deshidratador de aire caliente 


\subsection{Diseño experimental para extracción de polifenoles extraíbles y no extraíbles de Pleurotus ostreatus.}

Tanto para la cuantificación de los polifenoles extraíbles y para el método de la vainillina, se obtuvieron superficies de respuesta con el diseño central rotatorio $2^{\wedge} 2$ estrella obteniendo ensayos con 10 tratamientos cada uno. Mientras que para el método de Porter se utilizó el diseño Box Behnken y se obtuvo un ensayo con 15 tratamientos los cuales se muestran a continuación. Todos los análisis estadísticos se realizaron en el programa Statgraphycs Centurion XVI.II

Tabla 2. Tratamientos para polifenoles extraíbles ensayo 1.

\begin{tabular}{|c|c|c|}
\hline TRAT & MET-OH $/ \mathbf{H}_{\mathbf{2}} \mathbf{O}$ & $\mathbf{T}$ ( $\mathbf{m i n})$ \\
\hline 1 & $50 \%$ & 40 \\
\hline 2 & $50 \%$ & 40 \\
\hline 3 & $20 \%$ & 20 \\
\hline 4 & $80 \%$ & 20 \\
\hline 5 & $20 \%$ & 60 \\
\hline 6 & $80 \%$ & 60 \\
\hline 7 & $5 \%$ & 40 \\
\hline 8 & $95 \%$ & 40 \\
\hline 9 & $50 \%$ & 12 \\
\hline 10 & $50 \%$ & 68 \\
\hline
\end{tabular}

En este primer diseño para polifenoles extraíbles con metanol, se obtienen 10 tratamientos en el que se utilizan dos factores: proporción metanol /agua (20\%-80\%) y el tiempo que va de los 20 a 60 min. Cada tratamiento se realizó por triplicado. 
Tabla 3. Tratamientos para polifenoles extraíbles ensayo 2.

\begin{tabular}{|c|c|c|}
\hline TRAT & TEMP $\left({ }^{\circ} \mathbf{C}\right)$ & $\mathbf{T}(\mathbf{m i n})$ \\
\hline 1 & 30 & 40 \\
\hline 2 & 55 & 40 \\
\hline 3 & 30 & 20 \\
\hline 4 & 55 & 20 \\
\hline 5 & 42.5 & 44.14 \\
\hline 6 & 25 & 30 \\
\hline 7 & 60 & 30 \\
\hline 8 & 42.5 & 16 \\
\hline 9 & 42.5 & 30 \\
\hline 10 & 42.5 & 30 \\
\hline
\end{tabular}

Para el segundo ensayo con metanol se obtienen de igual manera 10 tratamientos, pero en este caso uno de los factores es la temperatura que va de $\operatorname{los} 30^{\circ} \mathrm{C}$ a los $55^{\circ} \mathrm{C}$, el tiempo se mantiene en el rango de 20 a 40 min. Cada tratamiento se realizó por triplicado.

Tabla 4. Tratamientos para polifenoles extraíbles ensayo 1.

\begin{tabular}{|c|c|c|}
\hline TRAT & ACETONA $/ \mathbf{H}_{\mathbf{2}} \mathbf{O}$ & $\mathbf{T}(\mathbf{m i n})$ \\
\hline 1 & 20 & 20 \\
\hline 2 & 80 & 20 \\
\hline 3 & 20 & 60 \\
\hline 4 & 80 & 60 \\
\hline 5 & 8 & 40 \\
\hline 6 & 92 & 40 \\
\hline 7 & 50 & 11 \\
\hline 8 & 50 & 68 \\
\hline 9 & 50 & 40 \\
\hline 10 & 50 & 40 \\
\hline
\end{tabular}

Para la extracción de polifenoles con acetona, se obtuvieron 10 tratamientos en los que se analizan dos factores, el rango de la proporción de acetona/agua que va del $20 \%$ al $80 \%$, y el tiempo de 20 a 60 minutos. Los extractos se realizaron por triplicado para cada uno de los tratamientos. 
Tabla 5. Tratamientos para polifenoles extraíbles ensayo 2.

\begin{tabular}{|c|c|c|}
\hline TRAT & TEMP $\left({ }^{\circ} \mathbf{C}\right)$ & $\mathbf{T}(\mathbf{m i n})$ \\
\hline 1 & 50 & 20 \\
\hline 2 & 35 & 12 \\
\hline 3 & 56 & 40 \\
\hline 4 & 35 & 68 \\
\hline 5 & 13 & 40 \\
\hline 6 & 20 & 60 \\
\hline 7 & 50 & 60 \\
\hline 8 & 20 & 20 \\
\hline 9 & 35 & 40 \\
\hline 10 & 35 & 40 \\
\hline
\end{tabular}

En el segundo ensayo de la extracción con acetona, se obtienen 10 tratamientos, pero en este caso se utiliza la temperatura $\left(20-50^{\circ} \mathrm{C}\right)$ y el tiempo en el mismo rango que el ensayo anterior $20-60 \mathrm{~min}$.

Tabla 6. Tratamientos para taninos condensados extraíbles.

\begin{tabular}{|c|c|c|}
\hline TRAT & TEMP $\left({ }^{\circ} \mathbf{C}\right)$ & T ( $\mathbf{m i n})$ \\
\hline 1 & 60 & 20 \\
\hline 2 & 30 & 50 \\
\hline 3 & 45 & 56 \\
\hline 4 & 23.78 & 35 \\
\hline 5 & 30 & 20 \\
\hline 6 & 45 & 13 \\
\hline 7 & 45 & 35 \\
\hline 8 & 60 & 50 \\
\hline 9 & 45 & 35 \\
\hline 10 & 66 & 35 \\
\hline
\end{tabular}

Para la cuantificación de los taninos condensados extraíbles, se obtuvieron 10 tratamientos como se observa en la tabla 6, en este caso el rango de temperatura de la reacción va de los 30 a los $60^{\circ} \mathrm{C}$, y el tiempo de extracción de 20 a 50 min. Los tratamientos se realizaron por triplicado. 
Tabla 7. Tratamientos para taninos condensados no extraíbles.

\begin{tabular}{|c|c|c|c|}
\hline TRAT & TEMP $\left({ }^{\circ} \mathbf{C}\right)$ & $\mathbf{T}(\mathbf{m i n})$ & VOL $(\mathbf{M L})$ \\
\hline 1 & 90 & 60 & 12.5 \\
\hline 2 & 110 & 60 & 12.5 \\
\hline 3 & 90 & 80 & 12.5 \\
\hline 4 & 110 & 80 & 12.5 \\
\hline 5 & 90 & 70 & 10 \\
\hline 6 & 110 & 70 & 10 \\
\hline 7 & 90 & 70 & 15 \\
\hline 8 & 110 & 70 & 15 \\
\hline 9 & 100 & 60 & 10 \\
\hline 10 & 100 & 80 & 10 \\
\hline 11 & 100 & 60 & 15 \\
\hline 12 & 100 & 80 & 15 \\
\hline 13 & 100 & 70 & 12.5 \\
\hline 14 & 100 & 70 & 12.5 \\
\hline 15 & 100 & 70 & 12.5 \\
\hline
\end{tabular}

Para la cuantificación de los taninos condensados por el método de Porter, se obtiene una serie de 15 tratamientos, en este caso se evalúan tres factores al mismo tiempo, temperatura de reacción $\left(90-110^{\circ} \mathrm{C}\right)$, tiempo de reacción $(60-80 \mathrm{~min})$ y volumen del solvente $(10-15$ $\mathrm{mL}$ ). Para cada uno de los tratamientos se realizaron duplicados.

\subsection{Polifenoles extraíbles por el método de Folin-Ciocalteu}

\subsubsection{Extractos metanólicos}

Una vez que se realizaron las extracciones metanólicas con las condiciones obtenidas del diseño experimental y se cuantificaron mediante el método de Folin-Ciocalteu, los datos se analizaron en el programa Statgraphycs Centurion XVI.II para la obtención de la superficie de respuesta que se muestra a continuación. 


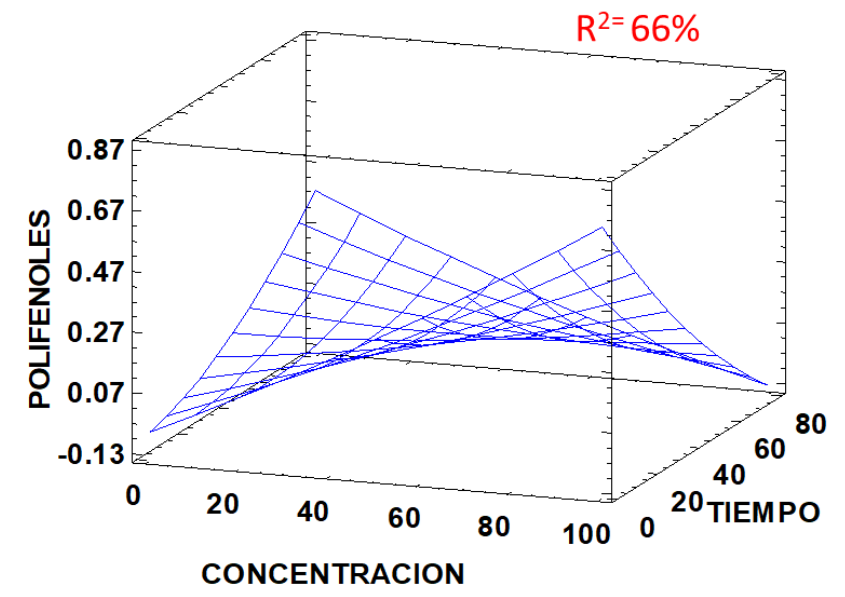

Figura 18. Superficie de respuesta de extractos metanólicos: concentración /tiempo.

En la superficie de respuesta es posible observar que a mayor concentración de metanol hay una mayor extracción de polifenoles, sin embargo, conforme el tiempo de extracción aumenta la concentración de polifenoles disminuye. El modelo matemático que describe esta superficie de respuesta es POLIFENOLES $=-0.0652826+0.00673069 *$ PROPORCIÓN + $0.00203464 *$ TIEMPO $+\quad+\quad 0.0000127736 *$ PROPORCIÓN^2 $0.00016452 *$ PROPORCIÓN*TIEMPO + 0.0000454069*TIEMPO^2

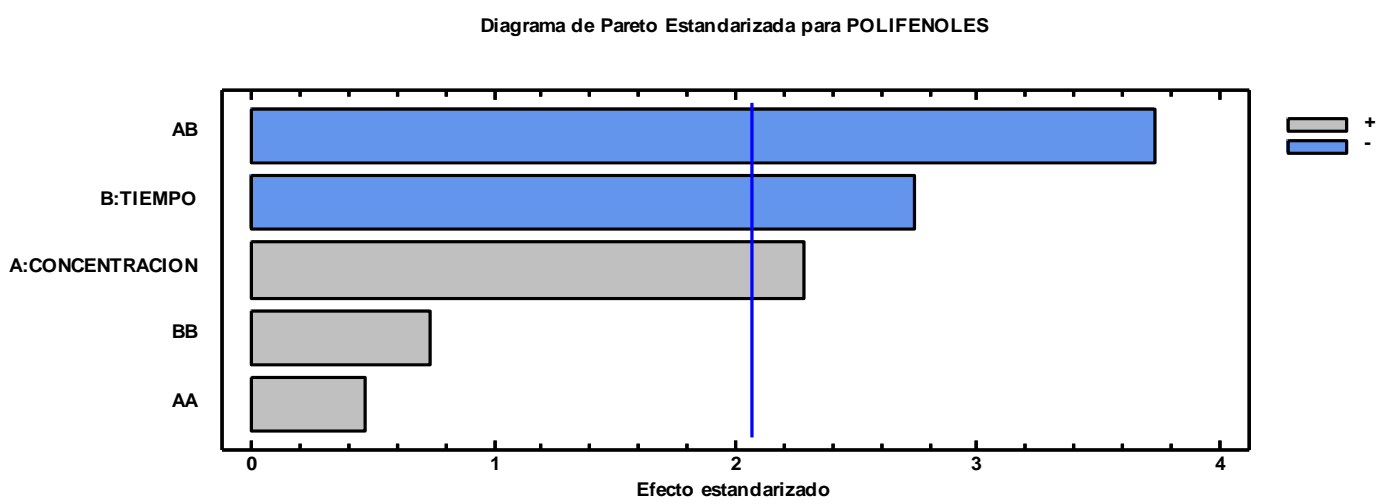

Figura 19. Diagrama de Pareto de extractos metanólicos: concentración / tiempo.

El diagrama de Pareto nos indica si los factores tienen efecto sobre el sistema que se está analizando. En este caso podemos observar que tanto el tiempo como la concentración tienen efecto real sobre el sistema, es decir que es importante el manejo de estos dos factores ya que una variación en estos puede afectar la extracción de los polifenoles. Cuando tenemos una 
mayor concentración de metanol en la solución de la extracción obtenemos una mayor concentración de polifenoles, sin embargo, no se requiere de amplios tiempos de extracción $(24$ h), esto puede deberse a que los polifenoles sufran alguna modificación, u oxidación conforme el tiempo de extracción incrementa.

En la siguiente tabla se muestra el tiempo y la concentración óptima de extracción para este ensayo.

Tabla 8. Condiciones óptimas de extracción de extractos metanólicos.

Factor Óptimo

Concentración

$92 \%$

Tiempo

$11 \mathrm{~min}$

Con un valor óptimo de $0.517 \pm 0.003 \mathrm{mg}$ EAG/g una vez que se obtuvo la concentración óptima se propuso agregar otra variable al experimento, que es la temperatura, para este segundo ensayo se obtuvo otra superficie de respuesta con el modelo matemático POLIFENOLES $=-1.12636+0.353025 *$ TEMPERATURA $+0.0479975 *$ TIEMPO $0.00217879 * T_{E M P E R A T U R A}^{\wedge} 2 \quad-\quad 0.00256061 *$ TEMPERATURA*TIEMPO + $0.000762322 * \mathrm{TIEMPO}^{\wedge} 2$, la cual se muestra a continuación,

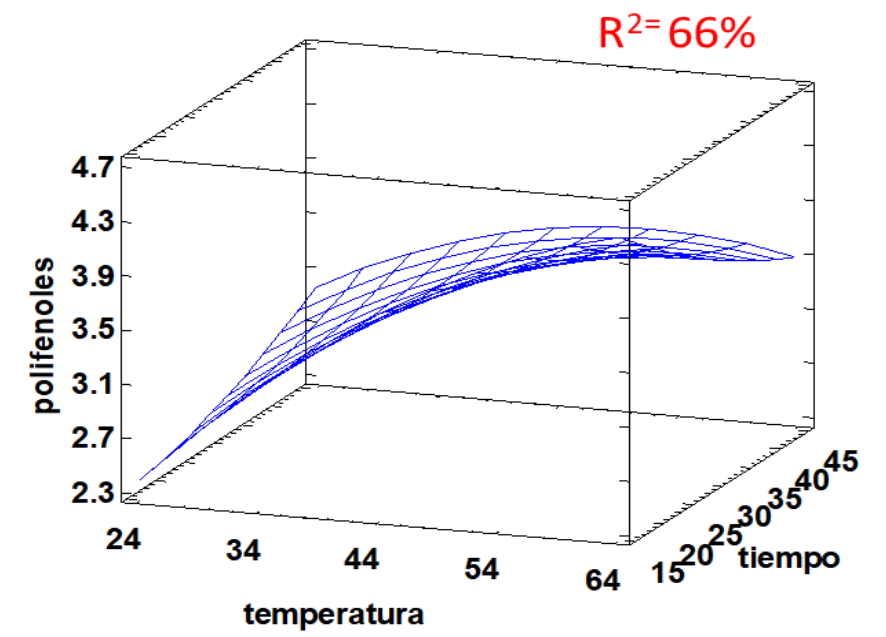

Figura 20. Superficie de respuesta de extractos metanólicos: temperatura/ tiempo. 
En esta superficie es posible observar que, a mayor temperatura, mayor es la concentración de polifenoles del extracto y una vez más es posible comprobar que a mayor tiempo, la concentración de polifenoles disminuye.

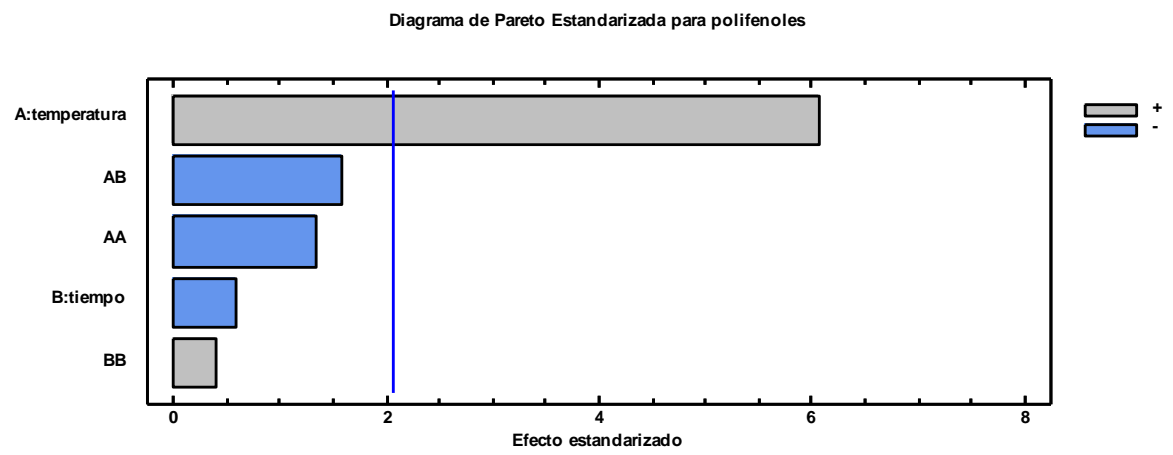

Figura 21. Diagrama de Pareto de extractos metanólicos: temperatura / tiempo.

En este sistema, el único factor que tiene efecto es la temperatura, el tiempo realmente no tiene un efecto significativo, sin embargo, los valores óptimos indican que un tiempo de 15 minutos es óptimo para la extracción de los polifenoles lo que también es posible observar en la superficie de respuesta.

Tabla 9. Condiciones óptimas de extracción de extractos metanólicos.

Factor Óptimo

Temperatura $\quad \mathbf{6 0}^{\circ} \mathbf{C}$

Tiempo $\mathbf{1 5} \mathbf{~ m i n}$

Con un valor óptimo de $4.34 \pm 0.003 \mathrm{mg}$ EAG/g mientras que por ejemplo Yildis, S. y col reportan una concentración de $1.768 \pm 0.082 \mathrm{mg}$ EAG/ g (los extractos se realizaron a temperatura ambiente, metanol al 99\% y 12 horas de extracción). Es probable que debido al incremento de la temperatura en el proceso de extracción se haya obtenido una mayor concentración de polifenoles totales en comparación con lo reportado en la literatura. 


\subsubsection{Extractos acetónicos}

Con la finalidad de extraer la mayor cantidad de polifenoles existentes en PO, se realizó un segundo ensayo en el que se realizaron extracciones acetona/agua. Después de obtener el diseño experimental, se realizaron las extracciones y se cuantificaron mediante FolinCiocalteu, los resultados se analizaron para obtener la superficie de respuesta que se muestra a continuación. POLIFENOLES $=1.16421-0.0249875^{*}$ TEMPERATURA + $0.000601506 *$ TIEMPO $\quad+\quad 0.000375842 *$ TEMPERATURA^$^{\wedge} 2+$ 0.0000858586*TEMPERATURA*TIEMPO - 0.0000698389*TIEMPO^2

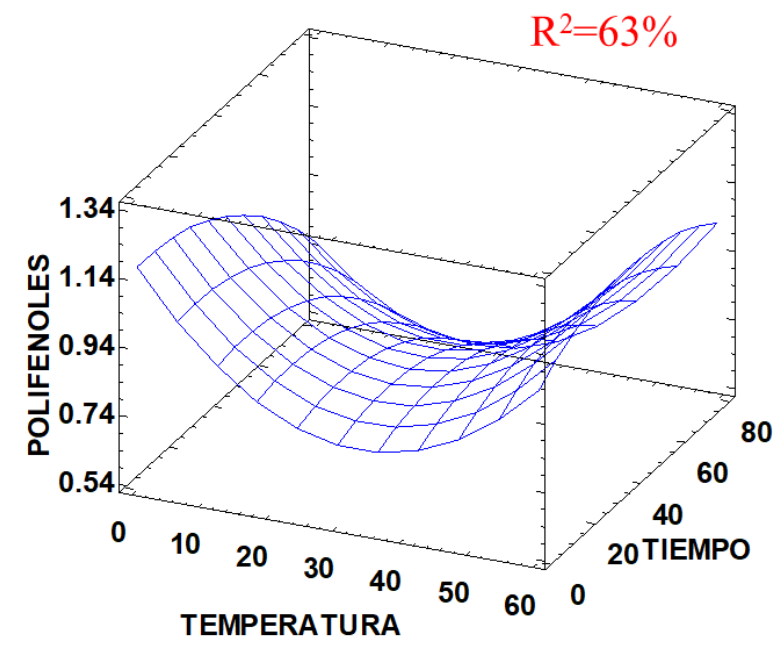

Figura 22. Superficie de respuesta de extractos acetónicos: temperatura/tiempo.

Para los extractos con acetona la concentración de polifenoles también incrementa conforme incrementa la temperatura, sin embargo, en este caso en tiempos cortos la concentración de

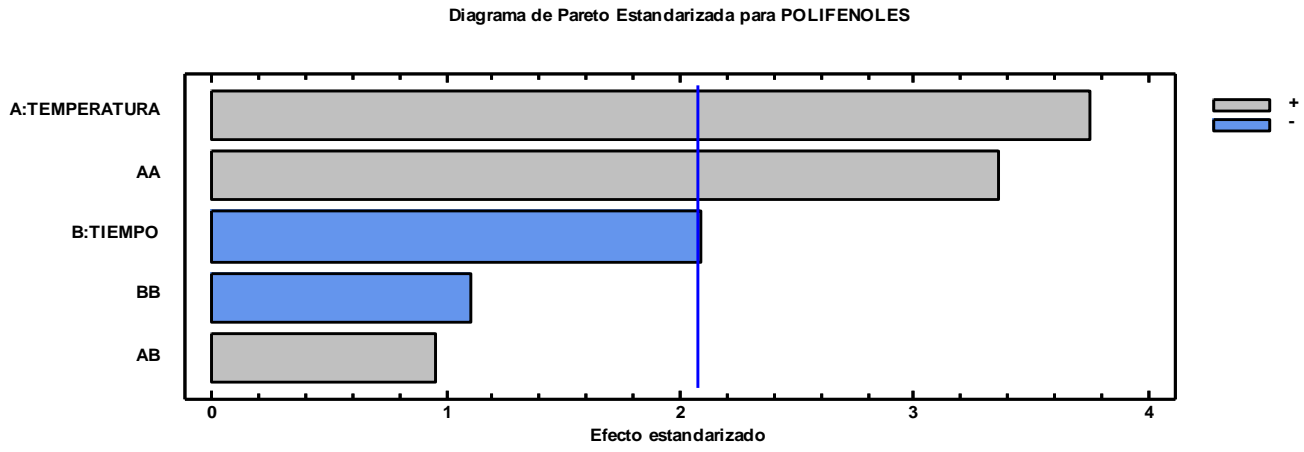

Figura 23. Diagrama de Pareto de extractos acetónicos: temperatura/tiempo. 
polifenoles disminuye, posteriormente incrementa, pero si se sigue avanzando en el tiempo la concentración de nuevo disminuye.

Es posible observar que tanto la temperatura como el tiempo siguen siendo factores que tienen efecto sobre el sistema (70\% acetona). Es decir que la concentración de polifenoles de la muestra se puede ver afectada si los factores no son utilizados de la manera adecuada. Las condiciones óptimas para la extracción obtenidas del análisis estadístico se muestran en la tabla 10, a diferencia de los extractos metanólicos en este caso el tiempo óptimo de extracción es de 40 min y la temperatura de $56^{\circ} \mathrm{C}$ la cual no está muy alejada de la temperatura óptima para los extractos metanólicos.

Tabla 10. Condiciones óptimas de extracción de extractos acetónicos.

\begin{tabular}{lr}
\hline Factor & Óptimo \\
Temperatura & $\mathbf{5 6}{ }^{\circ} \mathbf{C}$ \\
Tiempo & $\mathbf{3 8} \mathbf{~ m i n}$ \\
\hline
\end{tabular}

A estas condiciones óptimas se obtiene un valor de $1.05 \pm 0.02 \mathrm{mg}$ EAG/g de muestra. Con la finalidad de extraer la mayor concentración de polifenoles se realizó el segundo ensayo que arrojó la siguiente superficie de respuesta con modelo:

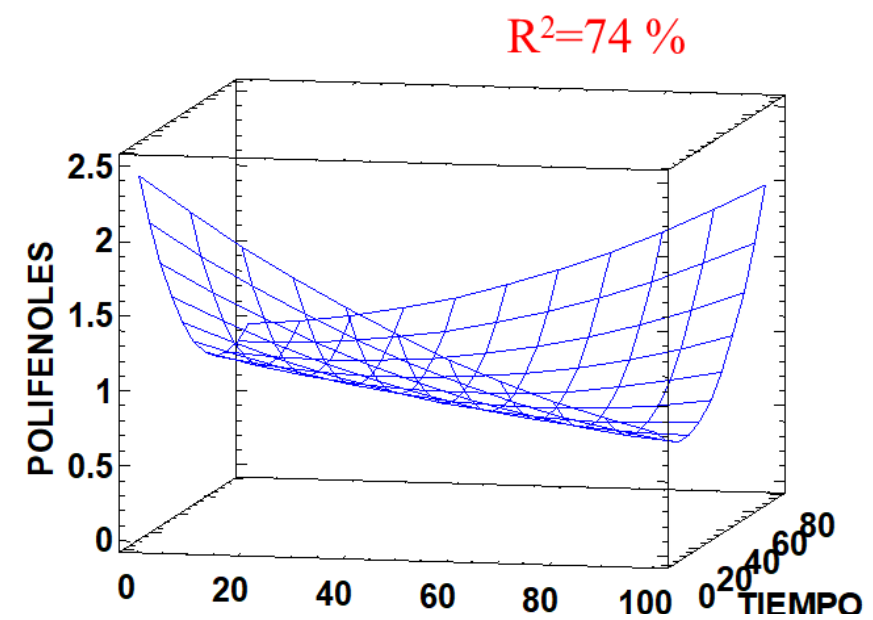

Figura 24. Superficie de respuesta de extractos acetónicos: tiempo/ proporción (agua/acetona). 
POLIFENOLES $=2.4276-0.024427 *$ PROPORCION $-0.0487331 *$ TIEMPO + $0.0000822812 * \mathrm{PROPORCION}^{\wedge} 2+0.000330808 * \mathrm{PROPORCION} * \mathrm{TIEMPO}+$ $0.000380208 *$ TIEMPO^ $^{\wedge}$

En este caso entre menor es la proporción de acetona y mayor es el tiempo de extracción, la concentración de polifenoles incrementa.

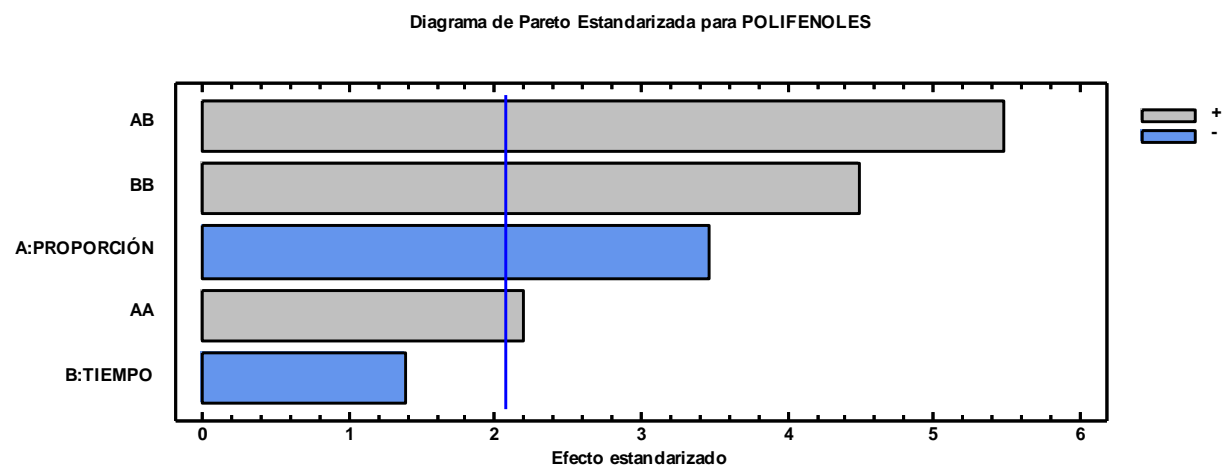

Figura 25. Diagrama de Pareto de extractos acetónicos: tiempo/proporción (agua/acetona).

La proporción de la solución y la interacción entre la proporción y el tiempo son factores que si presentan efecto sobre el sistema. Sin embargo, en este caso el tiempo no es un factor que tenga efecto, debido a lo anterior, no es necesario mantener la extracción durante tiempos prolongados (12 a 24 h). En el caso de la proporción la óptima es de 8\% acetona/agua.

Tabla 11. Condiciones óptimas de extracción de extractos acetónicos.

Factor Óptimo

PROPORCIÓN $\quad \mathbf{8} \%$

TIEMPO $\mathbf{1 1} \mathrm{min}$

Con estas condiciones se obtiene un valor de $1.75 \pm 0.02 \mathrm{mg}$ EAG/g. Es decir que, al variar la concentración del solvente incrementa la extracción de los compuestos polifenólicos extraíbles. Por otro lado, es posible observar que más que una extracción acetónica se tiene una extracción acuosa. Puesto que, en la optimización, la proporción de acetona es de $8 \%$ 
mientras que de agua se tiene un $92 \%$. Hasta el momento no se ha encontrado un artículo en el que se haga una extracción de este tipo.

\subsection{Flavonoides}

Para la cuantificación de flavonoides, previamente se realizó la curva patrón utilizando como estándar rutina (apéndice A). En este caso no se realizó una superficie de respuesta únicamente se llevó a cabo la metodología anteriormente descrita y se obtuvo una concentración de $0.018 \mathrm{mg}$ eq de rutina/ml. Además de que no se observó un cambio de coloración en las muestras analizadas como se reporta en la literatura. En el 2016 GonzálesPalma y col reportaron una concentración de $0.069 \pm 0.003 \mathrm{mg}$ eq de quercetina. En 2017 Yildiz y col. mencionan en su trabajo que no hay presencia de este tipo de compuestos polifenólicos, aunque en este caso utilizan quercetina como estándar. Por lo tanto, es posible decir que Pleurotus ostreatus no produce polifenoles de tipo flavonoides debido a que ningún espécimen que pertenezca al reino fúngico contiene la maquinaria enzimática necesaria para catalizar las rutas metabólicas de síntesis de flavonoides desde los compuestos fenólicos generados en la ruta del ácido siquímico. Además, según el departamento de agricultura de Estados Unidos (USDA), los hongos no se consideran como fuentes de flavonoides (Iwalokun, Usen, Otunba, \& Olukoya, 2007). Es posible que si se detecta algún contenido de flavonoides en hongos se deba a que el $\mathrm{AlCl}_{3}$ forma complejos con grupos hidroxilos que estén localizados próximos a grupos cetónicos y/o con hidroxilos dispuestos en posición orto, además de que el $\mathrm{AlCl}_{3}$ puede reaccionar con muchos de los compuestos fenólicos endógenos de los hongos cuyas moléculas incluyen esos grupos indicados como radicales (Ramírez Anguiano, 2009).

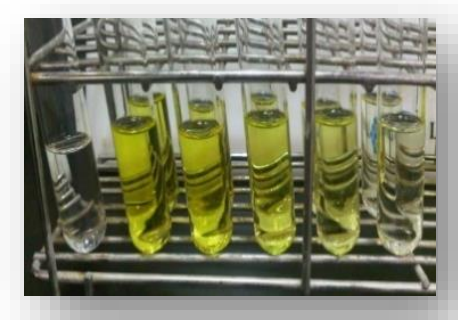

Figura 26. Reacción de flavonoides. 


\subsection{Taninos condensados extraíbles por el método de la vainillina.}

El método de la vainillina es un método complejo, debido a que la reacción no se lleva a cabo si este llega a entrar en contacto con el agua. El experimento se divide en dos etapas la primera consta de la obtención de los extractos y la segunda de la reacción de estos con la solución de vainillina. Por lo tanto, los factores que se utilizaron fueron el tiempo de extracción y el tiempo de reacción, después del análisis de resultados, se obtuvo la superficie de respuesta que se muestra a continuación. TANINOS CONDENSADOS $=-242.328+$ $12.9053 *$ TEMPERATURA + 1.44562*TIEMPO - 0.102667*TEMPERATURA^2 0.0246154*TEMPERATURA*TIEMPO - 0.00434484*TIEMPO^2

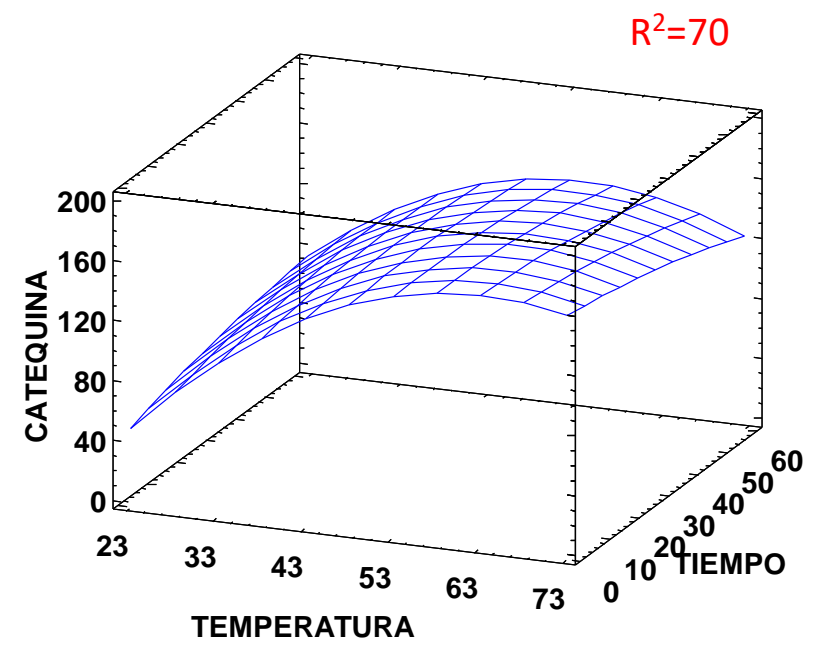

Figura 27. Superficie de respuesta de taninos condensados extraíbles.

La superficie de respuesta nos muestra que, si la temperatura de la reacción es muy baja, la cuantificación de los taninos condensados es menor, y conforme incrementa la temperatura, la cuantificación es mayor, sin embargo, después de los $63^{\circ} \mathrm{C}$ la cuantificación disminuye. En el caso del tiempo de extracción, entre mayor sea este, menor es la concentración de taninos condensados. 


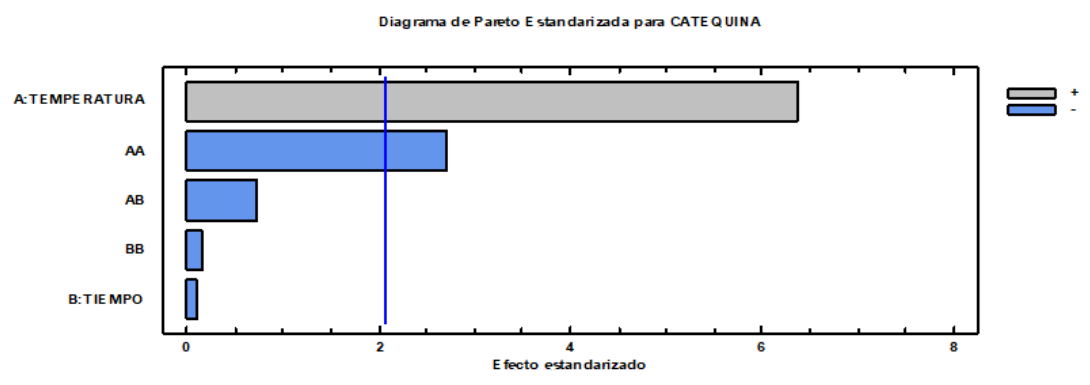

Figura 28. Diagrama de Pareto de taninos condensados extraíbles.

La temperatura en este caso es un factor que, si tiene efecto sobre el sistema, pero para el caso del tiempo no es así, el tiempo no es un factor que tenga efecto sobre la concentración de los taninos condensados. La optimización indica como se muestra en la tabla 12, que no es necesario un tiempo prolongado de extracción $(12$ h) para obtener la mayor concentración de taninos condensados, 13 minutos de extracción son suficientes. Y la temperatura óptima de la reacción para que se cuantifique una mayor concentración es de $61^{\circ} \mathrm{C}$.

Tabla 12. Condiciones óptimas para la cuantificación de taninos condensados extraíbles.

\begin{tabular}{ll}
\hline Factor & Óptimo \\
TEMPERATURA & $\mathbf{6 1}^{\circ} \mathbf{C}$ \\
TIEMPO & $\mathbf{1 3}$ min \\
\hline
\end{tabular}

Bajo estas condiciones se obtiene una concentración de $0.59 \pm 0.1 \mathrm{mg}$ eq de catequina por gramo de muestra seca. En 2011 Beas F y col, realizan una evaluación de taninos condensados de huitlacoche (Ustilago maydis) colectado en distintas regiones del país, la concentración de taninos condensados varía dependiendo del lugar de recolección y va desde los 0.322 hasta $1.4 \mathrm{mg}$ eq de catequina/ g de muestra seca. Yildiz y Col. obtienen $0.618 \pm$ 0.062, hasta los $3.691 \mathrm{mg}$ eq de catequina/g como mmáximo, sin embargo, en el ensayo que ellos realizan se compara P.O. que ha sido cultivado en diferentes sustratos. Los resultados que obtuvieron concluyen que la concentración de taninos condensados extraíbles, dependen del sustrato en el que el hongo fue cultivado. Es posible decir que Pleurotus ostreatus se 
encuentra dentro del rango reportado hasta ahora en la literatura, a pesar de que las metodologías reportadas en la literatura y las usadas en este ensayo no son exactamente las mismas. Algo más que cabe destacar es que existe la posibilidad de que la concentración de taninos condensados dependa del sustrato en el que los hongos sean cultivados. Ya que el método de vainillina funciona exclusivamente para taninos condensados del tipo Flavan-3ol meta-sustituidos, es posible decir que Pleurotus ostreatus produce taninos condensados de este tipo.

\subsection{Taninos hidrolizables por HPLC}

La mayoría de los constituyentes de los taninos hidrolizables son una mezcla de galatos de glucosa que pueden contener de tres a siete unidades de ácido gálico.

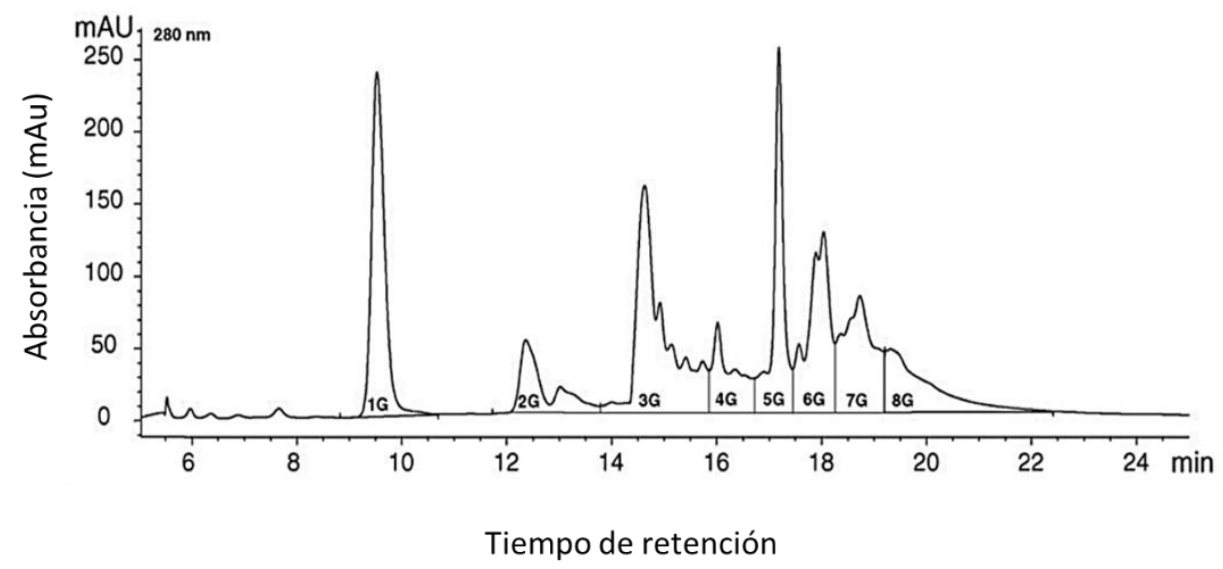

Figura 29. Cromatograma obtenido de la metilación de taninos hidrolizables de Pleurotus ostreatus, por fase reversa. 
En la tabla se muestra la concentración obtenida de cada uno de los galatos, la producción de metil-galato es expresada en gramos de metil-galato por gramo de tanino.

Tabla 13. Producción de metil galato de taninos hidrolizables, el rendimiento del metil galato es calculado de los pesos moleculares de los taninos y metil galato, y se expresa en gramos de metil galato/g de tanino.

\begin{tabular}{cc}
\hline Taninos hidrolizables & $\begin{array}{c}\text { Producción de metil-galato } \\
\text { ( g metil galato/g tanino) }\end{array}$ \\
\hline Monogaloil glucosa & $0.11 \pm 0.003$ \\
Digaloil glucosa & $0.10 \pm 0.01$ \\
Trigaloil glucosa & $0.08 \pm 0.05$ \\
\hline Tetragaloil glucosa & $0.01 \pm 0.1$ \\
\hline Pentagaloil glucosa & $0.13 \pm 00.3$ \\
Hexagaloil glucosa & $0.16 \pm 0.13$ \\
\hline Heptagaloil glucosa & $0.15 \pm .05$ \\
\hline
\end{tabular}

Hasta el momento no se ha encontrado en la bibliografía algún reporte sobre los taninos hidrolizables en Pleurotus ostreatus. Sin embargo, estos valores se encunetran por debajo de los obtenidos por Hartzfeld y colaboradores en 2002. También es posible observar que no existe un patrón en la concentración de los diferentes galatos respecto al número de unidades de ácido gálico unidos a la glucosa. 


\subsection{Taninos condensados no extraíbles por el método de Porter}

Esta superficie de respuesta se obtiene mediante el análisis de 3 factores: temperatura, tiempo y volumen del solvente.

CATEQUINA $=-19118.6+350.185 *$ TEMPERATURA $+45.4282 *$ TIEMPO 61.0185*VOLUMEN $\quad$ - $\quad 1.66377 *$ TEMPERATURA^$^{\wedge} 2$

0.440972*TEMPERATURA*TIEMPO + 2.06944*TEMPERATURA*VOLUMEN $0.0109954 * \mathrm{TIEMPO}^{\wedge} 2+0.486111^{*} \mathrm{TIEMPO}^{*} \mathrm{VOLUMEN}-6.50926 * \mathrm{VOLUMEN}^{\wedge} 2$

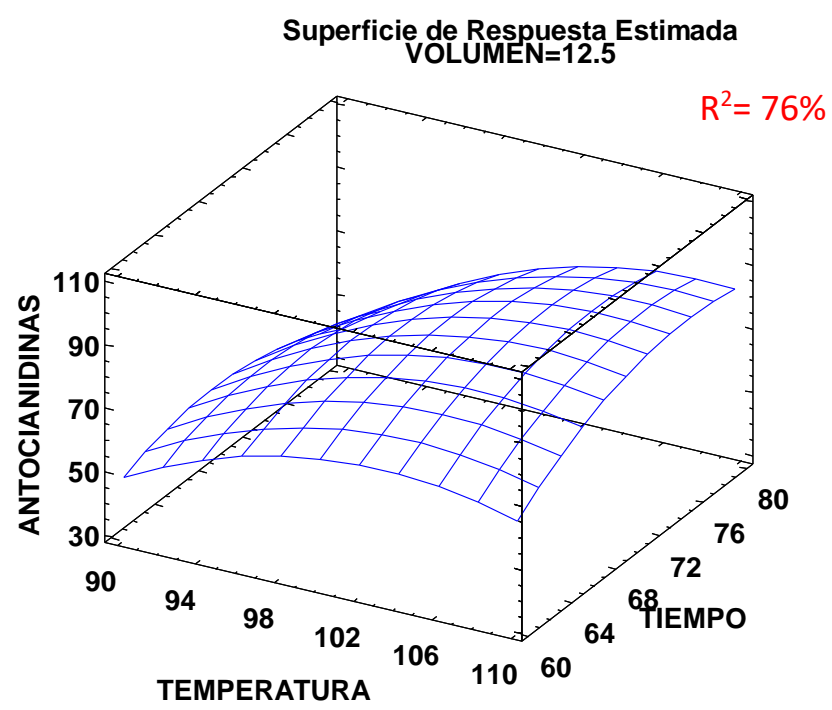

Figura 30. Superficie de respuesta de taninos condensados no extraíbles.

Es posible observar que conforme la temperatura aumenta se cuantifica una mayor concentración de proantocianidinas no extraíbles, sin embargo, a temperaturas cercanas a $110^{\circ} \mathrm{C}$ la concentración disminuye. Si el tiempo de reacción incrementa también lo hace la concentración. 


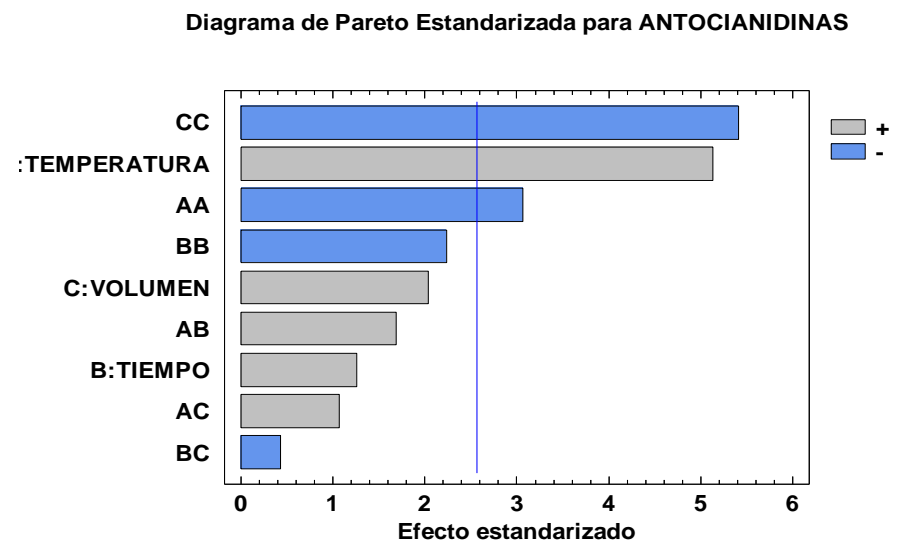

Figura 31. Diagrama de Pareto de taninos condensados no extraíbles.

El único factor que tiene un efecto real sobre la depolimerización de los taninos condensados no extraíbles es la temperatura, el diagrama de Pareto nos muestra que el tiempo y el volumen del solvente no son factores determinantes en la reacción. Sin embargo, es posible encontrar condiciones óptimas para la cuantificación de proantocianidinas obtenidas a partir de la depolimerización de los taninos condensados por el método de Porter. De esta manera después del análisis de los datos se obtienen las condiciones óptimas que se muestran en la siguiente tabla.

Tabla 14. Condiciones óptimas para la cuantificación de taninos condensados no extraíbles.

\begin{tabular}{|l|l|}
\hline Factor & óptimo \\
\hline TEMPERATURA & $\mathbf{1 0 4}^{\mathbf{C}}$ \\
\hline TIEMPO & $\mathbf{8 0} \mathbf{~}$ in \\
\hline VOLUMEN & $\mathbf{1 5} \mathbf{~} \mathbf{l}$ \\
\hline
\end{tabular}

Obteniendo una concentración de $0.63 \pm 0.1 \mathrm{mg}$ de proantocianidinas no extraíbles por cada $100 \mathrm{~g}$ de muestra seca. Debido a la complejidad tanto de la estructura química de los taninos condensados no extraíbles, así como a la de la matriz dietética de PO, es difícil poder cuantificar dichos compuestos, por ello hasta el momento no se ha encontrado en la literatura algún reporte de la concentración de taninos condensados no extraíbles de PO con la que 
podamos compararlo, sin embargo, este valor se encuentra cercano al de la manzana con piel (Jonagold) $0.79 \pm 9 \mathrm{mg}$ de proantocianidina $/ 100 \mathrm{~g}$ de muestra seca reportada por Pérez Jiménez y col en 2009.

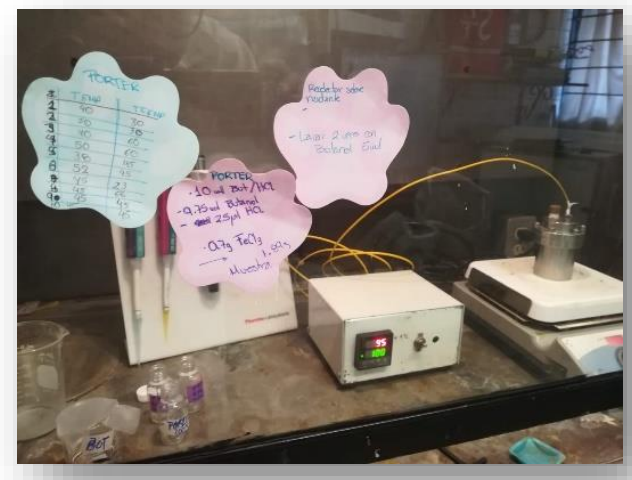

Figura 32. Reactor para método de Porter.

\subsection{Taninos condensados no extraíbles por HPLC- MS}

A raíz de la acción enzimática para la degradación de la pared celular, los sobrenadantes se inyectaron como se menciona en la metodología y se obtuvieron los resultados que se muestran en la siguiente tabla.

Tabla 15. concentración de taninos condensados no extraíbles por HPLC

\begin{tabular}{|l|c|}
\hline $\begin{array}{c}\text { concentración } \\
\mathrm{mg} / \mathbf{1 0 0} \mathrm{g} \text { de muestra }\end{array}$ \\
\hline monómeros & - \\
\hline díemeros & - \\
\hline trímeros & $0.11 \pm 0.03$ \\
\hline $\mathbf{4 - 1 0 u}$ & - \\
\hline $\mathbf{7 - 1 0} \mathrm{u}$ & $0.07 \pm 0.001$ \\
\hline polímeros & - \\
\hline Total NEPA & 0.18 \\
\hline
\end{tabular}

La concentración de taninos condensados no extraíbles por este método fue menor que la de la obtenida por el método de porter, esto pude deberse a que las condiciones (temperatura, $\mathrm{pH}$, tiempo de incubación) de la reacción para que la quitinasa utilizada pueda degaradar la quitina de la pared célular no hayan sido eficientes. Pérez Jiménez en 2009 comparan el uso 
de tres enzimas para la degradación de manzana, durazno amarillo y nectarina con piel, en este ensayo dependiendo de la enzima utilizada (pectinasa 690L, Depol 740L, Promod 439L) es la concentración de taninos condensados no extraíbles encontrados en cada una de las muestras, sin embargo, igual que en este caso, la concenración de taninos condensados cuantificada es menor que la obtenida por el método de porter. A continución se muestra el cromatograma obtenido.

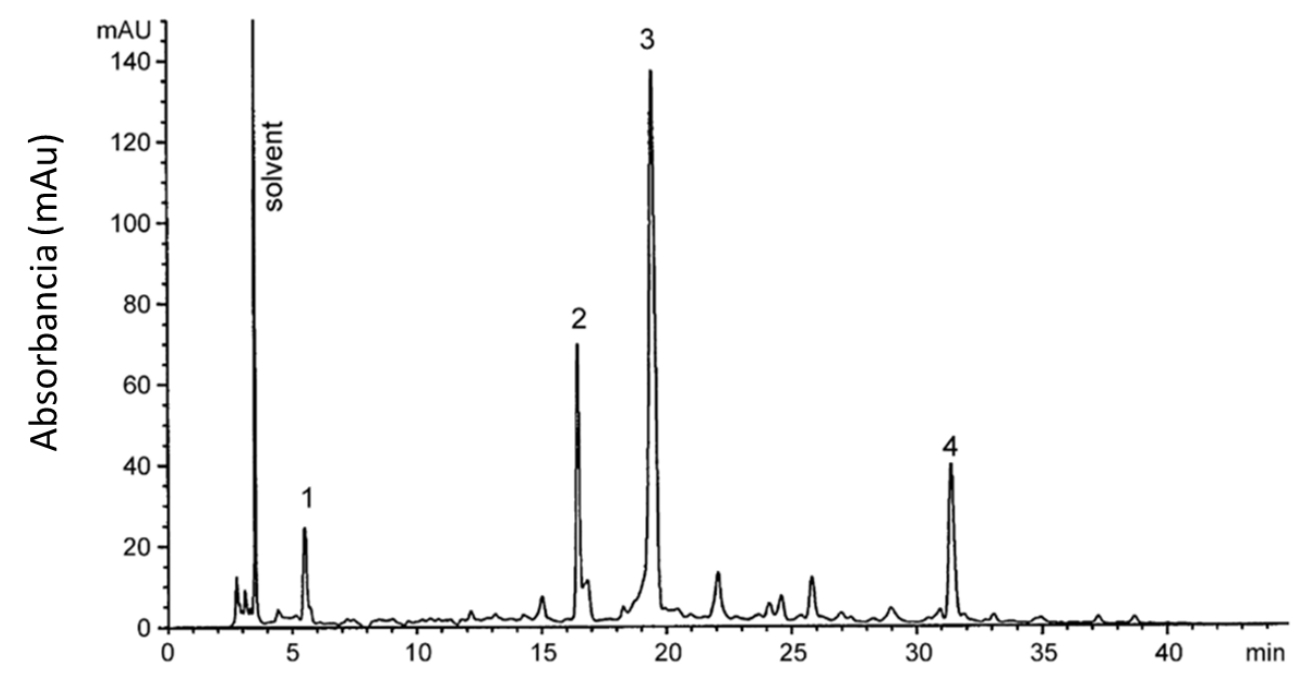

Tiempo de retención

Figura 33. Cromatograma obtenido de la degradación enzimática de Pleurotus ostreatus, por fase normal.

Sin embargo con éste método fue posible cuantificar la presencia de catequina y epicatequina presente en nuestras muestras.

\subsection{Polifenoles no extraíbles totales}

En la siguiente tabla se muestran los resultados obtenidos de la hidrólisis ácida, la concentración de polifenoles no extraíbles obtenidos a partir del rompimiento de la fibra dietética de Pleurotus ostreatus.

Tabla 16. Concentración de polifenoles no extraíbles totales.

\begin{tabular}{|c|c|}
\hline Tratamientos & $\begin{array}{c}\text { mg EAG/g muestra } \\
\text { seca }\end{array}$ \\
\hline $80^{\circ} \mathrm{C}$ x $90 \mathrm{~min}$ & $2.03 \pm 0.01$ \\
\hline $90^{\circ} \mathrm{C} \times 60 \mathrm{~min}$ & $1.5 \pm 0.01$ \\
\hline $80^{\circ} \mathrm{C} \times 1.4 \mathrm{~h}$ & $1.54 \pm 0.01$ \\
\hline
\end{tabular}


En este caso el tratamiento de $80^{\mathrm{a}} \mathrm{C}$ x $90 \mathrm{~min}$, presenta la mayor concentración de polifenoles no extraíbles, es posible que los polifenoles cuentificados en este ensayo incluya tanto a los taninos condensados como a los hidrolizables que se liberaron de la fibra dietética de nuestro hongo.

\subsection{Actividad antioxidante por inhibición del radical DPPH}

\subsubsection{Extractos metanólicos}

Una vez que se determinaron las condiciones óptimas para la extracción de los polifenoles, se realizaron las extracciones a esas condiciones y a los extractos optimizados se les evaluó la actividad antioxidante mediante la inhibición del radical DPPH ${ }^{*}$ en donde se obtuvo un

porcentaje de $61 \% \pm 0.001$ de inhibición. Beas y colaboradores en 2011 reportan una actividad antioxidante del $56.5 \%$ al 74.2\% de inhibición de DPPH ${ }^{\bullet}$ de extractos metanólicos de huitlacoche (hongo comestible), esta actividad varía dependiendo del lugar de origen del hongo. Es posible decir que Pleurotus ostreatus presenta actividad antioxidante que coincide con otro hongo reportado en la literatura. Sin embargo, la concentración de polifenoles extraíbles de extractos metanólicos es baja en comparación con otras plantas o frutos, así que no es posible explicar aún el por qué la buena actividad antioxidante de Pleurotus ostreatus y los hongos en general.

\subsubsection{Extractos acetónicos}

Una vez que se conocen las condiciones óptimas de extracción se realizaron las extracciones optimizadas para verificar que los extractos presentaran actividad antioxidante. En este caso se obtuvo un $71 \% \pm 0.008$ de inhibición del radical.

De igual manera que el caso anterior, el porcentaje de inhibición del radical, se encuentra dentro del rango reportado para el huitlacoche (Beas et al., 2011). 


\subsubsection{Taninos condensados extraíbles}

Se realizó la extracción optimizada de los taninos condensados extraíbles y a dichos extractos se les evaluó la actividad inhibitoria del radical $\mathrm{DPPH}^{\cdot}$ mostrando un $70 \% \pm 0.002$ de inhibición.

\subsubsection{Polifenoles no extraíbles totales.}

A los hidrolizados obtenidos se de la hidrólisis ácida se les evluó la actividad antioxidante obteniendo los resultados que se muestran en la tabla.

Tabla 17. Inhibición del radical DPPH de polifenoles totales no extraíbles.

\begin{tabular}{|l|c|}
\hline \multicolumn{1}{|c|}{ Tratamientos } & $\begin{array}{c}\text { \% de inhibición del } \\
\text { DPPH }^{\bullet}\end{array}$ \\
\hline $\mathbf{8 0}^{\circ} \mathbf{C} \times \mathbf{9 0}$ min & $76 \pm 0.006$ \\
\hline $\mathbf{9 0}^{\circ} \mathbf{C} \times \mathbf{6 0}$ min & $80 \pm 0.005$ \\
\hline $\mathbf{8 0}^{\circ} \mathbf{C} \times \mathbf{1 . 4}$ h & $85 \pm 0.004$ \\
\hline
\end{tabular}

\subsection{Evaluación de la actividad quelante de $\mathrm{Fe}^{2+}$}

\subsubsection{Extractos metanólicos}

A los extractos optimizados también se les evaluó su actividad quelante, es decir la capacidad de atrapar metales $\left(\mathrm{Fe}^{2+}\right)$, en este caso se presenta una actividad de $56 \% \pm 0.005$ de actividad quelante.

\subsubsection{Extractos acetónicos}

Los extractos acetónicos fueron los que presentaron una menor actividad quelante ya que ésta solo fue del $30 \% \pm 0.006$ de actividad quelante del $\mathrm{Fe}^{2+}$, esto puede deberse a que la naturaleza de los polifenoles extraídos depende del solvente con el que se extraen y debido a 
su estructura química poseen diferentes actividades, así como diferente potencia para cada una de estas actividades.

\subsubsection{Taninos condensados extraíbles}

Los extractos óptimos de taninos condensados extraíbles son los que presentan una mayor actividad quelante en comparación con los demás extractos ya que se alcanza un $75 \% \pm 0.01$ de actividad quelante.

Para la quelación de metales hasta el momento no se ha encontrado un ensayo en el que se evalúe esta capacidad en hongos, por lo tanto, no tenemos con que comprarlo.

\subsubsection{Polifenoles no extraíbles totales.}

Tabla 18. Actividad quelante de pofenoles no extraíbles.

\begin{tabular}{|lc|}
\hline \multicolumn{1}{|c|}{ Tratamientos } & \% Quelación $\mathbf{F e}^{2+}$ \\
\hline $\mathbf{8 0}^{\circ} \mathbf{C} \times \mathbf{9 0}$ min & $22 \pm 0.001$ \\
\hline $\mathbf{9 0}^{\circ} \mathbf{C} \times 60$ min & $22 \pm 0.001$ \\
\hline $\mathbf{8 0}^{\circ} \mathbf{C} \times 1.4$ h & $19 \pm 0.001$ \\
\hline
\end{tabular}

Es posible observar que la actividad antioxidante se mantiene cercana entre todas las muestras, donde el tratamiento que obtiene una mayor concentración de polifenoles, presenta actividad quelante de $22 \%$. Es posible observar que en general los polifenoles encontrados en Pleurotus, no presentan una actividad antioxidante cercana a la capacidad de inhibir el radical $\mathrm{DPPH}^{\bullet}$, lo cuál puede deberse a la estructura química de los mismos compuestos fenólicos presentes en el hongo. 
Tabla 19. Comparación de la actividad antioxidante.

\begin{tabular}{|c|c|c|c|c|}
\hline Extractos & $\begin{array}{c}\text { Condiciones óptimas } \\
\text { de extracción }\end{array}$ & Concentración & $\begin{array}{l}\text { Inhibición del } \\
\text { radical DPPH }\end{array}$ & $\begin{array}{l}\text { Quelación de } \\
\qquad \mathrm{Fe}^{2+}\end{array}$ \\
\hline $\begin{array}{c}\text { Metanólicos } \\
\text { (polifenoles totales) }\end{array}$ & $\begin{array}{c}\text { Met/Agua: } 92 \% \\
\text { Temperatura: } 60^{\circ} \mathrm{C} \\
\text { Tiempo: } 15 \mathrm{~min}\end{array}$ & $\begin{array}{l}3.3 \mathrm{mg} \mathrm{EAG/g} \\
\text { muestra. }\end{array}$ & $61 \% \pm 0.001$ & $56 \% \pm 0.005$ \\
\hline $\begin{array}{c}\text { Acetónicos } \\
\text { (polifenoles totales) }\end{array}$ & $\begin{array}{l}\text { Acetona/Agua: } 8 \% \\
\text { Temperatura: } 60^{\circ} \mathrm{C} \\
\text { Tiempo: } 15 \mathrm{~min}\end{array}$ & $\begin{array}{c}1.75 \mathrm{mg} \mathrm{EAG/g} \\
\text { muestra }\end{array}$ & $71 \% \pm 0.008$ & $30 \% \pm 0.006$ \\
\hline $\begin{array}{c}\text { Taninos condensados } \\
\text { extraíbles }\end{array}$ & $\begin{array}{l}\text { Temperatura: } 61^{\circ} \mathrm{C} \\
\text { Tiempo: } 13 \mathrm{~min}\end{array}$ & $\begin{array}{c}0.59 \mathrm{mg} \text { catequina/g } \\
\text { de muestra }\end{array}$ & $70 \% \pm 0.002$ & $75 \% \pm 0.01$ \\
\hline $\begin{array}{c}\text { Taninos } \\
\text { hidrolizables } \\
\text { extraíbles }\end{array}$ & & & & \\
\hline $\begin{array}{c}\text { Taninos condensados } \\
\text { no extraíbles }\end{array}$ & $\begin{array}{l}\text { Temperatura: } 104^{\circ} \mathrm{C} \\
\text { Tiempo: } 80 \mathrm{~min} \\
\text { Volumen: } 15 \mathrm{ml}\end{array}$ & $\begin{array}{c}0.63 \mathrm{mg} \mathrm{de} \\
\text { proantocianidinas } \\
\text { no extraíbles/g de } \\
\text { muestra. }\end{array}$ & -- & \\
\hline $\begin{array}{l}\text { Polifenoles totales } \\
\text { no extraíbles. }\end{array}$ & $80^{\mathrm{a}} \mathrm{C} \times 90 \mathrm{~min}$ & $\begin{array}{l}2.3 \pm 0.01 \mathrm{mg} \mathrm{de} \\
\text { ácido gálico/g } \\
\text { muestra seca }\end{array}$ & $76 \% \pm 0.06$ & $22 \% \pm 0.001$ \\
\hline
\end{tabular}

Los extractos de compuestos polifenólicos extraíbles y no extraíbles de Pleurotus ostreatus presentan actividad antioxidante tanto por la inhibición del radical $\mathrm{DPPH}^{\bullet}$ como por la capacidad de quelar metales como el $\mathrm{Fe}^{2+}$ el cual es de suma importancia ya que es un catalizador de especies reactivas de oxígeno. Con la evaluación de estos dos métodos antioxidantes podemos observar que dada la naturaleza de los compuestos polifenólicos tienen la capacidad de actuar en diferentes reacciones de óxido-reducción, sin embargo, la capacidad de quelar el ión $\mathrm{Fe}^{2+}$ de los polifenoles de $\mathrm{PO}$ es mucho menor en comparación con la capacidad de estabilizar radicales libres como el $\mathrm{DPPH}^{\circ}$, lo cual puede deberse a la estructura qímica de los polifenoles. Además, es posible notar que en PO encontramos taninos condensados del tipo flavan-3-ol meta-sustituido, así como taninos condensados no extraíbles que por el método de Porter son liberados en forma de antocianidinas (oligómeros 
de flavan-3-ol). También sabemos que dentro de PO es posible encontrar taninos hidrolizables del tipo galatos de glucosa que pueden contener de tres a siete unidades de ácido gálico. En la literatura se menciona que el $70 \%$ de los polifenoles encontrados en un alimento (vegetales y frutos) pertenecen a los polifenoles no extraíbles, sin embargo, esto no sucede en Pleurotus ostreatus, ya que como puede apreciarse en la tabla 14 la concentración de los polifenoles extraíbles es mayor que la de los no extraíbles. Por definición los polifenoles son metabolitos secundarios que producen las plantas como mecanismo de defensa, los hongos no pertenecen al reino vegetal, sino al fungi, por lo que la maquinaria metabólica no es la misma, sin embargo, aunque en menor concentración son productores de polifenoles extraíbles y no extraíbles que además presentan actividad antioxidante comparable con productos de origen vegetal con estos resultados aun no es posible explicar a qué se debe la buena actividad antioxidante de Pleurotus ostreatus. 


\section{CONCLUSIONES}

- El tiempo, la temperatura y la proporción metanol/agua, son factores que si tienen efecto en la extracción de polifenoles extraíbles de Pleurotus ostreatus. Las condiciones óptimas de extracción son: temperatura $60^{\circ} \mathrm{C}$, proporción $92 \%$ met $/ \mathrm{H}_{2} \mathrm{O}$ y tiempo de $15 \mathrm{~min}$.

- Los extractos metanólicos del cuerpo fructífero de Pleurotus ostreatus presentan actividad antioxidante mediante la inhibición del radical DPPH* en un $61 \%$ y también mediante la quelación del $\mathrm{Fe}^{2+}$ en un $56 \%$.

- El tiempo, la temperatura y la proporción acetona /agua, son factores que si tienen efecto sobre la extracción de polifenoles extraíbles de Pleurotus ostreatus. Con acetona no hay una buena extracción de polifenoles, para obtener una mayor extracción los extractos resultaron más bien ser acuosos y las condiciones óptimas de extracción son: temperatura $56^{\circ} \mathrm{C}$, proporción $8 \%$ acetona/ agua y tiempo de $11 \mathrm{~min}$.

- Los extractos acetónicos, presentan actividad antioxidante por inhibición del radical DPPH ${ }^{\circ}$ en un $71 \%$ y capacidad de quelar el $\mathrm{Fe}^{2+}$ en un $30 \%$.

- No hay presencia de flavonoides en el cuerpo fructífero de Pleurotus ostreatus debido a que los hongos no cuentan con la maquinaria necesaria para sintetizarlos.

- El método de vainillina cuantifica taninos condensados extraíbles, el tiempo no es un factor que tenga efecto sobre la extracción de los taninos condensados, sin embargo, la temperatura si lo es, obteniendo así que las condiciones óptimas para su cuantificación de taninos condensados extraíbles son temperatura $61^{\circ} \mathrm{C}$ de reacción y 13 minutos de extracción.

- En Pleurotus ostreatus es posible encontrar taninos condensados de tipo Flavan-3-ol meta- sustituidos. Los cuales presentan actividad antioxidante mediante la inhibición del DPPH' en un $70 \%$ y la capacidad de quelar el $\mathrm{Fe}^{2+}$ en un $75 \%$.

- Hasta el momento en P. ostreatus es posible encontrar galatos de glucosa que pueden contener de 3 a 7 unidades de ácido gálico. 
- Las condiciones óptimas para la cuantificación de taninos condensados no extraíbles mediante el método de Porter son: $104^{\circ} \mathrm{C}, 80 \mathrm{~min}, 15 \mathrm{ml}$.

- La concentración de polifenoles no extraíbles es menor que la concentración de polifenoles extraíbles.

\section{PERSPECTIVAS}

Durante la realización de la cuantificación de polifenoles no extraíbles mediante la hidrólisis ácida, en el sobrenadante se observó una separación de un precipitado color café, insoluble, pero cuando se rediluyo en dimetilsulfóxido, fue más fácil trabajar con este precipitado ya que se solubilizó. Haciendo una revisión bibliográfica se encontró que existe la posibilidad de que ese compuesto pertenezca a las melaninas ya que se encuentran en la pared celular de los hongos (Gow et al., 2017). La melanina es un pigmento ubicuo distribuído en todos los reinos biológicos. En general se ha descrito como un pigmento oscuro, negro o café; sin embargo puede presentar otros colores. Son moléculas de alto peso molecular, muy estables, amorfas, cargadas negativamente, resistentes a la degradación con ácidos pero suceptibles a la degradación con bases fuertes, hidrofóbicas, insolubles en agua o solventes orgánicos, las cuales son formadas por la polimerización oxidativa de compuestos fenólicos (Cano, 2008). Es posible entonces que en Pleurotus ostreatus la concentración de polifenoles sea tan baja en comparación con otros alimentos, debido a la formación de melaninas y que, entonces, los efectos benéficos a la salud que se le atribuyen al hongo se deban también a la presencia de melaninas. Por lo tanto la perspectiva de este trabajo es profundizar más en la investigación de las melaninas para verificar si presentan actividad biológica que pudiera tener efectos benéficos a la salud. 


\section{REFERENCIAS}

Álvarez, E., De la Rosa, A., López, J., Vázquez, A. \&, \& Wall, A. (2012). Taninos hidrolizables y condensados: naturaleza química, ventajas y desventajas de su consumo. Tecnociencia Chihuahua, 6(2), 84-93. https://doi.org/10.3305/nh.2015.31.1.7699

Andjelković, M., Van Camp, J., De Meulenaer, B., Depaemelaere, G., Socaciu, C., Verloo, M., \& Verhe, R. (2006). Iron-chelation properties of phenolic acids bearing catechol and galloyl groups. Food Chemistry, 98(1), 23-31. https://doi.org/10.1016/j.foodchem.2005.05.044

Arbaayah, H., \& Umi Kalsom, Y. (2013). Antioxidant properties in the oyster mushrooms (Pleurotus spp.) and split gill mushroom (Schizophyllum commune) ethanolic extracts. Mycosphere, 4(4), 661-673. https://doi.org/10.5943/mycosphere/4/4/2

Arce-vazquez, M. B., Fornué, E. D., Esther, M., \& Rosales, E. (2014). Journal of Chemical , Biological and Physical Sciences Amaranth (Amaranthus Hypochondriacus L .): Use of Lignocellulosic Biomass to Obtain Antioxidant extracts Through Acid Hydrolysis, $4(5), 61-73$.

Arranz, S., Saura-Calixto, F., Shaha, S., \& Kroon, P. A. (2009). High contents of nonextractable polyphenols in fruits suggest that polyphenol contents of plant foods have been underestimated. Journal of Agricultural and Food Chemistry, 57(16), 7298-7303. https://doi.org/10.1021/jf9016652

Beas, R. F., Loarca, G. P., Guzmán, S. H., Rodriguez, M. G., Vasco, N. L., \& Guevara, F. L. (2011). Potencial nutracéutico de componentes bioactivos presentes en huitlacoche de la zona centro de México. Revista Mexicana de Ciencias Farmaceuticas, 42(2), 3644.

Brand-Williams, W., Cuvelier, M. E., \& Berset, C. (1995). Use of a free radical method to evaluate antioxidant activity. LWT - Food Science and Technology, 28, 25-30. https://doi.org/10.1016/S0023-6438(95)80008-5

Cano, L. E. (2008). Melanina: implicaciones en la patogénesis de algunas enfermedades y su capacidad de evadir la respuesta inmune del hospedero Melanin: implications in some disease pathogenesis and its capacity to evade the host immune response. Infectio, 12(2), 128-148.

Cárdenas-Rodríguez, N., \& Pedraza-Chaverri, J. (2005). Especies reactivas de oxígeno y sistemas antioxidantes : aspectos básicos. Educación Química, 12(2), 164-173.

Chung, K. T., Wong, T. Y., Wei, C. I., Huang, Y. W., \& Lin, Y. (1998). Tannins and human health: A review. Critical Reviews in Food Science and Nutrition, 38(6), 421464. https://doi.org/10.1080/10408699891274273

Dai, J., \& Mumper, R. J. (2010). Plant phenolics: Extraction, analysis and their antioxidant 
and anticancer properties. Molecules, 15(10), 7313-7352.

https://doi.org/10.3390/molecules15107313

Elejalde Guerra, J. I. (2001). Estrés oxidativo, enfermedades y tratamientos antioxidantes. An. Med. Interna, 18(6), 326-335. https://doi.org/10.4321/S0212-

71992001000600010

F. A. Tomás-Barberán. (2003). Los polifenoles de los alimentos y la salud. Alimentacion, Nutricion Y Salud, 10, 41-53. Retrieved from http://digital.csic.es/bitstream/10261/18042/3/lecturaPDF.pdf

González-Palma, I., Escalona-Buendía, H. B., Ponce-Alquicira, E., Téllez-Téllez, M., Gupta, V. K., Díaz-Godínez, G., \& Soriano-Santos, J. (2016). Evaluation of the antioxidant activity of aqueous and methanol extracts of Pleurotus ostreatus in different growth stages. Frontiers in Microbiology, 7(JUL), 1-9. https://doi.org/10.3389/fmicb.2016.01099

González, F. (2010). Caracterización de compuestos fenólicos presentes en la semilla y aceite de chía (Salvia hispanica L .), mediante electroforesis capilar., 0-101.

Gow, N. A. R., Latge, J., Munro, C. A., De Groot, P. W. J., Hellingwerf, K. J., Klis, F. M., ... Gil, C. (2017). Cell Wall Architecture in Yeast : New Structure and New Challenges MINIREVIEW Cell Wall Architecture in Yeast : New Structure and New Challenges $\dagger$. Yeast, 9(3), 3341-3354. https://doi.org/10.1128/microbiolspec.FUNK0035-2016.Correspondence

Hagerman, A. E. (2002). Vanillin Assay. The Tannin Handbook, 1-4. https://doi.org/10.1021/jf00114a020

Hagerman, A. E., Zhao, Y., \& Johnson, S. (1997). Methods for Determination of Condensed and Hydrolyzable Tannins, (75), 209-222. https://doi.org/10.1021/bk1997-0662.ch012

Hartzfeld, P. W., Forkner, R., Hunter, M. D., \& Hagerman, A. E. (2002a). Determination of hydrolyzable tannins (gallotannins and ellagitannins) after reaction with potassium iodate. Journal of Agricultural and Food Chemistry, 50(7), 1785-1790. https://doi.org/10.1021/jf0111155

Hartzfeld, P. W., Forkner, R., Hunter, M. D., \& Hagerman, A. E. (2002b). Determination of hydrolyzable tannins (gallotannins and ellagitannins) after reaction with potassium iodate. Journal of Agricultural and Food Chemistry, 50(7), 1785-1790. https://doi.org/10.1021/jf0111155

Hossain, M. A., Shah, M. D., Gnanaraj, C., \& Iqbal, M. (2011). In vitro total phenolics, flavonoids contents and antioxidant activity of essential oil, various organic extracts from the leaves of tropical medicinal plant Tetrastigma from Sabah. Asian Pacific Journal of Tropical Medicine, 4(9), 717-721. https://doi.org/10.1016/S19957645(11)60180-6

Iwalokun, B. A., Usen, U. A., Otunba, A. A., \& Olukoya, D. K. (2007). Comparative phytochemical evaluation, antimicrobial and antioxidant properties of Pleurotus 
ostreatus. African Journal of Biotechnology, 6(15), 1732-1739. https://doi.org/10.5897/AJB2007.000-2254

Jeena, G. S., Punetha, H., Prakash, O., Chandra, M., \& Kushwaha, K. P. S. (2014). Study on in vitro antioxidant potential of some cultivated pleurotus species (oyster mushroom). Indian Journal of Natural Products and Resources, 5(1), 56-61.

Mau, J. L., Lin, H. C., \& Chen, C. C. (2002). Antioxidant properties of several medicinal mushrooms. Journal of Agricultural and Food Chemistry, 50(21), 6072-6077. https://doi.org/10.1021/jf0201273

Moreno Vallespir, J., \& Jaime. (2015). Extracción de compuestos antioxidantes del gel de Aloe vera. Optimización del proceso mediante la aplicación de la metodología de superficie de respuesta. Retrieved from http://dspace.uib.es/xmlui/handle/11201/1127

Mueller-Harvey, I. (2001). Analysis of hydrolysable tannins. Animal Feed Science and Technology, 91(1-2), 3-20. https://doi.org/10.1016/S0377-8401(01)00227-9

Owaid, M. N., Abed, I. A., \& Al-Saeedi, S. S. S. (2016). Properties of Fruit Bodies of Oyster Mushroom (Pleurotus Ostreatus) Cultivated on Some Local Cellulosic Residues in Iraq. Gida, 41(4), 189-195. https://doi.org/10.15237/gida.GD15072

Pérez-Jiménez, J., Arranz, S., \& Saura-Calixto, F. (2009). Proanthocyanidin content in foods is largely underestimated in the literature data: An approach to quantification of the missing proanthocyanidins. Food Research International, 42(10), 1381-1388. https://doi.org/10.1016/j.foodres.2009.07.002

Pérez-Jiménez, J., Díaz-Rubio, M. E., \& Saura-Calixto, F. (2013). Non-extractable polyphenols, a major dietary antioxidant: Occurrence, metabolic fate and health effects. Nutrition Research Reviews, 26(2), 118-129. https://doi.org/10.1017/S0954422413000097

Pérez-Jiménez, J., \& Torres, J. L. (2011). Analysis of nonextractable phenolic compounds in foods: The current state of the art. Journal of Agricultural and Food Chemistry, 59(24), 12713-12724. https://doi.org/10.1021/jf203372w

Pyrzynska, K., \& Pękal, A. (2013). Application of free radical diphenylpicrylhydrazyl (DPPH) to estimate the antioxidant capacity of food samples. Analytical Methods, 5(17), 4288. https://doi.org/10.1039/c3ay40367j

Quideau, S., Deffieux, D., Douat-Casassus, C., \& Pouységu, L. (2011). Plant polyphenols: Chemical properties, biological activities, and synthesis. Angewandte Chemie International Edition, 50(3), 586-621. https://doi.org/10.1002/anie.201000044

Quiñones, M., Miguel, M., \& Aleixandre, A. (2012). Los polifenoles, compuestos de origen natural con efectos saludables sobre el sistema cardiovascular. Nutrici??N Hospitalaria : Organo Oficial de La Sociedad Espa??Ola de Nutrici??N Parenteral y Enteral, 27(1), 76-89. https://doi.org/10.3305/nh.2012.27.1.5418

Ramírez Anguiano, A. C. (2009). Estudio de las propiedades bioactivas de hongos comestibles para el diseño de productos cárnicos funcionales, 1-245. 
Roth, J. V. (2009). Prediction interval analysis is underutilized and can be more helpful than just confidence interval analysis. Journal of Clinical Monitoring and Computing, 23(3), 181-183. https://doi.org/10.1007/s10877-009-9165-0

SAGARPA. (2016). Los hongos y setas, tradición de buena alimentación, 1-2.

Schofield, P., Mbugua, D.M., and Pell, A. N., \& Schofield, P., Mbugua, D. M., \& Pell, A. N. (2013). Analysis of Condensed Tannins. Animal Feed Science and Technology, 1(6), 168-182. https://doi.org/10.1016/S0377-8401(01)00228-0

Schofield, P., Mbugua, D. M., \& Pell, A. N. (2001). Analysis of condensed tannins: A review. Animal Feed Science and Technology, 91(1-2), 21-40. https://doi.org/10.1016/S0377-8401(01)00228-0

Soares, M. (1975). Review Articles. Government and Opposition, 10(4), 494-496. https://doi.org/10.1111/j.1477-7053.1975.tb00651.x

Wang, T., Jónsdóttir, R., \& Ólafsdóttir, G. (2009). Total phenolic compounds, radical scavenging and metal chelation of extracts from Icelandic seaweeds. Food Chemistry, 116(1), 240-248. https://doi.org/10.1016/j.foodchem.2009.02.041

Xie, Z., Huang, J., Xu, X., \& Jin, Z. (2008). Antioxidant activity of peptides isolated from alfalfa leaf protein hydrolysate. Food Chemistry, 111(2), 370-376. https://doi.org/10.1016/j.foodchem.2008.03.078

Yıldız, S., Yılmaz, A., Can, Z., Kılıç, C., \& Yıldız, Ü. C. (2017). Total Phenolic, Flavonoid, Tannin Contents and Antioxidant Properties of Pleurotus Ostreatus and Pleurotus Citrinopileatus Cultivated on Various Sawdust. Gida / the Journal of Food, 42(3), 315-323. https://doi.org/10.15237/gida.GD16099 


\section{APÉNDICES}

Apéndice A

Curva patrón de ácido gálico para la cuantificación de polifenoles totales por el método de Follin Ciocaltau.

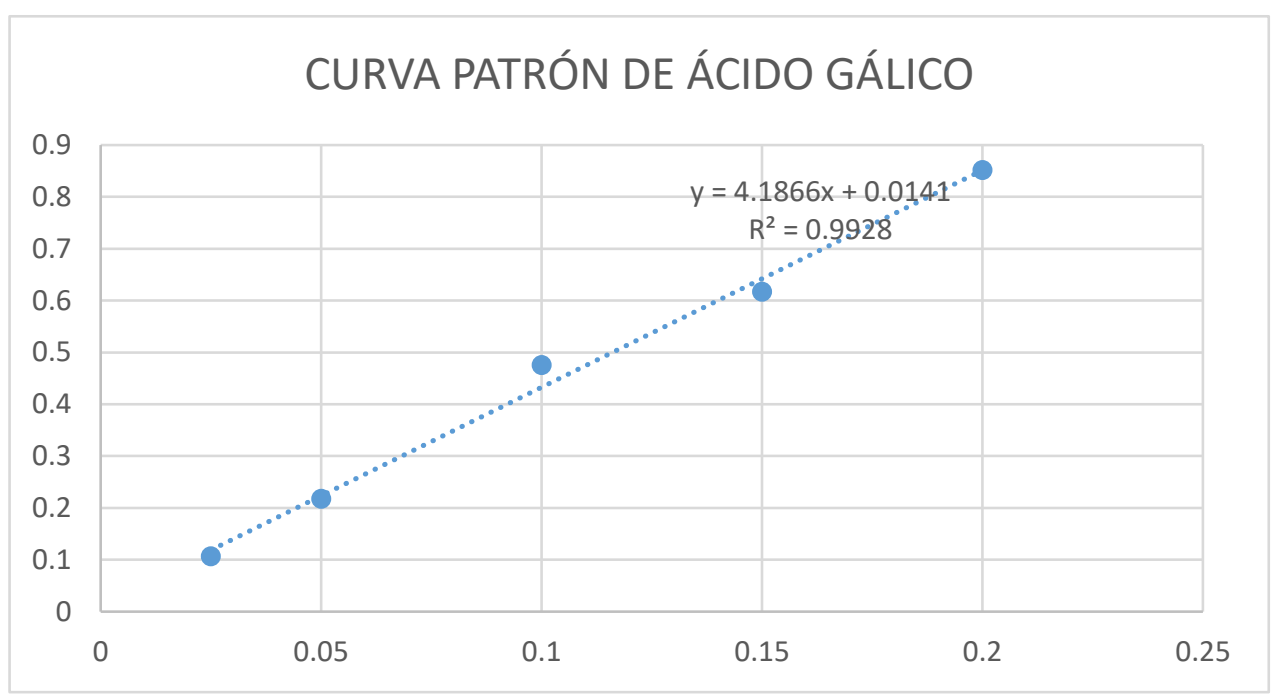

Curva patrón de rutina para la cuantificación de flavonoides

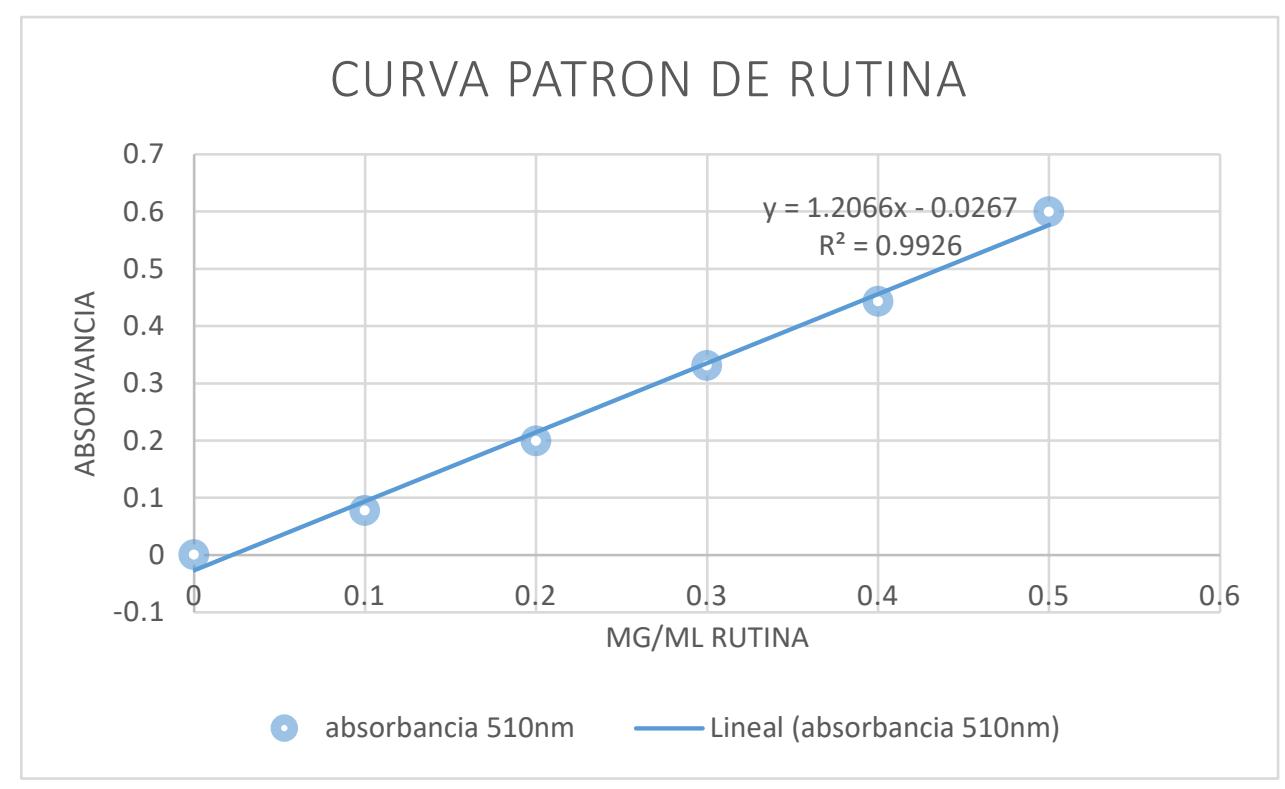


Curva patrón de catequina para taninos condensados extraíbles.

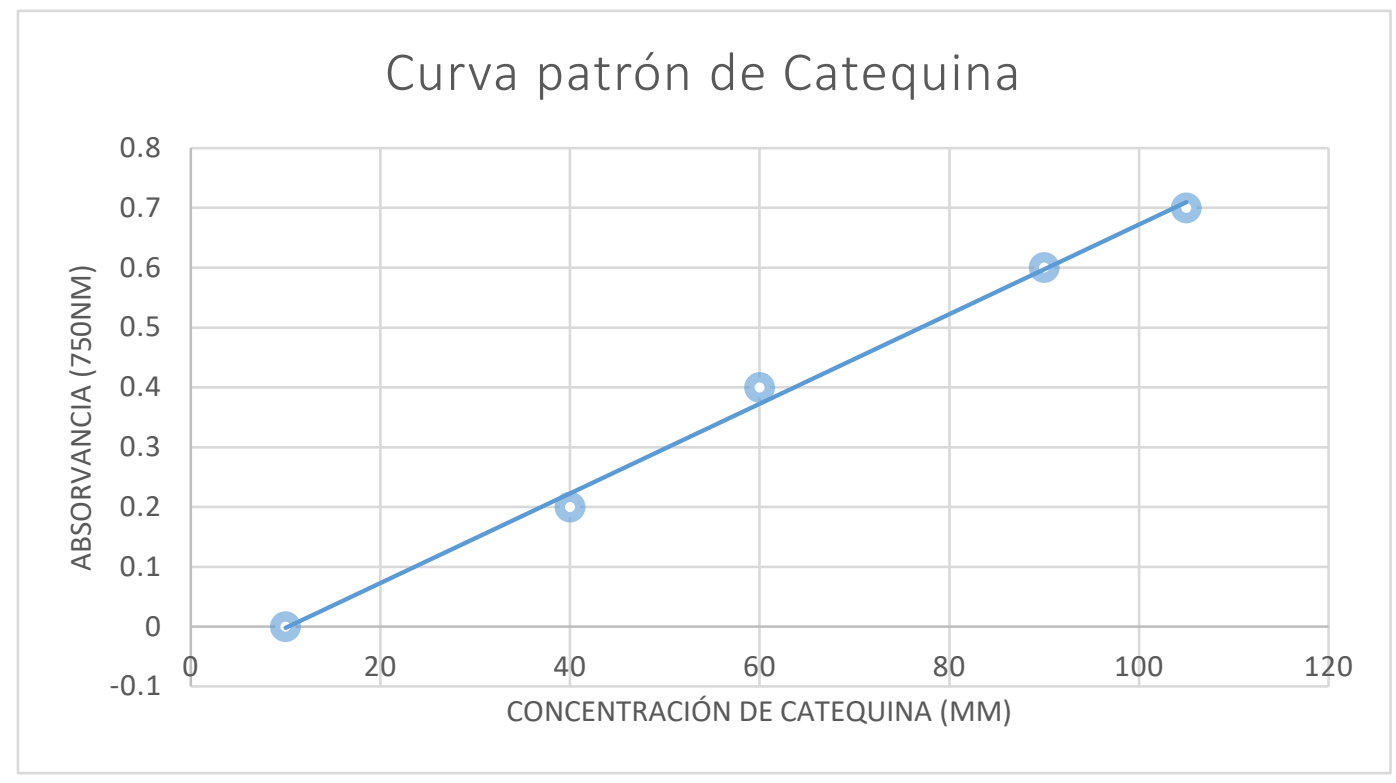

Curva patrón de taninos de algarrobo para taninos condensados no extraíbles.

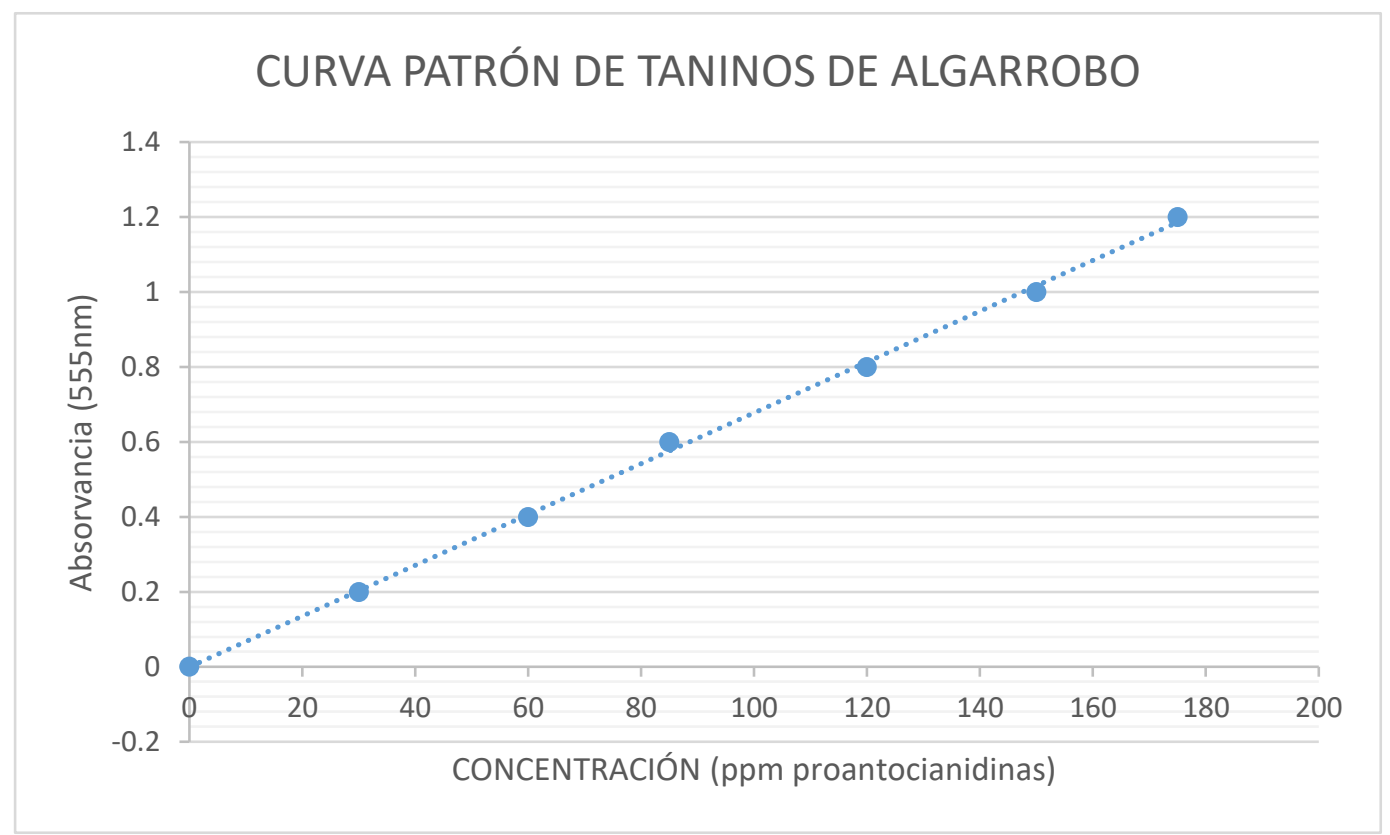




\section{Apéndice B}

Anáisis de varianza de extractos metánolicos del cuerpo fructífero de Pleurotus ostreatus de la proporción metanol $/ \mathrm{H}_{2} \mathrm{O}$ - tiempo.

\begin{tabular}{|l|l|l|l|l|l|}
\hline Fuente & Suma de Cuadrados & $G l$ & Cuadrado Medio & Razón- $F$ & Valor- $P$ \\
\hline A:CONCENTRACION & 0.0439994 & 1 & 0.0439994 & 5.23 & 0.0322 \\
\hline B:TIEMPO & 0.0628567 & 1 & 0.0628567 & 7.47 & 0.0122 \\
\hline AA & 0.00181252 & 1 & 0.00181252 & 0.22 & 0.6472 \\
\hline AB & 0.116929 & 1 & 0.116929 & 13.89 & 0.0012 \\
\hline BB & 0.00452416 & 1 & 0.00452416 & 0.54 & 0.4712 \\
\hline bloques & 0.00000710744 & 2 & 0.00000355372 & 0.00 & 0.9996 \\
\hline Error total & 0.185177 & 22 & 0.00841714 & & \\
\hline Total (corr.) & 0.413725 & 29 & & & \\
\hline
\end{tabular}

R-cuadrada $=55.2415$ porciento

R-cuadrada (ajustada por g.l.) $=41.0002$ porciento

Error estándar del est. $=0.091745$

Error absoluto medio $=0.0594458$

Estadístico Durbin-Watson $=1.60147(\mathrm{P}=0.0782)$

Autocorrelación residual de Lag $1=0.185783$

Análisis de varianza de extractos metanólicos del cuerpo fructífero de Pleurotus ostreatus de la temperatua - tiempo.

\begin{tabular}{|l|l|l|l|l|l|}
\hline Fuente & Suma de Cuadrados & Gl & Cuadrado Medio & Razón-F & Valor-P \\
\hline A:temperatura & 4.60081 & 1 & 4.60081 & 36.97 & 0.0000 \\
\hline B:tiempo & 0.0446638 & 1 & 0.0446638 & 0.36 & 0.5553 \\
\hline AA & 0.223174 & 1 & 0.223174 & 1.79 & 0.1942 \\
\hline AB & 0.316733 & 1 & 0.316733 & 2.54 & 0.1249 \\
\hline BB & 0.0209678 & 1 & 0.0209678 & 0.17 & 0.6854 \\
\hline bloques & 0.0021092 & 2 & 0.0010546 & 0.01 & 0.9916 \\
\hline Error total & 2.73817 & 22 & 0.124462 & & \\
\hline Total (corr.) & 8.07339 & 29 & & & \\
\hline
\end{tabular}

R-cuadrada $=66.0841$ porciento

R-cuadrada (ajustada por g.1.) $=55.2926$ porciento

Error estándar del est. $=0.352792$

Error absoluto medio $=0.24349$

Estadístico Durbin-Watson $=1.62361(\mathrm{P}=0.1192)$

Autocorrelación residual de Lag $1=0.184795$ 


\section{Apéndice B}

Anáisis de varianza de extractos acetónicos del cuerpo fructífero de Pleurotus ostreatus de temperatura - tiempo.

\begin{tabular}{|l|l|l|l|l|l|}
\hline Fuente & Suma de Cuadrados & Gl & Cuadrado Medio & Razón- $F$ & Valor-P \\
\hline A:TEMPERATURA & 0.122135 & 1 & 0.122135 & 14.07 & 0.0011 \\
\hline B:TIEMPO & 0.0376571 & 1 & 0.0376571 & 4.34 & 0.0491 \\
\hline AA & 0.0980727 & 1 & 0.0980727 & 11.30 & 0.0028 \\
\hline AB & 0.00796143 & 1 & 0.00796143 & 0.92 & 0.3485 \\
\hline BB & 0.0107026 & 1 & 0.0107026 & 1.23 & 0.2787 \\
\hline bloques & 0.000662534 & 2 & 0.000331267 & 0.04 & 0.9626 \\
\hline Error total & 0.190906 & 22 & 0.00867757 & & \\
\hline Total (corr.) & 0.52659 & 29 & & & \\
\hline
\end{tabular}

R-cuadrada $=63.7467$ porciento

R-cuadrada (ajustada por g.l.) $=52.2115$ porciento

Error estándar del est. $=0.0931535$

Error absoluto medio $=0.0726064$

Estadístico Durbin-Watson $=2.22357(\mathrm{P}=0.5943)$

Autocorrelación residual de Lag $1=-0.150386$

Anáisis de varianza de extractos acetónicos del cuerpo fructífero de Pleurotus ostreatus de tproporción acetona $/ \mathrm{H}_{2} \mathrm{O}-$ tiempo.

\begin{tabular}{|l|l|l|l|l|l|}
\hline Fuente & Suma de Cuadrados & Gl & Cuadrado Medio & Razón- $F$ & Valor-P \\
\hline A:PROPORCIÓN & 0.190091 & 1 & 0.190091 & 12.06 & 0.0022 \\
\hline B:TIEMPO & 0.0302835 & 1 & 0.0302835 & 1.92 & 0.1795 \\
\hline AA & 0.0752073 & 1 & 0.0752073 & 4.77 & 0.0399 \\
\hline AB & 0.472755 & 1 & 0.472755 & 30.00 & 0.0000 \\
\hline BB & 0.317202 & 1 & 0.317202 & 20.13 & 0.0002 \\
\hline bloques & 0.00630716 & 2 & 0.00315358 & 0.20 & 0.8201 \\
\hline Error total & 0.346655 & 22 & 0.0157571 & & \\
\hline Total (corr.) & 1.36462 & 29 & & & \\
\hline
\end{tabular}

R-cuadrada $=74.5969$ porciento

R-cuadrada (ajustada por g.l.) $=66.5141$ porciento

Error estándar del est. $=0.125527$

Error absoluto medio $=0.0920514$

Estadístico Durbin-Watson $=2.591(\mathrm{P}=0.8926)$

Autocorrelación residual de Lag $1=-0.324829$ 


\section{Apéndice B}

Anáisis de varianza de taninos condensados extraíbles del cuerpo fructífero de Pleurotus ostreatus de tiempo - temperatura.

\begin{tabular}{|l|l|l|l|l|l|}
\hline Fuente & Suma de Cuadrados & Gl & Cuadrado Medio & Razón-F & Valor-P \\
\hline A:TEMPERATURA & 19673.5 & 1 & 19673.5 & 40.57 & 0.0000 \\
\hline B:TIEMPO & 4.15886 & 1 & 4.15886 & 0.01 & 0.9271 \\
\hline AA & 3529.17 & 1 & 3529.17 & 7.28 & 0.0131 \\
\hline AB & 255.621 & 1 & 255.621 & 0.53 & 0.4755 \\
\hline BB & 13.1057 & 1 & 13.1057 & 0.03 & 0.8709 \\
\hline bloques & 1157.04 & 2 & 578.521 & 1.19 & 0.3222 \\
\hline Error total & 10668.9 & 22 & 484.951 & & \\
\hline Total (corr.) & 35872.7 & 29 & & & \\
\hline
\end{tabular}

R-cuadrada $=70.2589$ porciento

R-cuadrada (ajustada por g.l.) $=60.7958$ porciento

Error estándar del est. $=22.0216$

Error absoluto medio $=15.5068$

Estadístico Durbin-Watson $=2.4886(\mathrm{P}=0.8304)$

Autocorrelación residual de Lag $1=-0.256525$

Análisis de varianza de taninos condensados no extraíbles del cuerpo fructífero de Pleurotus ostreatus de tiempo- temperatura- volúmen.

\begin{tabular}{|l|l|l|l|l|l|}
\hline Fuente & Suma de Cuadrados & $G l$ & Cuadrado Medio & Razón- $F$ & Valor- $P$ \\
\hline A:TEMPERATURA & 1236.15 & 1 & 1236.15 & 6.74 & 0.0484 \\
\hline B:TIEMPO & 275.473 & 1 & 275.473 & 1.50 & 0.2749 \\
\hline C:VOLUMEN & 148.302 & 1 & 148.302 & 0.81 & 0.4097 \\
\hline AA & 1022.08 & 1 & 1022.08 & 5.58 & 0.0647 \\
\hline AB & 77.7826 & 1 & 77.7826 & 0.42 & 0.5436 \\
\hline AC & 107.065 & 1 & 107.065 & 0.58 & 0.4792 \\
\hline BB & 0.0446393 & 1 & 0.0446393 & 0.00 & 0.9882 \\
\hline BC & 5.9076 & 1 & 5.9076 & 0.03 & 0.8646 \\
\hline CC & 61.1112 & 1 & 61.1112 & 0.33 & 0.5887 \\
\hline Error total & 916.66 & 5 & 183.332 & & \\
\hline Total (corr.) & 3825.3 & 14 & & & \\
\hline
\end{tabular}

R-cuadrada $=76.0369$ porciento

R-cuadrada (ajustada por g.l.) $=32.9034$ porciento

Error estándar del est. $=13.54$

Error absoluto medio $=6.57716$

Estadístico Durbin-Watson $=2.42692(\mathrm{P}=0.5958)$

Autocorrelación residual de Lag $1=-0.292095$ 
Apéndice C

Algunos resultados de la presente tesis se presentaron en el siguiente foro especializado.

- VI Congreso internacional de Ciencia y Tecnología de alimentos 2019. 17 a 19 de septiembre del 2019, en San José, Costa Rica, ., Aplicación del método de superficie de respuesta para la cuantificación de taninos condensados de Pleurotus ostreatus. Salgado Castillo, S., Soriano Santos, J.

Algunos resultados de la presente tesis están próximos a presentarese en el siguiente foro especializado

- VI Encuentro Internacional sobre Biotecnología en la UATx 2019. 1 a 4 de diciembre de 2019. Tlaxcala, tlaxcala. Aplicación de Superficie de Respuesta para la Cuantificación de Taninos no Extraibles de Pleurotus ostreatus. Salgado, S.N, Pérez, J.A y Soriano, J. 